Portland State University

PDXScholar

Winter 3-4-2016

\title{
Assessing Sense of Place and Geo-literacy Indicators as Learning Outcomes of an International Teacher Professional Development Program
}

Nancee Hunter

Portland State University

Follow this and additional works at: https://pdxscholar.library.pdx.edu/open_access_etds

Part of the Educational Assessment, Evaluation, and Research Commons, Educational Methods Commons, Geography Commons, and the Teacher Education and Professional Development Commons Let us know how access to this document benefits you.

\section{Recommended Citation}

Hunter, Nancee, "Assessing Sense of Place and Geo-literacy Indicators as Learning Outcomes of an International Teacher Professional Development Program" (2016). Dissertations and Theses. Paper 2701. https://doi.org/10.15760/etd.2697

This Dissertation is brought to you for free and open access. It has been accepted for inclusion in Dissertations and Theses by an authorized administrator of PDXScholar. Please contact us if we can make this document more accessible: pdxscholar@pdx.edu. 
Assessing Sense of Place and Geo-literacy Indicators as Learning Outcomes of an International Teacher Professional Development Program

by

Nancee Hunter

A dissertation submitted in partial fulfillment of the requirements for the degree of

Doctor of Philosophy

in

Environmental Sciences and Resources

Dissertation Committee:

Teresa Bulman, Chair

Gwenda Rice

Heejun Chang Kimberely Brown

Portland State University 2016 


\begin{abstract}
This research explores the multifaceted benefits that accrue from learning within an international, experiential context. It uses a qualitative, case study approach employing pre and post surveys, in-situ observations, and semi-structured photo-elicitation interviews to analyze the Center for Geography Education in Oregon's (C-GEO) 2013 Overseas Teacher Institute--a professional development program that took 11 teachers to Russia, Mongolia, and China for a total of 17 days (plus two additional travel days) to learn about the cultural and physical geography of each place. The focus of the research is two-fold and examines processes involved in gaining, synthesizing and applying 1) a sense of place (the emotional ties between people and place), and 2) geo-literacy. The results of this study provide evidence that intensive professional development programs can increase teachers personal and professional knowledge, change their instructional practices, and may lead to improved student learning outcomes.
\end{abstract}




\section{TABLE OF CONTENTS}

Abstract

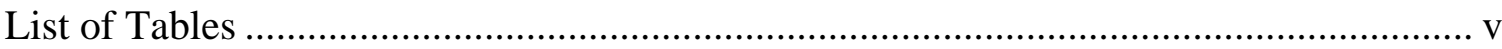

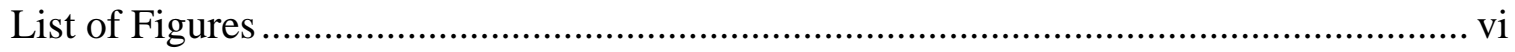

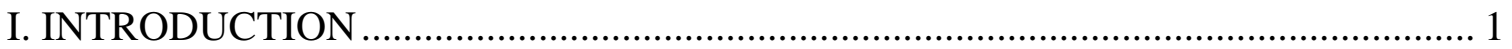

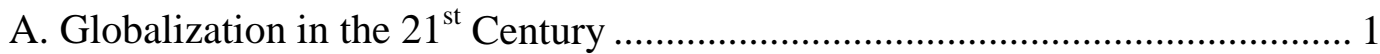

B. The Significance of Place in a Global Age ................................................. 1

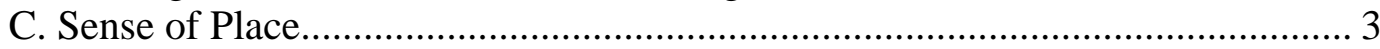

D. The Need for Teacher Professional Development and

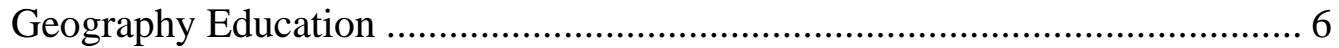

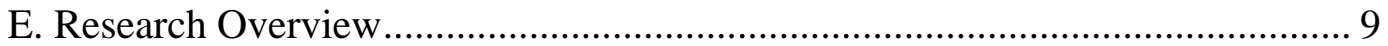

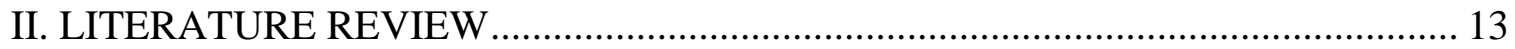

A. The Need for Geo-Literacy in a Globalized World ........................................ 14

B. Improving Teacher Professional Development Programs

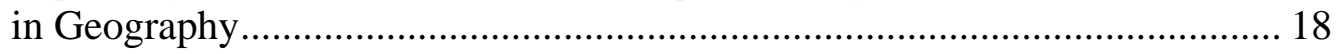

C. Phenomenology of Place ..................................................................... 20

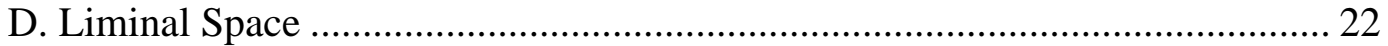

E. Experiential Learning Theory..................................................................... 24

F. Short-Term International Learning Experiences ............................................. 27

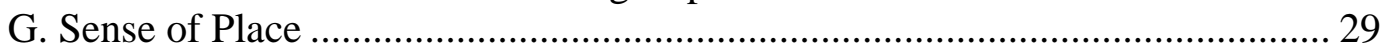

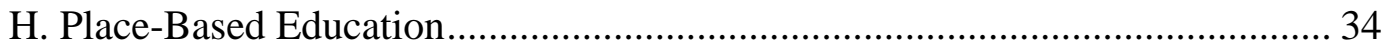

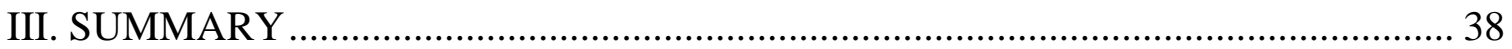

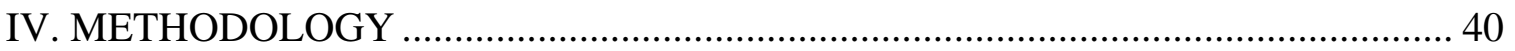

A. Methodological Approaches .......................................................................... 43

1. Pre- and Post-Surveys ................................................................................ 43

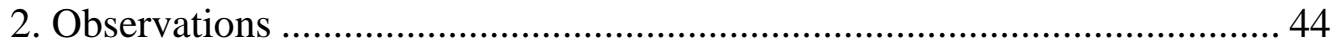

3. Photo-Elicitation Interviews ................................................................. 46

B. Methodological Advantages and Disadvantages............................................. 51

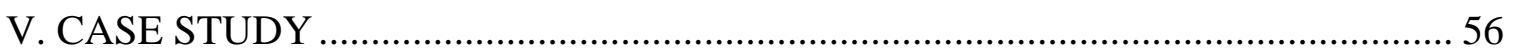

A. The Center for Geography Education in Oregon (C-GEO) ............................. 56

B. Participants ............................................................................................ 59

C. Why Teachers Chose to Participate in the C-GEO Eurasia Program ............... 60

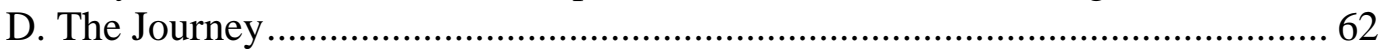

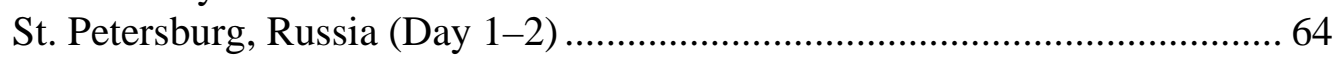

Moscow, Russia (Days 3-4) ........................................................................... 66

The Trans-Siberian Railway, Russia (Days 5-7)_........................................... 70

Irkutsk, Russia (Day 8) ............................................................................. 74

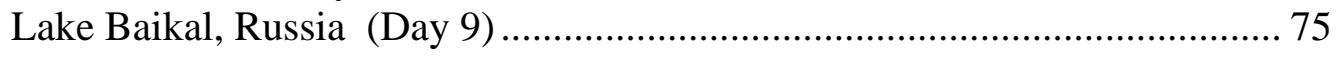


Ulaanbaatar, Mongolia (Day 10-11 and Day 14) .......................................... 76

Ger Camp in Terelj National Park, Mongolia (Day 12-13) ............................. 77

The Trans-Siberian Railway, Mongolia and China (Day 15) ........................... 80

Beijing and The Great Wall, China (Days 16-17)......................................... 80

E. Trains as Liminal Spaces.............................................................................. 82

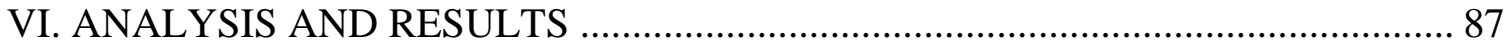

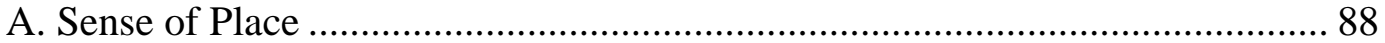

1. Natural Environments ............................................................................ 94

2. Culture and History .................................................................................. 99

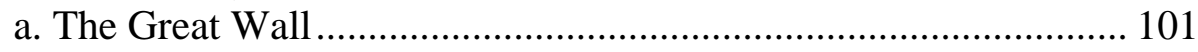

b. Designing a Sense of Place ........................................................... 107

c. The Russian Personality ................................................................ 111

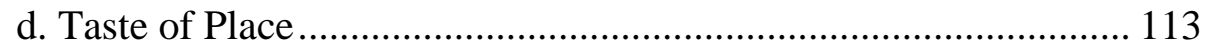

3. Personal Connections .............................................................................. 116

4. Professional and Intellectual Connections ................................................. 123

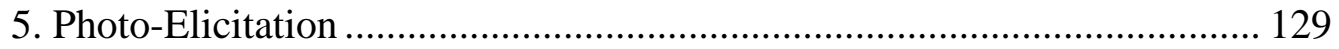

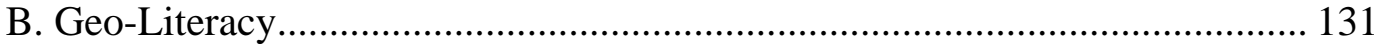

1. Geographic Skills and Knowledge .......................................................... 132

2. Ability to Teach and Use More Geography Concepts and Skills in Classrooms.......................................................................... 137

3. New Understanding and Appreciation for Other Cultures ........................ 138

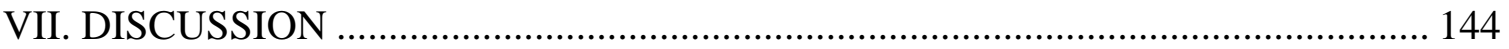

A. Key Findings .......................................................................................... 144

1. Stronger Connection to Home ……………………............................... 144

2. Photo-Elicitation as a Successful Method for Sense of Place Research................................................................... 145

3. Increased Teaching of Geography and Geo-Literacy Skills ....................... 146

4. Greater Acceptance of Cultural Diversity ................................................... 147

5. It Is Important to Focus on Individuality When Studying Sense of Place ................................................................ 147

B. Areas for Further Research .................................................................... 150

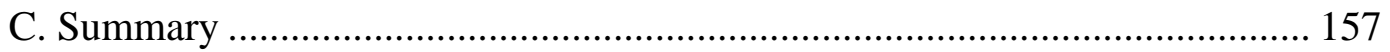

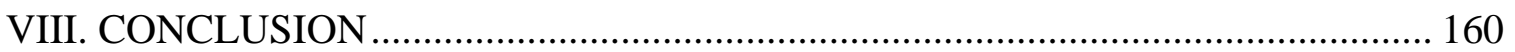

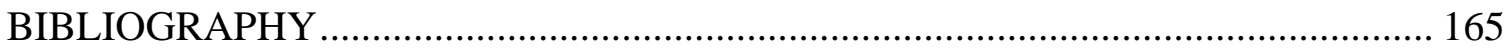


APPENDICES ....

Appendix A. OGA Summer Program in Eurasia:

Orientation Meeting of February 23, 2013

Appendix B. OGA Summer Program in Eurasia:

Orientation Meeting of May 18, 2013

Appendix C. Eurasian Institute Project Requirements ...................................... 183

Appendix D. Russia/Mongolia/China Itinerary .................................................. 185

Appendix E. OGA Advanced Summer Institute 2013 Application..................... 187

Appendix F. Eurasia Participant Pre-Post Survey ............................................ 192

Appendix G. Final Interview Questions ………………................................... 200 


\section{List of Tables}

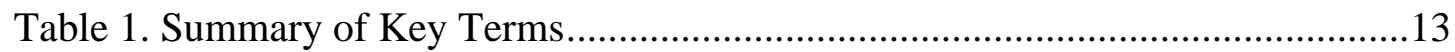

Table 2. Key Natural Environment Influences by Participant ..................................95

Table 3. Key Cultural Influences by Participant .....................................................100 


\section{List of Figures}

Figure $1.21^{\text {st }}$ century student outcomes and support systems ..................................

Figure 2. Percentage distribution of U.S. public school students enrolled in prekindergarten through 12th grade, by race/ethnicity: Selected years, fall 2001, fall 2011, and fall 2023

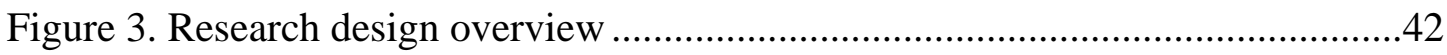

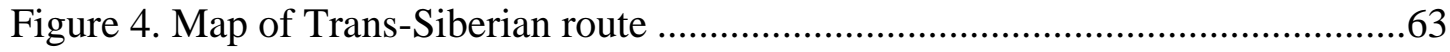

Figure 5. The word "PECTOPAH" is everywhere in Russia ..................................64

Figure 6. St. Basil's Cathedral, located on the Red Square in Moscow .....................67

Figure 7. Train compartment on the Trans-Siberian railway -

the teachers' home away from home for a large portion of the trip ...........................71

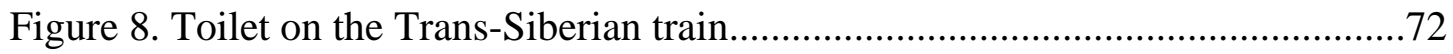

Figure 9. The white obelisk marking the border between Asia and Europe ................74

Figure 10. Photos of ger camp in Terelj National Park .........................................78

Figure 11. Chinggis Khaan memorial in Mongolia .................................................79

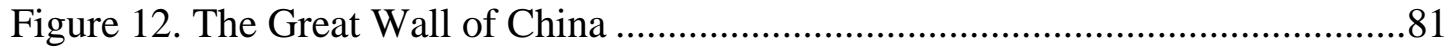

Figure 13. Train crossing through liminal space ................................................83

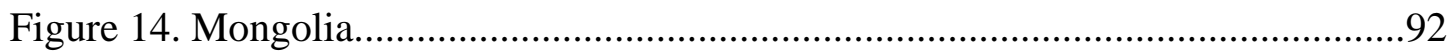

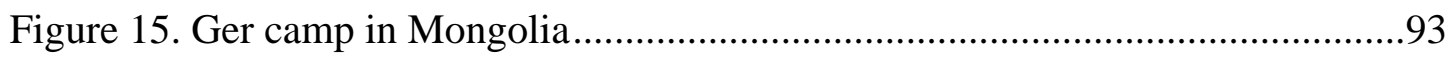

Figure 16. Correlation between perception of nature's beauty and

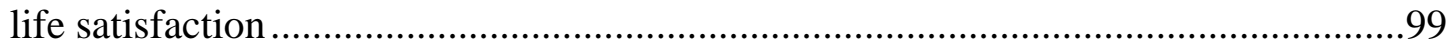

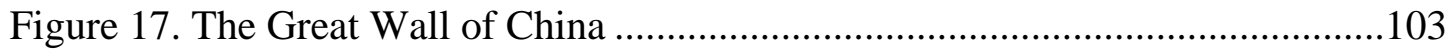

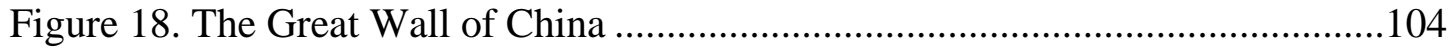

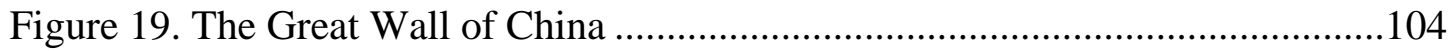

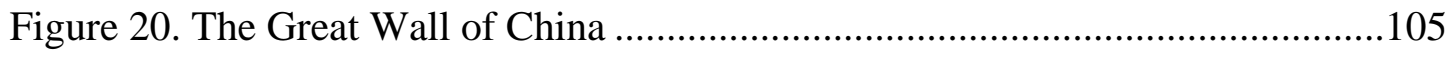

Figure 21. Layout of Moscow's Red Square .......................................................109 
Figure 22. Koteinicheskaya Embankment Building of the Seven Sisters

Buildings in Moscow …………………………....................................................109

Figure 23. St. Basil's Cathedral in Moscow's Red Square..........................................110

Figure 24. Photo exhibit at GUM Department Store on Red Square in Moscow......110

Figure 25. Mountains and sky above ger camp in Mongolia......................................117

Figure 26. Local berries from Russia...................................................................118

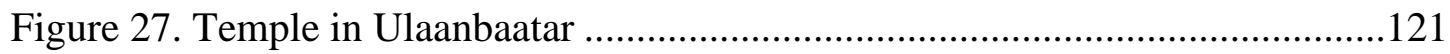

Figure 28. Mongolian teachers waving goodbye after school visit ...........................127 


\section{INTRODUCTION}

\section{A. Globalization in the $21^{\text {st }}$ Century}

Globalization is the acceleration and intensification of interaction and integration among the people, businesses, government and non-government agencies of different nations (American Forum for Global Education 2003). It can be viewed as a "complex connectivity" (Tomlinson 1999, 20) — the speeding up, deepening, and spreading out of global interconnectedness. Basic human necessities, such as currency, clothes, food, and communication, are increasingly being traded around the world. In addition, more people are traveling more frequently and for longer distances, interacting with others and receiving new information along the way. As a result of these experiences, one's sense of self necessarily changes as well. Tomlinson $(1999,20)$ suggests that globalization "alters the context of meaning construction ... it affects people's sense of identity, the experience of place and of self in relation to place."

Globalization is inherently geographic and the resultant changes in economic, cultural, technological, and political conditions require consideration of the way space, place, and time are configured and reconfigured (Dicken 2004). According to Martin (1999, 15-16), "Globalization may well have eliminated space....but it has by no means undermined the significance of location, of place."

\section{B. The Significance of Place in a Global Age}

Geographic units, spatial levels, or "scales" (e.g., local, regional, national, global) are socially constructed concepts and are key to understanding a variety of political, socio-cultural, economic, and environmental phenomena (Herod and Wright 2002; Sheppard and McMaster 2004). Globalization is shaped by, and in turn, prompts a 
reexamination of these customary scales. Global flows of capital, labor, goods, and services have challenged national and state political and regulatory capacities. They have given rise to such transnational and multinational entities as the European Union, the World Trade Organization, and the North American Free Trade Agreement (Smith 1995). Cultural identities and allegiances have also been altered by globalization as people migrate or see their geographical references realigned by political and economic restructuring.

For decades, geographers have considered sense of place in the context of globalization. The theoretical discourse around place and identity in a globalized world has been polarizing. According to David Harvey (1989, 1990, 1993), globalization processes have led to a dissolution of place and a fragmentation of contemporary identities which, in turn, has led to a rise in xenophobia and reactionary place-bound politics as people search for old certainties and struggle to construct a more stable, or “bounded," place identity. On the other hand, Doreen Massey $(1991,1994)$, while not discounting a rise of xenophobia, takes issue with Harvey's account. She suggests that there is nothing inevitably reactionary about an identification with place and that it is the nature of that identification process that determines the politics of place identities (Massey 1994). She argues for a more progressive sense of place — one within which place is understood as the unique point of connection in a wider series of flows (Massey 1991). Rather than see identities as "singular, fixed and static" or interpreting places as "bounded enclosed spaces defined through counter position against the Other who is outside" (Massey 1994, 168), Massey attempts to connect with the challenges of globalization and celebrate the politics of difference. 
The research presented in this study supports Massey's point of view by characterizing places as social moments of experiences and understandings, which in turn allows a sense of place that integrates in a positive way the local and the global (Massey 1994). As such, this analysis contributes to the existing theoretical discourse on place in a time of globalization by examining how people relate to place(s) in the face of all this movement and intermixing and the individual and collective meanings that are given to particular place(s).

\section{Sense of Place}

Place can be described in terms of many multidimensional physical and psychological attributes. All places are unique — with features that give them personality and distinguish them from other places. A particular environment (e.g., a school) contains many features and experiences (e.g., walls, a gym, a cafeteria, classrooms, people, clothing, books, the languages spoken). Simply cataloging these, however, does not provide enough to define the specific qualities of the place; and, as the geographic scale increases, collections of similar places can be found. For instance, a city or town is made up of several schools, along with houses, apartment buildings, government offices, and businesses; a country is made up of cities and towns; and continents consist of many countries. In addition to understanding the scale of a place, attributes of physical geography help to define a place (e.g., weather, landforms, soil type, plant or animal life). Attributes of human geography (e.g., people and cultures) also help to define a place through languages, religions, types of settlements, transportation corridors, economies, and governments. At the same time, place includes those elements or interactions between elements that influence the meaning individuals give to a place through 
personal, social, and cultural processes (Altman and Low 1992; Burd 2008), as well as how they perceive it through their senses.

Sense of place emerges from involvement between people and place and can be defined as "the set of meanings and attachments that individuals or groups associate with a particular location" (Williams and Stewart 1998; Hudson 2001). Individuals' psychological sense of place or "place attachment" can be understood in many ways: as an experience, beliefs about the relationship between self and place, feelings about the place (e.g., how residents feel towards their hometown) or an assessment of the place in relation to alternatives (e.g., a feeling that "this place is not as interesting as others one has visited"). Sense of place can also be described as the individual's incorporation of the experience or meaning of the place into the larger concept of self. Harold Proshansky $(1978,152)$ coined the term "place identity" to denote the dimensions of self that define an individual's personal identity in relation to a physical environment. Hummon (1986, 34) reinforces this view by defining place identity as "an interpretation of the self that uses place — a significant, symbolic locale — as a sign or locus of identity." He considers places environmental contexts with real consequences for people and emphasizes ties between the place and the people.

A great affection for places and a shared sense of identity can be the source of some of humankind's greatest joys but can also be the breeding ground for conflict. In a globalized world, distance no longer provides the same degree of protection or insulation that it once might have. However outdated or inapplicable, longstanding mental maps and entrenched views and practices can be difficult to change (Harth 2007; Rock, D. and Schwartz, J. 2006). Many racial and ethnic clashes, for instance, can be traced back to 
such place attachments. Yet, a rejection of such affections to create a utopian, unicultural world is, by no means, realistic. While the pressures of a global life certainly have the potential to reduce someone into a feeling of "placelessness" — a sort of non-place quality manifest in uniformity, standardization and disconnection from context (Relph 1976) - a perfectly placeless world, would make such experiences as travel pointless. On the other hand, a world full of completely unique places, would make travel enormously difficult and unrewarding because nothing would be familiar. It is, in fact, the endless possibilities that exist along the continuum of place and placelessness - the many similarities and differences among places — that make them comprehensible to individuals and, in turn, give rise to special qualities and meanings.

For purposes of this research, sense of place is defined as the quality that allows individuals to appreciate the differences and similarities among places. It is triggered by the landscapes and the people one encounters and is experienced through a combination of sight, hearing, smell, movement, taste and touch, as well as imagination, background, purpose, and anticipation. It is both an individual and intersubjective attribute, closely connected to community as well as to personal memory and self. It is also variable. Some people are not particularly interested in the world around them, and place for them is mostly a lived background; others take a more active approach, paying close attention to the overall character of the places they encounter.

A pragmatic sense of place can be an essential component in developing effective ways to cope with $21^{\text {st }}$ century challenges. Globalization has the ability to change people's sense of place by "altering the context of meaning construction . . . it affects people's sense of identity, the experience of place and of self in relation to place" 
(Tomlinson 1999, 20). Building a sense of place for global citizens requires recognition and strategic response to the changes that a more globalized world presents. As a nation, there is a critical need to rethink the best ways to prepare U.S. K-12 students, as young citizens, to meet both the challenges and the opportunities of an increasingly dynamic and interconnected global age.

\section{The Need for Teacher Professional Development and Geography Education}

Globalization and the associated social changes have prompted permanent changes in student and teacher education. Teachers and school leaders are being asked to equip students with the competencies they need to become active citizens and workers in the $21^{\text {st }}$ century. The Partnership for $21^{\text {st }}$ Century Skills, a coalition of businesses, education leaders, and policymakers, has developed a vision for student success, which includes both $21^{\text {st }}$ century student outcomes and $21^{\text {st }}$ century learning support systems (Figure 1). 


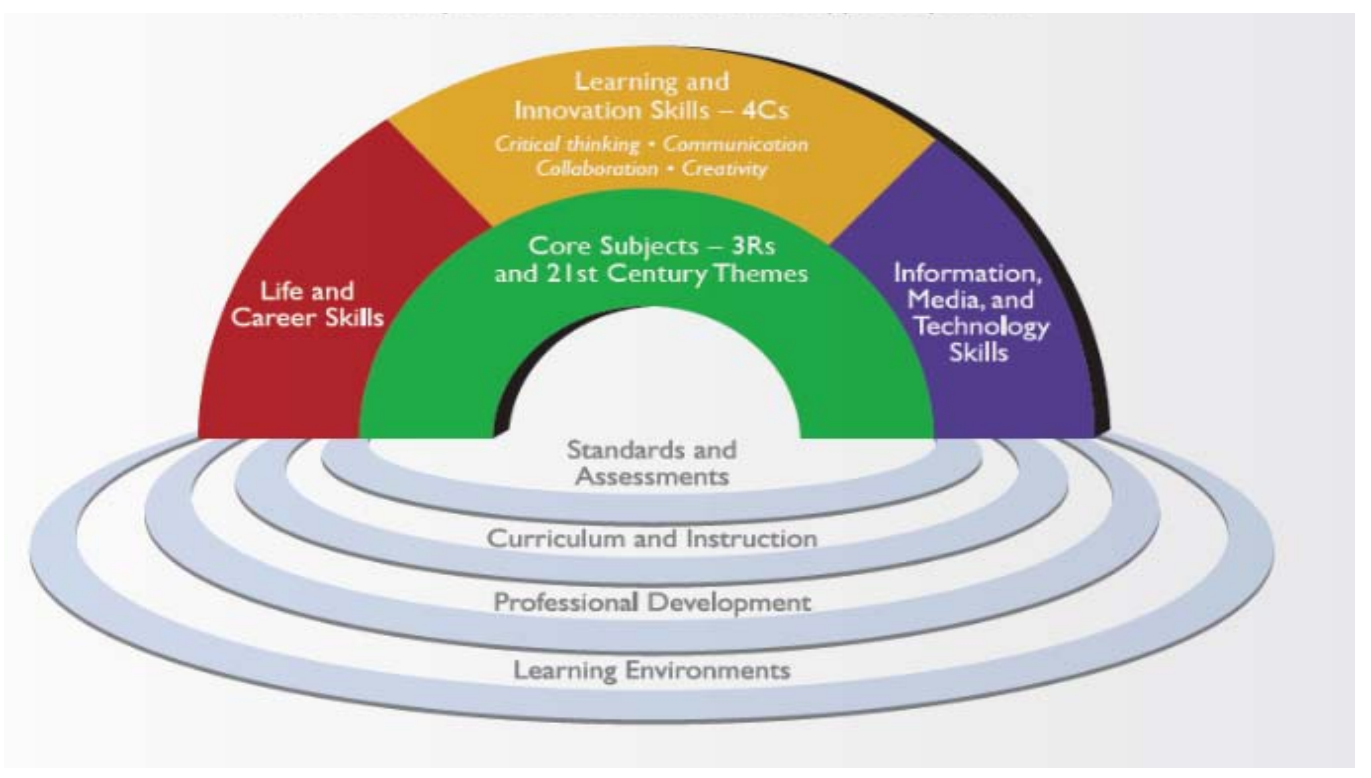

Figure 1. $21^{\text {st }}$ century student outcomes and support systems (Source: Partnership for $21^{\text {st }}$ Century Learning)

Research shows that an inspiring and informed teacher is often considered the most important factor influencing student learning and achievement (George Lucas Foundation-Edutopia 2008; Tucker P.D. and Stronge, J.H. 2005; Rice, J.K. 2003). As such, educational scholars and policy makers are demanding professional development opportunities for teachers that will help them enhance their knowledge and develop new instructional practices. For example, a report released by The Teaching Commission $(2004,11)$, proposes a multifaceted approach to helping teachers succeed, one that includes "ongoing and targeted professional development." Another example comes from the Center for Public Education, which released a report in 2013 entitled Teaching the Teachers: Effective Professional Development in an Era of High Stakes Accountability (Gulamhussein, 2013), which emphasizes effective teacher professional development as the linchpin in education reform. The Road Map Project focuses on large-scale 
improvement of K-12 education in geography education, and also considers education of teachers a key issue for improvement (Schell, Roth, and Mohan 2013).

For the purposes of this research, professional development is defined as the ongoing learning and application of new knowledge and skills in order to improve job performance and, in the case of teachers, that allows them to implement best educational practices. The expression "best practices" is a common term used to describe what works well based on time-tested methods in a particular situation or environment. If a professional is following "best practices," he or she is aware of current research and benefits from the latest knowledge, technology, and procedures in their field of work. In education, the term is used for a wide variety of activities and approaches intended to improve learning for teachers and students. For the basis of this study, "best educational practices" is defined as the wide range of individual activities, policies, and programmatic approaches to achieve positive changes in teacher or student attitudes or academic behaviors (Arendale 2013).

According to The George Lucas Educational Foundation-Edutopia (2008), the best teacher professional development programs emphasize subject-matter mastery. At the same time, the American Association of Colleges of Teacher Education and the Partnership for $21^{\text {st }}$ Century Skills (2010), each suggest that efforts must go beyond providing content knowledge by preparing teachers to personalize learning experiences in order to ensure that every student has a chance to succeed, and preparing teachers to deal with increasing cultural diversity in their classrooms and differences in learning styles. These efforts to improve content knowledge and teaching practice are interconnected and both are critical to the transformation of educator preparation and ongoing training. 
Globalization and an increasingly diverse pre K-12 student population also suggests that geography education is an absolute necessity in education curriculum. This research explores this nexus of professional development, sense of place, and geo-literacy.

Geography — the study of places and the relationships between people and their environments (National Geographic 2015) — has been described as "learning for living and a science with a strong futuristic emphasis" (Gritzner 2003, 90-91). It is also a timehonored discipline that provides the essential knowledge needed to ensure that America's citizens are prepared to assume responsible and enlightened leadership in today's complex and demanding global community. The need for geography education or "geoliteracy" in the $21^{\text {st }}$ century spans every grade level in the nation's education system and extends beyond offering a simple, stand-alone geography course. Geographic concepts should be incorporated into the teaching of all subjects. According to Schell, Roth, and Mohan (2013), these needs can and should be addressed through carefully designed and properly implemented instructional materials and professional development — through learning experiences that captivate learners' attention, develop their inquiry and thinking skills, and increase their understandings of the physical and cultural aspects of place. These learning experiences should also inspire and support teachers to share their ideas, challenges, student work, and resources in professional learning communities (Schell, Roth, and Mohan (2013).

\section{E. Research Overview}

This research aims to identify and assess evidence for the multifaceted benefits that accrue from learning within an international, experiential context. The primary purpose is to examine the ways in which a short-term international teacher professional 
development program influences the participants' geo-literacy and sense of place, and to a lesser degree, their teaching practices. More specifically, the study uses a qualitative, case study approach to analyze the Center for Geography Education in Oregon's (CGEO) Overseas Teacher Institute, a teacher professional development program that takes teachers on an international learning experience for 3-4 weeks in order to gain first-hand insights about the geography of a particular place, including the cultures that make-up the location and the physical landscapes that make it unique and special. Based on the literature review, the research assumes significant value related to the interdisciplinary nature of geography education for K-12 teachers of all subjects. It also assumes the best way to learn about a place is in-situ and that that such place-based experiences are integrated into the identities and practice of participants, hence influencing their overall sense of place. In addition, the study includes a relatively novel methodological approach, called photo-elicitation, which may be of importance for those designing placebased education professional development programs.

The specific research questions for this study are:

1. Does the international teacher professional development experience impact a participant's sense of place in meaningful ways?

2. How does the international teacher professional development experience influence the individuals' knowledge and attitudes about place?

3. Does the international teacher professional development experience improve teachers' geo-literacy?

The research also examines whether teaching practices changed because of the experience and training, and assessed how that experience was communicated to students in the classroom. However, the teaching practice analysis was not a primary question because several of the participating teachers are in unique situations that do not allow them to work directly in K-12 classrooms (e.g., one teacher works with adults) and hence 
there is simply not enough data to make any general conclusions on this point. It is included, however, because it suggests a starting point for further research.

To assess the ways in which C-GEO's Overseas Teacher Institutes influence the participants' senses of place and geo-literacy, the following mixed research methods are used:

- pre- and post-surveys to assess how participant geographic understanding has changed as a result of the international teacher professional development experience;

- observations and note-keeping during the international experience to ascertain and document pivotal moments in which sense of place or attitude is created or shifts; and

- photo-elicitation interviews approximately one year after the international experience to explore how participants give meaning to the human interactions and place of study and how those meanings are applied in the classroom.

This study makes a unique contribution toward understanding the importance of professional development program in the teaching profession in that it is new, timely research on factors not directly examined. Research has examined how people develop a sense of place, but there is little research that links sense of place to international programs involving teacher professional development. Nor has there been a good deal of focused research on the geographic learning derived from this type of professional development program. Most international education research focuses on student outcomes, not teacher learning outcomes. In addition, previous studies on international learning have not typically examined the "lifeworld" perspective — how different experiences, activities, and contacts make up the world of an individual life. For example, they do not address the important question of whether the participants had previous international experiences nor do they examine the type of environment where the 
participants currently reside or that they call home. It is conceivable that participants who are from rural versus urban environments or those that have never traveled to other countries will have different attitudinal or behavioral changes due to international professional development. Using an in-depth, qualitative approach, this study seeks to identify how these individual factors influence the teacher participants. Having this information can help inform designers of international experiences and teacher professional development programs, education and geography researchers, as well as school teachers and administrators, about better construction of such learning experiences. As such, the results have clear research and practical implications for geography education and teacher professional development programming. 


\section{LITERATURE REVIEW}

By better knowing the world, an individual better knows oneself — whether at home, or as members of the global community. This research examines the geographic understanding that results from eleven teachers' international professional development experiences, as well as the processes involved in gaining and synthesizing a new or redefined sense of place. It draws upon numerous concepts from a variety of academic disciplines. Table 1 defines these terms at a glance, and the following review of the literature further clarifies how these terms are relevant to this study.

Table 1. Summary of Key Terms

\begin{tabular}{|l|l|l|}
\hline \multicolumn{1}{|c|}{ Term } & \multicolumn{1}{|c|}{ Definition } & \multicolumn{1}{c|}{ Source } \\
\hline Globalization & $\begin{array}{l}\text { The acceleration and intensification of } \\
\text { interaction and integration among the } \\
\text { people, companies, and governments of } \\
\text { different nations. }\end{array}$ & $\begin{array}{l}\text { The American Forum for Global } \\
\text { Education 2003 }\end{array}$ \\
\hline Sense of Place & $\begin{array}{l}\text { The set of meanings and attachments that } \\
\text { individuals or groups associate with a } \\
\text { particular location }\end{array}$ & $\begin{array}{l}\text { Williams and Stewart 1998; } \\
\text { Hudson 2001 }\end{array}$ \\
\hline Phenomenology & $\begin{array}{l}\text { A form of inquiry that focuses on human } \\
\text { perceptions and experiences }\end{array}$ & Merleau-Ponty 2002; Willis 2001 \\
\hline Lifeworld & $\begin{array}{l}\text { The totality of an individual person's } \\
\text { direct involvement with the places and } \\
\text { environments experienced in ordinary life } \\
\text { without accepting the analytical separation } \\
\text { of subject from object }\end{array}$ & Buttimer and Seamon 1980 \\
\hline $\begin{array}{l}\text { Experiential } \\
\text { Education }\end{array}$ & $\begin{array}{l}\text { A philosophy and methodology in which } \\
\text { educators purposefully engage with } \\
\text { learners in direct experience and focused } \\
\text { reflection in order to increase knowledge, } \\
\text { develop skills and clarify values }\end{array}$ & $\begin{array}{l}\text { Association for Experiential } \\
\text { Education 2013 }\end{array}$ \\
\hline
\end{tabular}

Continues on next page 
Table 1, continued. Summary of Key Terms

\begin{tabular}{|l|l|l|}
\hline \multicolumn{1}{|c|}{ Term } & \multicolumn{1}{c|}{ Definition } & \multicolumn{1}{c|}{ Source } \\
\hline $\begin{array}{l}\text { Place-Based } \\
\text { Education }\end{array}$ & $\begin{array}{l}\text { Learning that is by design situated in } \\
\text { places, which are spatial or physical } \\
\text { localities that are given meaning by human } \\
\text { experience in them or relating to them }\end{array}$ & Semken 2012 \\
\hline Geo-Literacy & $\begin{array}{l}\text { The understanding of human and natural } \\
\text { systems and geographic and systematic } \\
\text { decision-making. }\end{array}$ & Edelson 2011 \\
\hline Photo Elicitation & $\begin{array}{l}\text { A method with “the simple idea of } \\
\text { inserting a photograph into a research } \\
\text { interview" to allow a different interview } \\
\text { communication than word-only interviews. }\end{array}$ & Harper 2002, 13 \\
\hline Liminal Space & $\begin{array}{l}\text { A blurry boundary zone between two } \\
\text { established and clear spatial areas. }\end{array}$ & Turner 1974 \\
\hline
\end{tabular}

\section{A. The Need for Geo-Literacy in a Globalized World}

Globalization stresses worldwide interdependence beyond any national, regional, ethnic, or racial boundary and, in turn, makes it important for people to understand how human and natural systems connect places to one another - the very core of geographic knowledge. Individuals lacking this knowledge are essentially living in a world without the context of cultures and customs and one that is devoid of characteristic landscape features and spatial relevance (Gritzner 2003).

Geographic literacy, or geo-literacy, is a broad term that encompasses the overall competence of an individual's geographic knowledge. Edelson (2011) defines geoliteracy as a long-standing idea consisting of three components (interactions, interconnections and implications) that create the ability to use geographic understanding and reasoning to make far-reaching decisions. It is through geo-literacy that people are better able to understand the complexity of the world, both as a whole and at different 
geographic scales. In addition, they are better equipped to appreciate how their decisions affect others (and vice versa), and to recognize the interconnectedness between humans and the environment.

Globalization places a premium on the geo-literacy of the American citizenry, yet geographic knowledge has long been recognized to be at poor levels in the United States. According to Harth (2007), many Americans lack even rudimentary knowledge of international affairs, not to mention relevant skills, productive perspectives, or even a commitment to engagement. The National Geographic-Roper geographic literacy surveys of 2002 (National Geographic 2002) and 2006 (National Geographic 2006) both indicate low scores in overall geographic awareness and understanding of recent U.S. high school graduates. According to the 2006 final report: "Taken together, these results suggest that young people in the United States...are unprepared for an increasingly global future. Far too many lack even the most basic skills for navigating the international economy or understanding the relationships among people and places that provide critical context for world events" (7). For instance, one in five 18-24 year olds could not locate the Pacific Ocean on a world map and believed the Amazon River is in Africa; one in ten could not even locate the United States (National Geographic 2006). Nearly half of these young Americans would both miss a conference call scheduled in a different time zone and travel in the wrong direction in an evacuation (Harth 2007). More recently, the results of the National Assessments of Educational Progress (NAEP) in geography, conducted in 2014 by the United States Department of Education — designed to measure what our nation's students know and can do in geography — revealed no significant changes in the geography scores for eighth-graders since either the first assessment year (1994) or the 
previous assessment in 2010 (NAEP 2014). Some good news is that in 2014, 27 percent performed at or above the "Proficient" level in geography, and therefore demonstrate solid academic performance and competency over the subject matter. The average score, however, was 261 out of 500, exactly the same as it was in 2010 (National Center for Education Statistics 2015).

Despite the obvious need for global awareness and skills, the unsettling reality is that in our current education system teachers usually receive little schooling in geography, and, as a result, pass on limited information to students. Merryfield (2000) suggests that most teachers have not been prepared to teach for diversity and do not understand the impact of globalization on the lives of their students and communities. At the same time, many experts suggest that schools and international organizations have increasingly moved away from educating children about global citizenship and international relations, suggesting that the problem has been spiraling since the 1930s, when traditional geography courses were replaced by social studies (Duckett 1993).

At the same time, it is argued that as part of the general mandate of social studies education, all K-12 students need to develop geo-literacy. For example The College, Career, and Civic Life (C3) Framework for Social Studies State Standards, conceptualized by individual state leaders in social studies education and supported by fifteen professional organizations, represents four core social studies content areas: civics, economics, geography, and history (National Council for the Social Studies 2013). However, the C3 Framework simply provides guidance to states on upgrading state social studies standards and does not outline specific content that needs to be taught. While 
many states have begun implementation work, as of August 2014, no states have adopted the National Curriculum Standards for Social Studies (Lipton 2014).

Additional research concludes that many social studies teachers have little or no coursework in geography, and that most state certification programs in social studies do not require geography for licensure (Bednarz, Stoltman, and Lee 2004; Mohan 2009). Without the necessary coursework or training in geography, there is now a shortage of geography teachers in America's schools with these skills (Brysch 2014). At the same time, geography has never received a dedicated funding stream. As a result, America is facing a crisis in geographic literacy which is jeopardizing the nation's global competitiveness, position of diplomatic leadership, and ability to fill and retain over 500,000 high-wage jobs in geospatial technology in the next decade (The Borgen Project Admin 2013).

On February 14, 2013, the Teaching Geography is Fundamental Act was crafted by the National Geographic Society Education Foundation (2013). It was intended to establish a federal funding program ( $\$ 15$ million per year for five years) to improve and expand geographic literacy among K-12 students in the United States by improving professional development programs for teachers offered through institutions of higher education. As of July 2014, the legislation had not been passed, despite increasing efforts to put geography back into the core content of K-12 education, making it even more necessary to have geographically trained teachers. The overall trend is a growing need for improved teacher preparation and professional development opportunities to ensure that our teachers are equipped with the appropriate skills to be effective in their classrooms (Bednarz, Stoltman, and Lee 2004). 


\section{B. Improving Teacher Professional Development Programs in Geography}

There is evidence that intensive professional development programs can help teachers to increase their knowledge and change their instructional practices (Serpell and Bozeman 1999; Jacob and Lefgren 2002; Desimone et al. 2002; Miles et al. 2004; Strong et al. 2004). Results from the 2010 National Assessment of Education Progress (NAEP) demonstrate that teacher professional development leads to better student outcomes (National Geographic Education Foundation n.d.). For test-takers in the $8^{\text {th }}$ grade, overall scores were significantly higher for students with teachers who reported attending civics, geography, or history-related conferences or workshops in the previous two years. Another report prepared for the Institute of Education Sciences by Regional Educational Laboratory Southwest and administered by Edvance Research (Yoon et al. 2007), shows that average control-group students would have increased their achievement by 21 percentile points if their teacher had received substantial professional development. More specifically, teachers that had more than 14 hours of professional development showed a positive and significant effect on student achievement from professional development, whereas those involved with the least amount of professional development (5-14 hours total) showed no statistically significant effects on student achievement (Yoon et al. 2007). In addition, time to reflect on teaching and to confer with colleagues can be invaluable for promoting more meaningful and effective instruction.

Similar to teachers in other subject areas, geography teachers need to possess not only geographic content knowledge, but also the skills that best facilitate diverse learning and promote the skills that are in demand by today's employers. Multinational companies worldwide are looking for employees with a global mindset and international 
experiences. According to research conducted by the Economist Intelligence Unit (2010), companies will become larger and more global in the next ten years, handling operations in more countries than they do today. A global survey of 572 executives representing companies with either an international presence or plans for international expansion, conducted by the Economist Intelligence Unit (2012), shows that almost nine in ten respondents to the survey think their company's number of overseas clients will increase in the next three years, while $77 \%$ believe that their companies will have an operational presence in more countries than they do now. The overwhelming majority (nearly 90\%) believe that if cross-border communication were to improve at their company, then profit, revenue and market share would all improve as well (Economist Intelligence Unit 2012). Respondents regard "differences in cultural traditions" (51\%) and "different workplace norms" (49\%) as the greatest threats to the smooth functioning of cross-border relationships (Economist Intelligence Unit 2012). Nandita Gurjar, global head of human resources at Infosys, one of the world's largest information technology services companies based in India, agrees that cultural awareness and cross-border ambitions go hand in hand: "We are a global company. We simply cannot progress without the know how and experience to deal with other cultures" (Economist Intelligence Unit 2012, report summary).

At the same time, educational researchers and practitioners are finding that in order to transform practice, experiential methods should be implemented (Klein and Riordan 2011). Professional development must immerse teachers in content, involve extended time both in total hours and in scope, allow teachers to both apply and reflect on their learning, and must occur in a collaborative community of peers (Lieberman and 
McLaughlin 1992; Ball and Cohen 1999; Cohen and Hill 2001; Garet et al. 2001;

Loucks-Horsley et al. 2003; McLaughlin and Talbert 2001, 2006).

\section{Phenomenology of Place}

The term "place," at its simplest definition, is a "physical environment or space" (Merriam Webster 2012). Place is revealed in its geography - the physical landscape, the human and cultural environment, and how these elements interact with each other to make a place unique. The study of place is a core focus for geography. From a geographic perspective, place is distinguished from space when endowed with value and meaning (Tuan 1977), and a given locality or landscape can hold widely divergent meanings for different individuals or cultures (Gruenewald 2003). Relph (1976) and Tuan (1975) suggest that places are always perceived differently. This is because the cultural background, socialization, education, gender, age, and socioeconomic situation of each individual varies (Tuan 1975). According to Tuan, the world is always the same, and it is only interpreted or understood in a unique way (Tuan 1975). J. B. Jackson (1984, 152) suggests that "it is place, permanent position in both the social and topographical sense, that gives us our identity." As such, research that investigates how people connect to and develop relationships with places can be integral to better understanding the knowledge systems and cultural identities of groups and individuals. These connections form the basis for what people think about place-centric values, rootedness, social identity and their own personal relationships with people and places — both in new environments and in their home communities.

Place is something that must be experienced rather than described (Relph 1976; Buttimer 1980; Casey 1996). Relph (1976) refers to his research approach as "a 
phenomenology of place." Phenomenology is a form of inquiry that focuses on human perceptions and experiences (Merleau-Ponty 2002; Willis 2001). One of phenomenology's great strengths is that it offers a broad framework for approaching the study of human-place interactions — an approach that examines and explains human situations, events, meanings, and experiences as they are known in everyday life but typically go unnoticed because they are beneath the level of conscious awareness (Seamon 2000).

Nineteenth century philosophers Franz Brentano, Edmund Husserl and Martin Heidegger laid the philosophical and scientific foundations for phenomenology, arguing that the world is perceived and experienced through phenomena, including "seeing, hearing and other sensitive relations" (Delanty and Strydom 2003, 29). In his formative work A Geography of the Lifeworld, David Seamon (1979) advocated for the use of phenomenology in the study of human-environmental experience because of its descriptive basis and holistic approach to the question of being human. The concept of the "lifeworld," much studied by human geographers in the 1970s and 1980s, encompasses the totality of an individual person's direct involvement with the places and environments experienced in ordinary life without accepting the analytical separation of subject from object (Buttimer and Seamon 1980).

This research uses a phenomenological research approach to study teacher education experiences in geography. In seeking to understand the lived experiences of teachers on a 19-day international professional development experience, the teachers' particular lifeworlds are taken into account. That is, the way in which, for each individual, the world is "lived, experienced and acted upon" (Graumann 2002, 98). Using 
this approach allows for an in-depth exploration of the international experience as it is lived, with particular emphasis on how the teachers construct meanings related to sense of place. The assumption of phenomenology of particular value for this research is that person and world "are intrinsically connected, literally, interdependent" (Graumann 2002, 98).

\section{Liminal Space}

The concept of liminality (derived from the Latin word limen, meaning threshold) was first introduced by ethnologist Arnold Van Gennep in 1909 in his Rites of Passage (Van Gennep 1909 [english translation, 1960]). In this publication, he proposed that all rites of passage — or "transitions" in life — are marked by three stages: separation (preliminal), transition (liminal), and incorporation or re-aggregation (post-liminal). The separation phase signifies "the detachment of the individual or group either from an earlier fixed point in the social structure, from a set of cultural conditions (a state), or from both" (Turner 1969, 94). During the middle, or "liminal" stage, the subject, or "passenger," stands at the "threshold" between their previous ways of structuring identity, time, or community, and a new way, which the ritual establishes. Turner (1969) refers to this as a state of "betwixt and in-between": a time where one does not belong to the society that they were previously a part of and they are not yet reincorporated into the new society. In the third phase, the passage is consummated and the subject is reassimilated into society with a "new" identity or status.

Geographers and other social scientists have further explored the notion of liminality as it relates to the concepts of time and space. More specifically, the term liminal space describes a transitional (and, often, transformational) area or zone through 
which we pass that is different from one's normal space (King-Irani 2006). In fact, it is this very act of movement and escape from daily routines, which signifies that the destination will be a liminal space. As such, short-term travel, often initiated as an escape from daily life, provides an excellent example of liminal space. During this time, the traveler suspends social status and home influences, as though he is living in between the two realities. Victor Turner relates travel to liminality as the potential for "what may be" (Turner and Turner 1978, 3). Beckstead (2010, 387) further discusses that with travel, “every step leads away from what is familiar towards unfamiliar settings and uncertain horizons which allows for novel and ambivalent experiences." In other words, travel is a journey into the unknown, which allows the traveler to be open to whatever experiences may come their way.

At the same time, travelers often pass through numerous liminal spaces (e.g., airports, hotels, rivers, roads, and borders). Trains and train stations exemplify the concept of liminal space. A train journey will take travelers past signs marking the entry and exit of boundaries — places divided and sub-divided into a complex web of overlapping patterns that include public and private lands, sacred spaces, historic areas, unique natural resources, parks, neighborhoods, and more. These spaces can often suggest the beginning of new and exciting possibilities. Hence, passengers move through in a physical and mental state of transition, often focusing more on the experiences awaiting them in other places than on the space they temporarily inhabit. Thoughts, like the moving train, whiz by the mind's eye and these moments of time in liminal space can help to reveal the different ways that individuals may perceive their experience. 


\section{E. Experiential Learning Theory}

Phenomenology of place relates closely to experiential learning theory (ELT),

another theoretical framework that guides this study. ELT is defined as "a philosophy and methodology in which educators purposefully engage with learners in direct experience and focused reflection in order to increase knowledge, develop skills and clarify values" (Association for Experiential Education 2013, n.p.). It stems from an emerging trend in teacher professional development concerned with learning from first-person experiences and holistic perspectives that go beyond content to include the construction of knowledge, attitudes, beliefs, and the transfer of learning (Kolb and Kolb 2005).

The foundation for ELT was described in Dewey's Experience and Education (1938), in which he states that experiences are the building blocks of learning and knowledge is constructed from past as well as new experiences. He emphasized that a learning experience does not just happen; it is a planned event with meaning. This theory is still equally as relevant all these years later. Roberts (2003) later added that learning is enhanced if the learner's quality of experience is high and the knowledge gained from the experience is transferable. With experiential learning the meaning is reaffirmed by the learners. Dewey (1933) asserted that experience followed by reflection results in growth. Reflection, applied to the act of learning, encourages learners to use critical thinking to examine information and ideas. Dewey defined reflective thought as "active, persistent, and careful consideration of any belief or supposed form of knowledge in the light of the grounds that support it and the further conclusions to which it tends" (Dewey 1933, 118).

Some people go through life viewing their experiences as isolated, unrelated events, instead of linking and constructing meaning from the experiences. The act of 
reflection involves linking a current experience to previous learnings (a process called "scaffolding"). It also involves drawing forth cognitive and emotional information from one's various senses (e.g, visual, auditory, kinesthetic, tactile). Reflection is an integral part of the experiential learning process, giving learners multiple avenues for engaging with complex ideas and allowing for broader meaning. Ideally, teachers should be able to imitate this process by reflecting on their own learning experiences and involving students in those reflections. Unfortunately, however, this need for reflection is often overlooked in the design of teacher professional development programs (Beavers 2009).

At the same time, there is a vital need for teachers to bring practical experiences into the classroom so that there is a link to reality that will better prepare the student for life experiences. Students need to be able to test ideas discussed in the classroom on real life situations. There is research indicating that U.S. high school (and college) graduates are unprepared for the workplace (Sheehy 2012; Achieve 2005). Yet, students have reported that their learning is improved when "learning experiences were practical and experiential" (Clarke 1998, 102).

This research examines experiential learning within the context of Putnam and Borko's (2000) work on situated cognition and teacher education. They write that "the physical and social contexts in which an activity takes place are an integral part of the activity, and that the activity is an integral part of the learning that takes place within it" (4). In other words, both the location and the context of learning are essential for what and how learning happens: "For some purposes ... situated learning experiences for teachers learning outside of the classroom may be important — indeed essential — for powerful learning" (6). Putnam and Borko (2000, 5) also emphasize the importance of 
providing "the cognitive tools — ideas, theories, and concepts — that individuals appropriate as their own through their personal efforts to make sense of experiences." It is also important to note that according to Pine and Gilmore $(1998,99)$, "experiences are inherently personal, existing only in the mind of an individual who has been engaged on an emotional, physical, intellectual, or even spiritual level. Thus, no two people can have the same experience."

An experiential approach to professional development can be especially beneficial for teachers of geography wanting to enhance their skills in geographic content and pedagogy. While they may learn through experiences such as reading geography books or watching geography-related documentaries, they are likely to benefit more from traveling, as it adds to their own content knowledge base and enriches the classroom experience for students (Drummond 2001). International experiences provide teachers with a global perspective. As Chickering and Braskamp (2009) have argued, developing and internalizing a global perspective is an essential part of a holistic teacher professional development paradigm. Cushner (2007) and Young (2010) show that firsthand experiences in a foreign environment improve teachers' understanding and ability to empathize with the diverse learners in today's classrooms. Certainly, simply being in a new place does not guarantee change, but for an American teacher who may have grown up around little cultural diversity, the knowledge gained through an immersion experience abroad has the possibility of radically changing their perspective. Often the areas of competence or social status that give them a strong sense of identity in America are no longer recognized when traveling internationally. This cultural immersion experience, accompanied by the learning of new skills and content, has the potential to 
lead a teacher to adopt improved teaching approaches in the classroom. Hence, the preparation of globally minded teachers, who will ultimately impact our students, should also include international learning opportunities (Schell, Roth, and Mohan 2013; PalmerMoloney and Bloom 2001).

\section{F. Short-Term International Learning Experiences}

Educators use such terms as "study abroad," "international experience," and "education abroad" interchangeably. According to the American Council on Education (2000), an "international experience" includes learning a foreign language, hosting international students, or studying, working or traveling abroad. Most institutions define short-term international experiences as programs that last less than a semester or quarter, yet there is a great deal of variation within the short-term category and there is no “average." For the purposes of this study, the short-term international learning program being examined lasted 19 days and took place in Eurasia (Russia, Mongolia, and China). The program included: two preliminary orientation sessions, which "set the stage" and provided important, relevant geography content lessons (See Appendices A-C); local school visits in Russia and Mongolia; a tour of the Russian Geographical Society; extensive travel via the Trans-Siberian Railway; many days exploring different urban and rural environments and included a knowledgeable tour guide from the region, as well as two university-educated professors.

International learning experiences have the potential to transform teachers as well as their students. They provide the means to enrich the K-12 curriculum and encourage a holistic approach to teacher professional development. An international environment its location, its people, and its culture - can have a deep and lasting impact on 
individuals who have experienced it first-hand. Perceptions may be changed, notions challenged, and most importantly, a broader world perspective developed. Current research supports the idea that teachers begin to develop global competency skills when they are exposed to other cultures and provided with meaningful personal and professional experiences abroad. Stachowski (2000) conducted research with student teachers placed in nearly 20 countries; they collectively reported improvements in their leadership, public speaking, cross-cultural communication, and problem-solving skills. They also felt they were more confident in their role as teachers as a result of their international experience. Learning abroad also helps develop cultural awareness, improves overall communication abilities, and may increase foreign language skills (Opper, Teichler, and Carlson 1990), all of which are crucial to educators in today's classrooms. In recent years, the racial and ethnic composition of the United States shifted. In 2007, about 14\% of the U.S. population was born outside of the United States (Aud and Fox 2010). At the same time, over $60 \%$ of elementary and secondary school students spoke a language other than English at home. Minorities are projected to make up 55\% of the population by 2050 (Aud and Fox 2010). In the U.S., 22\% of jobs were tied to international trade in 2009 (Aud and Fox 2010). Yet, today's students know very little about important global issues (National Geographic 2006). Globally competent teachers have the potential to develop their students' worldviews, and teach them skills that will make them more competitive in today's workforce. They are also more sensitive to the needs of diverse learners and able to teach them how to navigate an increasingly globalized society (Wang et al. 2009; Ismail et al. 2006). 
Unfortunately, however, these types of international experiences are difficult to incorporate into traditional teacher education programs. Financial considerations and risk management issues, for instance, can create serious challenges to providing sustainable international programs for teachers. In response to this need, many globally-focused informal education organizations have developed some form of learning abroad program that enables teachers to gain essential international experience, which in turn can develop their global competency so that they can better meet the needs of students. Such programs include: National Geographic's Grosvenor Teacher Fellowship Program, state geographic alliance institutes, The Korea Society, The Goethe Institute, Earthwatch, Toyota International Teacher Education Program, Study Canada, Global Links Global Educator's Program, The Asia Society, and Fulbright Teacher Exchange. These programs are designed to ensure that the international experience enhances sense of place and leads to a greater understanding of geography, yet there is limited research available to prove these assertions. Leaders of these programs are increasingly being asked to provide evidence that their programs and initiatives are producing the intended results. If these opportunities are to be sustained — and new programs established — then additional studies on the impacts of these experiences are critical, making this type of research imperative. To date, there is no research relating international teacher professional development programs to participant's sense of place, and only limited research on how these experiences influence classroom practices.

\section{G. Sense of Place}

Geographers have long been interested in understanding the concept "sense of place," and the idea that everything that happens to individuals is affected by their 
surroundings (including other people and the places within which one lives, works, and travels). Sense of place examines how people experience space beyond its physical properties and the sensory experiences that help create "place attachment" - the emotional ties between people and place (Kyle and Chick 2007). Investigating sense of place has been a research focus in numerous academic disciplines (e.g., anthropology, geography, land-use planning, psychology, sociology, resource management, and tourism studies), and while the meaning of the term varies slightly based on the discipline in which it used, all definitions address an individual's personal connection with a particular spatial location. The National Trust for Historic Preservation calls sense of place "those things that add up to a feeling that a community is a special place, distinct from anywhere else" (Stokes, Watson, and Mastran 1997, 192). Sanger (1997, 4), who has discussed sense of place within the context of environmental education, defines it as "an experientially based intimacy with the natural processes, community, and history of one's place." Yet, sense of place, has traditionally been the concern of geographers, who have long spoken of the importance of place as the unique focus distinguishing geography from other disciplines. Geographers Yi-Fu Tuan, Edward Relph, and Anne Buttimer are regarded as the pioneers in using experiential perspectives to reflect on place and the more elusive term, "sense of place" (Cresswell 2004). For this research, "sense of place" is defined as the set of meanings and attachments that individuals or groups associate with a particular location (Williams and Stewart 1998; Hudson 2001); the group being studied is $\mathrm{K}-12$ teachers and the particular place is Eurasia.

Sense of place involves awareness about a place and the attributes that differentiate it from other places (Tuan 1980). More specifically, it is the connection 
between an individual and the environment based on a combination of place attachment (emotional bonding to a place) and place identification (cognitive structures that foster social and individual identity related to place) (Rollero and De Piccoli 2010). Relph (1976) addresses the way in which individuals actually experience place. The concept of place incorporates all of the following: (1) location, (2) characteristics that distinguish it from other places, (3) spatial constructs and interactions, (4) particularities within the context of a larger framework, (5) continual revision in response to change, and (6) characterizations of place in the belief systems of individuals. Relph (1976) describes a continuum of sense of place development based on a steady accumulation of experience. According to this view, those who have spent the most time in a setting (e.g., have participated most fully in the life of the home or community) will have the strongest attachment. However, Tuan (1977) notes that a sense of place may also develop quite rapidly in "chosen places," where dramatic landscapes and intense experiences can lead quickly to attachment. It will be this latter assertion that will be tested in this research in an attempt to identify whether or not short-term international learning experiences can effectively develop or enhance participants' senses of place.

Place is an integral part of existence and the more powerful the memory of place, the more it shapes our notion of the world and our place in it (Taylor 2001). It is the remembered experience that is real for an individual and the way it is remembered reveals personal meanings. The knowledge of a place and the emotional attachment one feels toward a particular setting — whether positive or negative — helps to frame one's self-image. Thus, sense of place is the result of a cognitive view of the physical world in which the individual lives (Proshansky, Fabian, and Kaminoff 1983). Ching and Creed 
$(1997,22)$ take this concept a step further when they suggest that "place is rarely, if ever, the sole dimension of identification. Rather, place inflects other dimensions such as race, class, gender, and ethnicity." Relph (1976, preface), too, explicitly states that "place and sense of place do not lend themselves to scientific analysis, for they are inextricably bound up with all the hopes, frustrations, and confusions of life." As such, this study will follow a descriptive research approach using qualitative methods to assess sense of place.

Sense of place provides an important conceptual framework for exploring a broad array of issues in contemporary education. By revealing and analyzing the complex relationships between the experience of a place and attributes of that place, the study of sense of place in education has particular significance for teachers in today's diverse classrooms. According to Sanger (1997), increasing one's sense of place can be used to enhance teaching and learning outcomes.

As indicated earlier, there are significant increases in America's minority populations, and this trend will likely continue. For instance, according to the National Center for Educational Statistics (2015), from fall 2002 through fall 2012, the number of white students enrolled in public elementary and secondary schools decreased from 28.6 million to 25.4 million, and their share of public school enrollment decreased from 59 to 51 percent. In contrast, the number of Hispanic students enrolled during this period increased from 8.6 million to 12.1 million students, and their share of public school enrollment increased from 18 to 24 percent (Figure 2). 


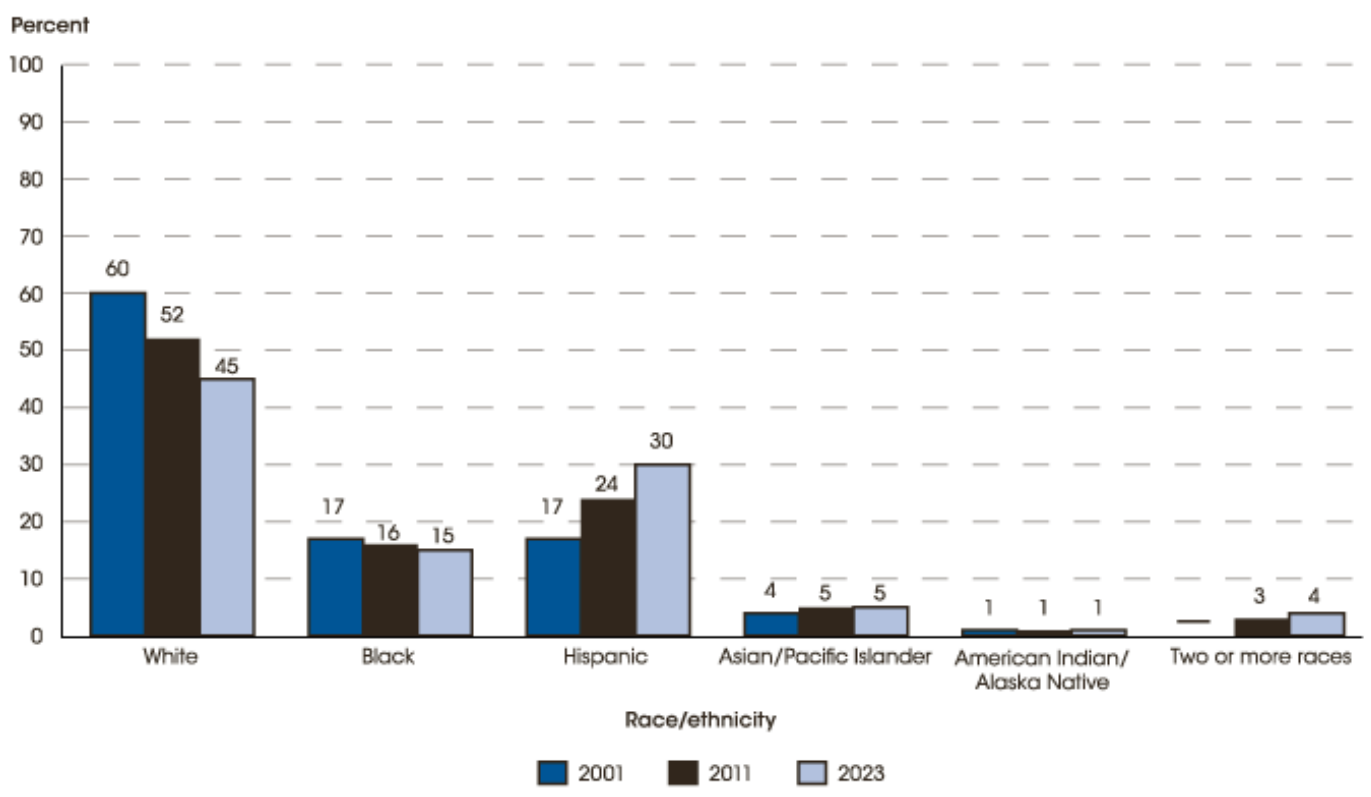

Figure 2. Percentage distribution of U.S. public school students enrolled in prekindergarten through 12th grade, by race/ethnicity: Selected years, fall 2001, fall 2011, and fall 2023 (Source: U.S. Department of Education, National Center for Education Statistics, Common Core of Data) Notes: Race categories exclude persons of Hispanic ethnicity. Prior to 2008, separate data on students of two or more races were not collected. Detail may not sum to totals because of rounding. Data for 2023 are projected.

In the midst of this expanding student diversity, the teaching force remains at the opposite extreme. According to Boser (2014), the demographics of the teacher workforce have not kept up with student demographics. In a 2011 state-by-state analysis, the Center for American Progress found that students of color made up more than 40 percent of the school-age population, whereas teachers of color were only 17 percent of the teaching force (Boser 2014).

While examining these statistics, it is fairly easy to understand why culturallyminded educators and administrators are calling for schools to begin a concerted effort to provide for today's students the skills, attitudes, and knowledge they will need to be successful in the multi-cultural and interdependent world in which these students will live and work as adults. Among these competencies are the ability to be multilingual and the 
ability to be cross-culturally competent (Scott 2001). Culture is not just a list of holidays or shared foods, religious traditions, or language; it is a lived experience unique to each individual. In this global era, it is the job of educators to stimulate the intellectual development of the students they teach. In order to do this effectively, they must reach out to their students in ways that are culturally responsive and appropriate. At the same time, today's teachers must examine their own cultural assumptions and the stereotypes by being aware of what they bring into the classroom and avoiding possibilities of hindering interconnectedness. Culturally congruent curricula and culturally aware teachers have been demonstrated to offset the well-documented disengagement in learning science among many urban and minority student populations (Bouillion and Gomez 2001).

A geography curriculum is a key as it integrates the natural and cultural meanings of a place as context for learning. In fact, the concept of place is one of the five fundamental themes of geography: "All places on the surface of the earth have distinguishing human and physical characteristics that interrelate with each other" (Lanegran and Peters 1993, 55). Knowing and understanding the meaning and significance of place, the changing physical and human characteristics of place, and how relationships between humans and the environment lead to a sense of personal and community identity is fundamental to geographic inquiry (Boehm and Bednarz 1994).

\section{H. Place-Based Education}

Place-based education is a pedagogical philosophy that aims to improve learners' sense of place by using various aspects of place as educational tools. Place-based education is situated (i.e., it focuses on a specific place) and, like geography, it is 
multi-disciplinary. It is also informed by the diverse cognitive meanings and affective attachments that tie people to places. This educational approach engages the multiple meanings of places in curriculum and pedagogy, enabling learners to find meanings in, and form attachments to, the places under study (Semken et al. 2010). It also promotes learning that is rooted in the unique history, culture, economy, environment, and art of a particular place (Sobel 2004).

Place-based education is a relatively new term, appearing only recently in the education literature. However, the concept has been promoted for over 100 years. For instance, when John Dewey $(1915,91)$ advocated for an experiential approach to student learning, he indicated that it should be done in the local environment in order to help students connect with their particular corners of the world: "Experience [outside the school] has its geographical aspect, its artistic and its literary, its scientific and its historical sides. All studies arise from aspects of the one earth and the one life lived upon it."

Proponents of place-based education often envision a role for it in achieving local ecological and cultural sustainability (Haymes 1995). As such, place-based education is often focused on students' immediate backyard, schoolyard, neighborhood, or community. This provides a good starting point, particularly for younger audiences, by fostering students' connection to place and helping them to learn to appreciate the world by understanding where they live and taking action in their own backyards and communities. Yet, in our increasingly global society, neighborhood and community are not what they used to be and, at some point, students and adult learners need to move beyond their local context. While not denying that there is a specificity to place, Massey 
$(1991,28)$ proposes that place should not be viewed as a single, local community, but rather as a manifestation of dynamic "local and global social, economic, and communications relations." She also believes that globalization can actually intensify the sense of the local.

A survey of the literature on place-based education reveals characteristic patterns to this still-evolving approach that make it distinctive (e.g., many place-based education learning programs include a participatory action or "service-learning" component), yet at the same time it is very closely tied to geography and experiential education (e.g., the content is specific to the geography of place; it is also inherently multidisciplinary and experiential). In addition, all of these education philosophies aim to connect place with self and community. An understanding of the relationships among place-based education, geography education, and experiential education is beneficial because each focus has been developed somewhat separately by educators who have produced curriculum materials and instructional practices that could be useful within the other arenas.

Some critics of place-based education believe that the primary goal of schooling should be to prepare students to work and function in a highly technological and consumer-oriented society. In contrast, place-based educators believe that education should prepare people to live and work in a way that sustains the cultural and ecological integrity of the places they inhabit. To do this, people must have knowledge of ecological patterns, systems of causation, and the long-term effects of human actions on those patterns (Orr 1994). One of the most compelling reasons to adopt place-based education is to provide students with the knowledge and experiences needed to actively participate in the democratic process. Place can serve as a central organizing principle for a socially 
relevant pedagogy. As such, integrating the approaches of place-based education can make geography education more relevant and a geographic perspective can help placebased education programs more effectively promote social justice and environmental sustainability (Isreal 2012). 


\section{SUMMARY}

In this globalized world, there is a critical need for geo-literacy. It is through geoliteracy that people can begin to recognize the interconnectedness between humans and the environment. In turn, the geo-literate are better able to make decisions at different geographic scales and to appreciate how their decisions affect others (and vice versa). One key way to improve geo-literacy is by offering high-quality teacher professional development programs that immerse teachers in geographic content and involve extensive total hours and scope. According to Yoon et al. (2007), teachers with substantial hours of professional development have been shown to have a positive effect on student achievement. In addition, the act of reflection (drawing forth cognitive and emotional information from one's various senses) is vital if teachers are to effectively bring their experiences into the classroom. Learning is enhanced even more if the knowledge gained is transferable and occurs in a collaborative community of peers. To better understand what makes professional development effective, and the benefits of such programs, additional studies on the impacts of these experiences are critical, making this type of research imperative.

This research examines experiential learning within the context of a short-term international professional development experience for teachers which aims to develop a global perspective. The particular focus of this study is on understanding the impact of this professional development program on teachers' geo-literacy and sense of place with some investigation as to how these learning outcomes are applied in the classroom. Several qualitative methods are applied to assess this case study, including pre and post surveys, researcher as participant-observer, and photo-elicitation interviews. 
In addition, the study uses a phenomenological research approach to identify whether or not short-term international learning experiences can effectively develop or enhance participants' senses of place. The concept of place incorporates all of the features that give it personality and distinguish it from other places. The emotional bond between person and place is referred to as one's sense of place or place attachment. Dramatic landscapes and intense experiences can lead quickly to attachment. Phenomenology's great strength is that it offers a broad framework for approaching the study of human-place interactions, which allows for a descriptive basis encompassing the whole of an individual person. In this case, the teachers' lifeworlds are taken into account, allowing for an in-depth exploration of the international experience as it is lived, with particular emphasis on how the teachers construct meanings related to sense of place. Liminal spaces, particularly time on the train, also help to reveal the different ways that individuals perceived their experience. 


\section{METHODOLOGY}

This research delves deeply into the experiences of 11 teachers who participated in the 2013 Center for Geography Education in Oregon (C-GEO) Eurasia Institute, with a focus on understanding the geo-literacy learning outcomes and the subjective construct referred to as "sense of place." As such, a qualitative model was accepted as the most appropriate means for capturing "authentic identity" which is sensed more than measured (Binder 2008). Quantitative analysis is rarely used to explain people's behavior and simply does not contribute as well to an understanding of the meaning of place-based experience (Creswell 1998). In addition, this research aims to present a detailed view of the phenomenon within a specific setting rather than broad generalizations across populations. Because of the significant amount of anecdotal information, in the form of direct participant quotes, that is presented in this paper, it is important to note the following: in some cases, the direct quotes were slightly modified by the researcher for flow and readability but only when there was no ambiguity as to what the intention was, or what the correct version should be.

In concert with the qualitative methods, the use of a case study and phenomenological approach allows for a close examination of the rather complex experiences of a single event or phenomenon of interest, in its natural real-life context. More specifically, these approaches provide the ability to examine the professional development as a whole, giving an in-depth look at the experience from multiple perspectives (Creswell 2007; Merriam 1998). As indicated, the case for this study involves the experiential, international professional development program, which was 
conducted by the C-GEO in summer 2013. The teachers' experiences are documented through interviews, observations, and surveys.

Data collection occurred before, during, and after the international experience. At the pre-trip orientation participants received a consent form and were asked to provide signatory consent to participate in the project. They also received the researcher's contact information so that they could ask questions about the process or their involvement at any time, as necessary. As part of this process, participants were also asked to choose a pseudonym by which they would be known in the presentation of the results. Participants were not told a great deal about the research upfront so as to not bias their answers to the pre-survey, but once they completed the pre-survey and as part of the in-person orientation they were provided with a more comprehensive overview of the research including general goals and the various expectations of them as participants in the research project.

Given the emphasis on narrative interpretation, it was not necessary to control for the variety of teacher experiences and insights. What was important, however, was effectively documenting differences in the learners' backgrounds and experiences prior to participating in this program. Examples include whether or not this was a first time encounter with foreign travel; what they defined as their own culture and heritage; and any associations that they had with the place they would be visiting. Figure 3 provides an overview of the research design for this project. 


\begin{tabular}{|c|c|}
\hline $\begin{array}{l}\text { Phase } 1 \text { - Preparation } \\
\text { (February-May 2013) } \\
\text { Recruit Participants (n=11) } \\
\text { Pre-Meetings } \\
\text { - Administer Pre-Survey } \\
\text { - C-GEO assignments: to learn about } \\
\text { relevant geography concepts }\end{array}$ & $\begin{array}{l}\text { Phase } 2 \text { - Case Study: Data Collection } \\
\text { (July 2013) } \\
\text { Travel to/from and around Russia, Mongolia, } \\
\text { China (19 days total) - "The Case Study" } \\
\text { In-situ observations by researcher (participant- } \\
\text { observer) } \\
\text { Collect } 12 \text { Sense of Place (SOP) photos per } \\
\text { person }\end{array}$ \\
\hline Develop Interview Instrument & \\
\hline 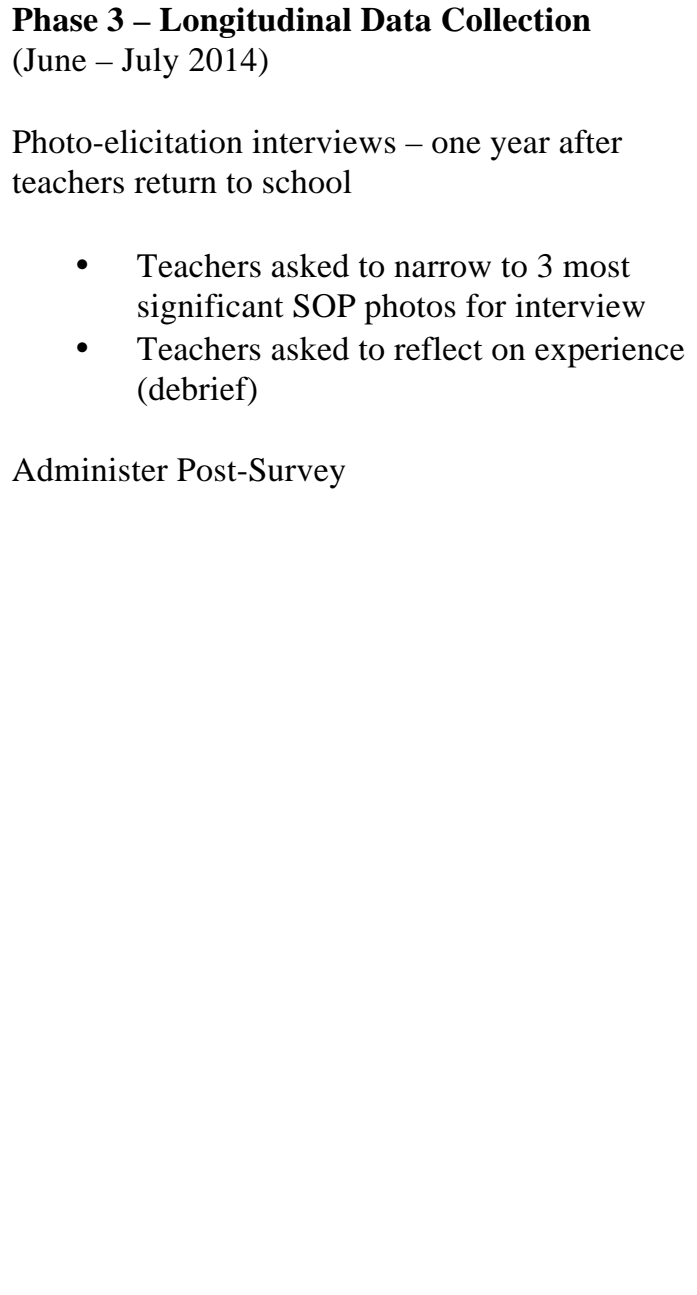 & 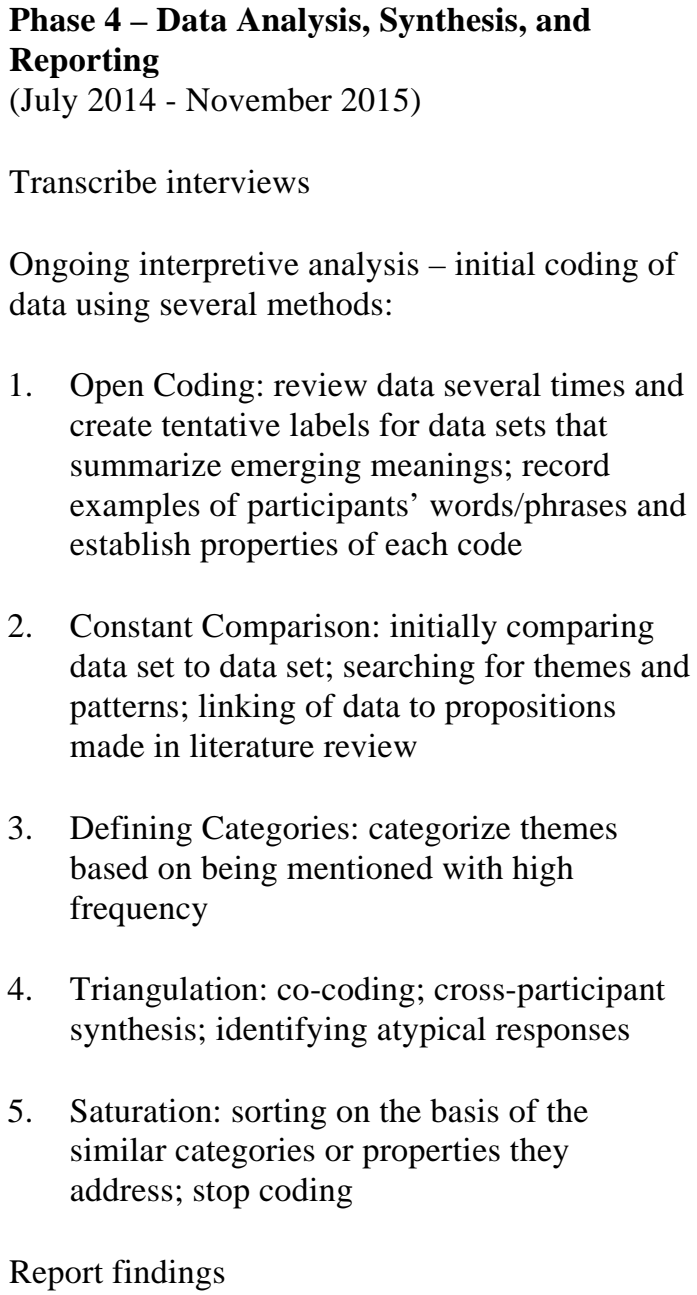 \\
\hline
\end{tabular}

Figure 3. Research design overview 


\section{A. Methodological Approaches}

This qualitative, case study research investigates the C-GEO professional development program in Eurasia using the following multiple sources of evidence:

- pre- and post-survey of teacher participants before and after the experience to assess how their geo-literacy, sense of place, and teaching practice changed as a result of the international teacher professional development experience (see Appendix F);

- observations conducted during the international experience to ascertain and document pivotal moments in which sense of place or attitude was created or shifted; and

- photo-elicitation interviews after the international experience to explore how participants give meaning to the human interactions and place of study and how those meanings are applied in the classroom (see Appendix G).

NOTE: Other materials examined for research purposes include Appendix A, B, $\mathrm{C}, \mathrm{D}$, and $\mathrm{E})$

\section{Pre- and Post-Surveys}

In order to measure the teachers' knowledge, attitudinal, and behavioral changes as a result of the international teacher professional development experience, two surveys were administered, one at the start of the program and the other at the conclusion of the overseas trip. The surveys were administered in person in order to facilitate accurate data collection and analysis (see Appendix F). The goal of the pre-survey was to capture a baseline understanding of their perceptions and knowledge about the places they would be visiting and to better comprehend their current teaching environments. The survey included questions about their geographic knowledge of Eurasia in addition to their current teaching practices. Examples of questions asked included: why they wished to participate in this international learning experience; why they chose the C-GEO Eurasia program; what they hoped to learn; and what they knew about Eurasian culture and 
people. In addition, background information about their life experiences and demographic data was collected.

\section{Observations}

In-situ observations were used to gather insights into the impact of place on participants. I (the researcher) adopted the role of participant-observer. As indicated earlier, the best way to enter a person's lifeworld is to participate in it. Hence, the use of this in-depth methodology allowed me to participate in the daily activities of the C-GEO overseas program over the full 17-day program (plus two travel days), as well as both of the six-hour pre-orientations. The process of conducting this type of field work involved gaining entry into the community, participating in as many different activities as possible, clarifying my findings through informal conversations, as well as keeping organized, structured field notes to facilitate the development of a narrative that explains various sense of place and geo-literacy learning outcomes to the reader. As a participantobserver, I established a close relationship with participants, while at the same time attempting to stay aware of, and objective toward, unique learning situations and opportunities. In addition to the maintenance of a journal of observations related to teacher experiences, I allowed for time to reflect upon the meaning of those various situations, enabling me to facilitate a better understanding of individual and group behaviors and activities.

Observational data resulted in detailed descriptions of teachers' interactions with people and landscapes in order to provide further insights on how place meanings were being constructed. Specific areas of focus included: challenges and affirmations related to navigating new cultures and environments; how teachers interacted with people they 
encountered; how teachers interacted with the physical environments; what symbols of place and experience were reflected in their conversations; how they made meaning of the professional development; new behaviors related to personal development that emerged out of their on-site experience; and epiphanies regarding their philosophy on teaching.

Participant observation is used as a mainstay in a variety of disciplines, and, as such, has proven to be a beneficial tool for producing studies that provide accurate representation of an individual, group or culture (Kawulich, 2005). A main strength of observational studies is that they allow the researcher to see how participants actually behave rather than what they say they do (Kawulich, 2005). A further strength of this methodology is that it offers ways of studying behavior without presenting the same ethical problems that other methods might (e.g. experimental design). While problems with invasion of privacy could be raised, I addressed this upfront by obtaining appropriate informed consent from each of the participants.

There are obvious trade-offs when using participant observation as a methodology for research. The researcher is able to get an "insider" point of view and the information may be much richer than that obtained through other research methods, such as those which recruit participants to come to the researcher. On the other hand, observational studies are difficult to replicate and since there is little or no control of extraneous variables, one cannot make cause and effect statements (Kawulich, 2005). Observations can also be very time consuming and require careful preparation. For example, researchers may not always be in a position to take notes and at times must rely on their memory. This is a problem as they may forget details and are unlikely to remember direct 
quotations. There is also the problem of observer bias; if the researcher becomes too involved they may lose objectivity (Kawulich, 2005). There is always the danger that the researcher will "see" what they expect (or want) to see. In turn, they could selectively report information instead of noting everything they observed, thus reducing the validity of their data. Knowing this is a common concern in observational studies, I chose to classify and record the data using a method called event sampling (McLeod 2015). As such, I decided in advance what types of behaviors (events) were of interest and recorded them as they occurred naturally; other types of behaviors were ignored (McLeod 2015). In this case, I focused on "events" as conversations where the participants directly identified an appreciation or disdain for place, described personal meanings tied to a place, expressed newfound geographic knowledge, or other aspects of developing their sense of place or geo-literacy. I also recognized that observations, alone, may not provide information about what participants are thinking or feeling, critical components of sense of place. Hence participant-observation was combined with the other methodologies (prepost surveys and photo-elicitation interviews) in order to provide a more complete picture of the learning outcomes of interest (i.e., geo-literacy and sense of place).

\section{Photo-Elicitation Interviews}

This research used applied photography to examine the subjective meaning of place. Photo elicitation is the simple idea of inserting a photograph into a research interview. It provides an effective method for investigating how people give meaning to particular locations. In this case, photo elicitation takes a collaborative form, where the interviewees (as opposed to the researcher), serve as the photographers and the photographing itself forms an active part of the inquiry. The photographs represent 
aspects of the individual's personal meaning and subjective experience and are intended to support the communication about these complex topics, while at the same time allowing the participant a greater level of self-expression.

At the second pre-trip orientation, participants were provided with detailed information about the photo-elicitation process. On the first day of the actual journey, each participant was provided with a single-use, 12-exposure, film camera and asked to take photos during the trip of things about the place that meant the most to them. I kept the instructions regarding what and where to photograph to a minimum in order to avoid biasing content and location of pictures, with the following examples provided as clarification of the types of things to be photographed: people, buildings, landscapes, etc. In the end, anything that the participants chose to photograph was considered appropriate. Because cameras contained film (as opposed to digital files), the participants were not able to delete any photo that they took. At the end of the experience, the researcher collected the cameras and developed the film. The pictures were then digitized and sent to the participants for review. There were some challenges with poor film quality and the participants' ability to always capture what they wanted with the research cameras; hence they were ultimately allowed to exchange any of the digitized photos with appropriate images that they had taken with their own, personal cameras. However, each participant was limited to twelve total photos in the initial phase and later asked to narrow down to a total of three per person. The final three photographs were then used in concert with the interview data to provide the empirical basis for analysis.

One-on-one, post-trip interviews were held at the end of the school year following the trip (May and June, 2014) with a focus on how teachers developed place meaning 
from their experience in Eurasia and how their geography curriculum and teaching-styles were modified based on the experience. Data collection using interviews is usually achieved by face-to-face meetings, but with the increasing technological possibilities, a new and creative way to access people was explored. Specifically, several of the interviews were conducted over the Internet using the software application Skype and Vodburner - an application that records the Skype video call for future reference and transcription. The in-person interviews were conducted in neutral locations convenient to each interviewee and each lasted approximately 1-2 hours. Pre-established interview questions were asked of all participants (see Appendix G), but interviews often progressed a bit differently, depending on the participant.

As part of the original plan, but not revealed to the participants initially so as not to bias them and in order to incorporate reflection into the process, each participant was expected to reduce the number of photos to only three. One week prior to the scheduled interview, each teacher was asked to narrow the photos down to the most meaningful three photos. These photos were then used to guide the photo-related interview questions. For example, interviewees were asked to describe the content of each photo; what they were attempting to represent with each photo; what was meaningful about the photos; why they took the particular photos; and why they chose those final three photos for the interview. In addition, program participants were asked to speak about their experiences learning abroad; their interpretation of the cross-cultural learning experience; their strongest memories; the ways in which they understand themselves differently as a result of the experience; and the extent to which their understanding of geographic issues changed as a consequence of the international professional development program. For a 
full list of interview questions, see Appendix G. The questions were selected based upon previous research. I examined the various interviews and surveys that have been used effectively to capture gains in sense of place (Semken et al, 2009; Williams, 2000; Williams and Vaske, 2003). Although some personal information was collected in the pre-survey, the photo elicitation interviews expanded on the areas of personal history and background contexts, such as why the teachers wanted to participate in this experience; why they chose the C-GEO program specifically, and what they previously knew about Eurasia's culture and people. The survey instrument was tested with the previous year's C-GEO international professional development participants who were going to spend three weeks in Turkey. It was retooled based on feedback from the group.

All interviews were digitally recorded, but participants were also given the option to turn off the recording if they wanted to at any time (none of them chose to do this). Afterwards, the recordings were transcribed and analyzed using the constant comparative method (Glaser and Strauss 1967). The goals of this approach were to: (a) identify emerging patterns; and (b) gain an understanding of participant experiences. During transcription of the audio recordings, initial themes emerged. In further data analysis, common themes and repeated terms were noted. Those themes and terms were then clustered and coded based on shared or related meaning.

An open coding strategy (Strauss and Corbin 1990) was developed in order to examine the imagery chosen by teachers and to identify themes and categories that yielded an understanding of what was being represented (See Figure 3). Specific examples of coding for this project are the keyword lists for natural and cultural environments illustrated in Table 2 and Table 3 in Section VI. Through constant 
comparison, I sought specific evidence of how individual place meanings were constructed and maintained, in addition to identifying the themes and meanings which seemed to be shared among participants. The patterns discovered, based on the photoelicitation interviews, were compiled and reanalyzed in order to confirm or disconfirm themes across and between participants. Analysis continued until no more patterns could be identified and I felt that the data had been completely represented by current codes or themes.

When photographic images are used to convey information, it is important to consider the content of the photograph and the intent of the photographer. Hence the following questions were asked of the participants as it related to their chosen sense of place photos:

- Tell me about these photos.

- Describe the content.

- What is being represented?

*I also made note of how the images were situated within the natural environment and how well photos related to and exhibited Eurasia's historical and cultural development and uniqueness.

- How do you feel about what is being represented in the photo(s)?

- How does what the image represents make you feel?

- Why did you choose these photos?

- What is meaningful to you about them?

- What was your personal experience as it relates to each photo?

- How did you feel about the narrowing down process of the photo component and did it serve as part of your reflective process? Explain.

By asking these questions, I was able to get "into" the scene — and into the mind of the photographer, who made a series of decisions about where, when, and how to take the photograph. To assess a photograph thoughtfully, it is important to consider those 
decisions. As the photographer decides where to stand, moves the camera, or zooms in on the object of the photo, he or she deliberately selects what to include in the image. For example, Alice chose only to include the mountains and clouds above the group ger camp site, which she describes as follows:

This [photo] is in Mongolia when we were out in the gers and it was just the mountains are so similar to home. I cut the bottom of the photo because I just wanted the mountains; our camp was at the bottom of the scene. (Alice)

This is a good example of how important it is to understand the photographer's intention and choices regarding what to include or exclude in the image. So many of the participants included photos of the ger camp as one of their three sense of place images because of the meaningful experiences they had there. Yet, Alice is the only one that cropped out the actual gers from her photo in order to show only the mountains and clouds. Without her interpretation, the researcher would not necessarily know that this picture had any connection to the ger camp experience. In photo-elicitation research it is critical that the researcher take the time to understand the various decisions made while taking the photograph, which in turn directly affects the message(s) conveyed by the photograph. Decisions about the setting of a photograph or subject placement helps to tell the photographers sense of place story.

\section{B. Methodological Advantages and Disadvantages}

The strength of qualitative research for this study is its ability to provide complex textual descriptions of how people experience a sense of place and retain geographic knowledge. It also provides a rich, detailed picture about why people act in certain ways, and their feelings about these actions. I have chosen case study methodology in order to collect detail that would not normally be easily obtained by other research designs, such 
as experiments or surveys (Rowley 2002). Certainly, a limitation of this particular research is that the sample does not include representatives of all community interests (e.g., it has geographic and racial limits). The focus on subjective meaning and use of qualitative, case study methodologies also favored a relatively small sample in this study $(\mathrm{n}=11)$ and therefore, the results cannot be generalized to a larger population. The use of the individual as the unit of analysis and in-depth investigation of subjective meaning also means that other possible foci were abandoned (e.g., gender differences or student outcomes). In addition, because three very distinct countries (i.e., Russia, Mongolia, and China) were visited over a short period of time as the setting for the study, the blurring between places is not discussed in depth and the individual places were often grouped by participants or researcher into one geographic region - Eurasia. However, the depth and complexity of the chosen research methodologies allows an analysis of sense of place not available in other methodologies.

It is also important to note that meaningful learning is a slow and uncertain process. Some teachers change more than others through participation in professional development programs (Fennema et al. 1996; Franke et al. 2001; Knapp and Peterson 1995). Further, some elements of one's knowledge and practice are more easily changed than others. Interviews have many benefits, such as allowing researchers to understand how meanings differ between people, exploring topics more in-depth, and giving respondents an opportunity to raise additional issues. Using images to stimulate discussion elicits information and minimizes power imbalance between the interviewer and the respondents. However, when exploring place-related information in the context of geographical research, interviews may also impose restrictions. For instance, 
interviews often do not take place "on location" (i.e., during an interview a respondent has no direct contact with the place or objects he or she is talking about). The information revealed in the interviews is based only on one's mental image of the place, or one's memories. It is challenging then to capture small nuances, multi-sensual dimensions and each person's lifeworld using only the interview method. Tuan (1975) and Thrift (2008) insist that those nuances make up a substantial part of what place means to people and how place influences them. In addition, according to various authors (Prosser 1999; Pink 2007; Edwards and Bhaumik 2008), much of an individual's knowledge about the world, and consequentially about places, is built on the visual. Therefore, the use of photographs is incorporated into the interviews.

However, finding the ideal approach to collecting and analyzing the visual data in this case did came with some minor challenges, particularly because there is little guidance in methods literature. For example, the use of film-based, disposal cameras was not successful (because of poor film quality and the participants simply preferred the ease of modern digital cameras), and in the end, the use of participant's personal digital cameras worked exceedingly well for all involved. At the same time, the idea of limiting the initial sense of place research-based photos to 12 per individual did prove to be an important component, as it kept the participants focused on the task. Another challenge of using the photo-elicitation method was the possibility of coincidental things being overrated. For example, objects or events which were encountered frequently could be overemphasized as meaningful. On the other hand, the participants provided a relatively unique array of photos and the similar photos were consistently of places that proved to 
have a great deal of meaning to the individuals based on all of the research methods (i.e., not just limited to photo data).

Photo elicitation produces a different kind of information by evoking feelings and memories that relate to the photograph's particular form of representation. At the same time, a key concern of visual research is how meaning is given to images. Photography can be incorporated into a research process in several ways. It can be used as a researcher-led or respondent-led technique. In the case of the latter, asking respondents to take photos of their everyday environment can be beneficial as it allows the researcher to get an overview of people's interaction with places without "intruding on their daily schedules or following them around" (Cele 2006, 155). Taking photos can be an empowering experience as participants are in charge of the process and get to represent the things they choose, when and from whichever perspective they want. As such, the respondents obtain more control over the way in which the information they provide is interpreted. In addition — and an especially important aspect in geographical research — this method enables the research participants to be inspired by direct contact with their environment. Another benefit of combining interviews with photography is that the participants were later able to reflect on their photographs, as they related to their most impactful memories from the experience - a process that proved to be valuable. For example, one participant suggested that choosing three [photos] was a good analysis for this study.

It was a reflective process and was really helpful. Lots of times I come home from a trip and never really look at my photos again. This process helped me to recall the memories. 
Another participant indicated that

it was challenging to take such a huge trip and to narrow to only three photos, but it made me think and I had to come back to my photos and I had to analyze them because of this interview. With past travel, I never come back to my photos. This process made me think.

In the end, the combination of methods used in this study provided unique benefits and allowed the participants to express themselves both individually and in a group context, using a number of different access points. The different opportunities to elicit information were useful for involving the views of individuals who may have felt shy or less articulate in any one particular context. And, the use of photography, in particular, served as a catalyst for communicating about place without the presence or influence of the group or the researcher. The research is also in line with the rapid developments and decreasing prices of technology. At the same time, general interest in and use of novel research methods has sharply increased within research disciplines dealing with people and places (Pink 2007). 


\section{CASE STUDY}

\section{A. The Center for Geography Education in Oregon (C-GEO)}

The Center for Geography Education in Oregon (formerly Oregon Geographic Alliance) is a non-profit organization dedicated to geography education. The mission of the Center for Geography Education in Oregon (C-GEO) is to improve geography education and awareness in Oregon by increasing the public awareness of the importance of geographic education and placing emphasis on geography in grades $\mathrm{K}-12$, and to improve geographic teaching methods and materials. C-GEO provides professional development for geography teachers regarding course content and pedagogy. Many of the professional development opportunities that C-GEO offers include international experiences.

C-GEO is part of the National Geographic Network of Alliances for Geographic Education (Alliance Network). The Alliance Network is a group of educators united to support geographic literacy. The alliances are based on partnerships between university faculty and K-12 educators. These state-based organizations connect educators, provide professional development and promote educational innovation at state and local levels. Since 1986, National Geographic and the Alliance Network have worked to catalyze geography education reform across the United States, Canada, and Puerto Rico.

In 2002, researchers at the Mid-continent Research for Education and Learning investigated the impact of the Alliance Network by comparing the achievement of students of alliance teachers with a carefully matched sample of students who had taken the 2001 National Assessment of Educational Progress geography assessment (National Geographic Education Foundation n.d.). The study found that students of teachers who 
had been involved in the Alliance Network had statistically higher levels of achievement when compared with students of similar demographic backgrounds. Another major finding of the study was that "Alliance students tended to perform better on questions pertaining to understanding U.S. geography, reading maps and drawing and interpreting maps" (National Geographic Education Foundation n.d.). In addition, "the teacher demographic variable that significantly impacted student achievement was the frequency with which the teacher participated in the Alliance summer institutes" (National Geographic Education Foundation n.d.).

C-GEO offered a distinct learning opportunity for teachers in the 2013 Advanced Summer Institute, which allowed 11 Oregon teachers to travel by rail through Russia, Mongolia, and China. This experience serves as the case study for this research. The 2013 teacher professional development opportunity focused not only on teaching geoliteracy skills, but also on building a sense of place in order to improve classroom teaching of geography among participants. To achieve these goals, teachers spent 17 days (plus two additional travel days) in an intensive learning program which included homestays, school visits, and interaction with national geography society's scholars (see Appendix D for itinerary). In terms of this research, the C-GEO program provides a holistic picture of how international, experiential education processes can be designed for teacher professional development and what it looks like in practice.

Pre-departure materials and two, day-long pre-trip orientations addressed valuable topics on core geographic concepts, how to prepare for travel abroad, about the Russian, Mongolian and Chinese cultures and landscapes, and planned itineraries (see Appendices A-D for detailed information). A major goal of the program was to improve teachers' 
content knowledge in geography. Underpinning the C-GEO program is the rationale that international learning experiences are invariably life changing and build teachers' capacity to operate effectively as active and informed local and global citizens - and to teach their students to do the same. Teachers do this through connecting with peers in other countries, experiencing diverse cultures, and developing new understandings of their place in the world. Since active learning and being able to discuss and teach geographic concepts is a key element of the C-GEO program, before the teachers left the U.S. and as the group traveled in Eurasia, they were asked to identify examples of, explain, and reflect on each of the following geographic concepts:

Continentality_ - The impact of a large landmass on climate and weather patterns. Continentality usually results in more extreme temperature ranges.

Transhumance - A pattern of regular seasonal movement or migration by human groups. Transhumance is a form of pastoralism, where livestock is moved seasonally between one area of pasture and another.

Migration_ - the movement of goods and people from one place in the world to another for the purpose of taking up permanent or semi-permanent residence, usually across a political and/or geographical boundary.

Urbanization — The state of being or becoming a community with urban characteristics. When two or more metropolitan areas grow until they combine, the result is often referred to as a megalopolis.

Origin and diffusion - The process through which certain characteristics (e.g., cultural traits, ideas, disease) spread over space and through time. This is accomplished through the movement of people and goods (migration) and communication systems. 
Human-Environment Interactions - The physical and human characteristics of a place provide keys to understanding the interrelationships between humans and their environments. People modify the natural environment to meet their needs (e.g., they build houses or dams; plow and irrigate fields) and the environment impacts people's lives (types of houses they build or crops they can plant).

\section{B. Participants}

Participants were eleven K-12 teachers living in Oregon and enrolled in a 17-day (plus two additional travel days) C-GEO international teacher development program during the summer of 2013. Any Oregon K-12 teacher who had completed a previous C-GEO institute, and all Oregon pre-service teachers, were eligible to apply for the program. Acceptance into this program was based on an application process (see Appendix E) and was the decision of the C-GEO co-coordinators, at their sole discretion. All of those selected for the experience were encouraged, but not obligated, to participate in this research. Participants were made aware of the research possibility as part of the first of two pre-trip orientations (which occurred on February $23^{\text {rd }}, 2013$ at Portland State University). They were then approached in person at the second pre-trip orientation on May $18^{\text {th }}, 2013$ and asked if they would be willing to participate in the study. All of the eleven teacher participants agreed and were recruited for the research. They varied in age (ranging from early 20s to mid-50s), teaching experience (from pre-service to veteran teachers) and gender (two males and nine females). All of the participants were Caucasian. One of the participants had never traveled outside of the state, nor been on a train, plane, or boat, while some others had significant experience traveling overseas, including some who had participated in past C-GEO international learning programs. All 
were made familiar with the professional development structure, its objectives, and their expected roles via the two pre-trip orientations, each of which lasted approximately six hours.

\section{Why Teachers Chose to Participate in the C-GEO Eurasia Program}

Before describing in detail the learning impacts related to sense of place and geoliteracy, the participants' reasons for choosing to participate in this international learning experience were examined. The question was asked as part of the survey instrument and while the reasons varied from personal to professional goals, the responses overwhelmingly indicated a desire to broaden their knowledge base and to enhance their teaching, as indicated by the following example from Susan: "I want to expand my firsthand knowledge of the region and to take what I learn and create vivid [rich] learning experiences for my students."

The world is full of great teachers, despite the fact that educational systems in many countries, including the United States, struggle to provide high quality teacher professional development programs. Highly motivated teachers recognize the importance of staying current on global issues, learning more about the world around them, and interacting with other people from all walks of life. In turn, they find a way to continue their education in a way that works for them. The teachers that chose to spend three weeks away from the familiar — their families, their homes, and their communities — to explore Eurasia first-hand with C-GEO, all understood that this opportunity would not only change them as individuals, but also as professionals. They explicitly endeavored to participate in and gain from this rich experience so that they could improve their own knowledge and become better teachers. Not only did they learn about other cultures and 
landscapes, but they expressly gained from the interactions that C-GEO arranged with other teachers and geographers in Russia and Mongolia. Observations during these encounters included commiseration among the different groups of teachers regarding the lack of respect they often felt from students, parents, or the community and the challenges of delivering lessons to students who are accustomed to anytime, anywhere entertainment and learning that has come with the Internet. Yet, despite these and many other stated challenges, they also shared a deep commitment toward a vision of what excellent education will produce, and bonded over their various plans to make it happen. As Susan says,

I love to learn about schools and lifestyles in other parts of the world. When I met with the teachers in Mongolia, we shared stories about how we are actively instilling an interest in environmental responsibility and opening our students minds to the larger world while at the same time encouraging pride in our respective communities. (Susan)

Edith explains a connection she made after talking with one of the Mongolian

teachers when she says,

Unfortunately, Mongolian public schools are just not set up to accommodate the needs of disabled students. Hearing about those special needs going unmet was very difficult. Knowing this, and hearing of the Mongolian teacher's persistence in her endeavor to give her students a quality education, ignited a new dedication in me to do the same for my future students. (Edith)

Many of the teachers also indicated the specific desire to enhance their understanding and appreciation of different cultures. Kelsey, for example, states that her reason for participating in the C-GEO Advanced Summer Institute in Eurasia was "to enrich my understanding of Eurasian cultures and places.” Amber explains, I always wanted to see Mongolia and Eastern Europe. This gives me the opportunity to explore and experience places I don't live in and to share the stories of other cultures, as examples of the similarities and specialness 
of different cultures, with others -- many of whom do not travel or experience other cultures. (Amber)

Today's teachers must be prepared to educate diverse students about diverse topics (Dean 2007). The C-GEO international professional development experience was viewed by almost all the research participants as an opportunity to do something different with their lives, fulfill long-held dreams and develop or enhance personal strengths. They chose to travel a long way from home, in some cases leaving North America for the first time in their lives. For a small minority, the contrast between their home country and the Eurasian countries visited was overwhelming in terms of language, landscape, and cultural differences, but the majority accepted the challenges and developed a range of personal strengths and skills which they felt helped them become more confident, articulate, and resourceful. Participants reflected that the frustrations, stressful situations, and other challenges they encountered from time to time also played a part in enabling them to cope with adversity, both in the international setting and in their home environment.

\section{The Journey}

The C-GEO Summer Institute in Eurasia provided teachers with ample opportunities to immerse themselves in the physical and cultural geography of Eurasia, as they journeyed nearly 5,000 miles $(8,000 \mathrm{~km})$ along the Trans-Siberian Railway, from St. Petersburg, Russia, to Beijing, China (Figure 4). Participants crossed two continents, traveled through six time zones and experienced ever-changing landscapes, including the Gobi Desert and Lake Baikal. They learned about the cultures of Eurasia, stopping to experience daily life in cultural capitals and remote villages with visits to museums, 
schools, and private homes. The route traced the Amur River through narrow valleys, past villages along the steppes, and through the Ural Mountains.

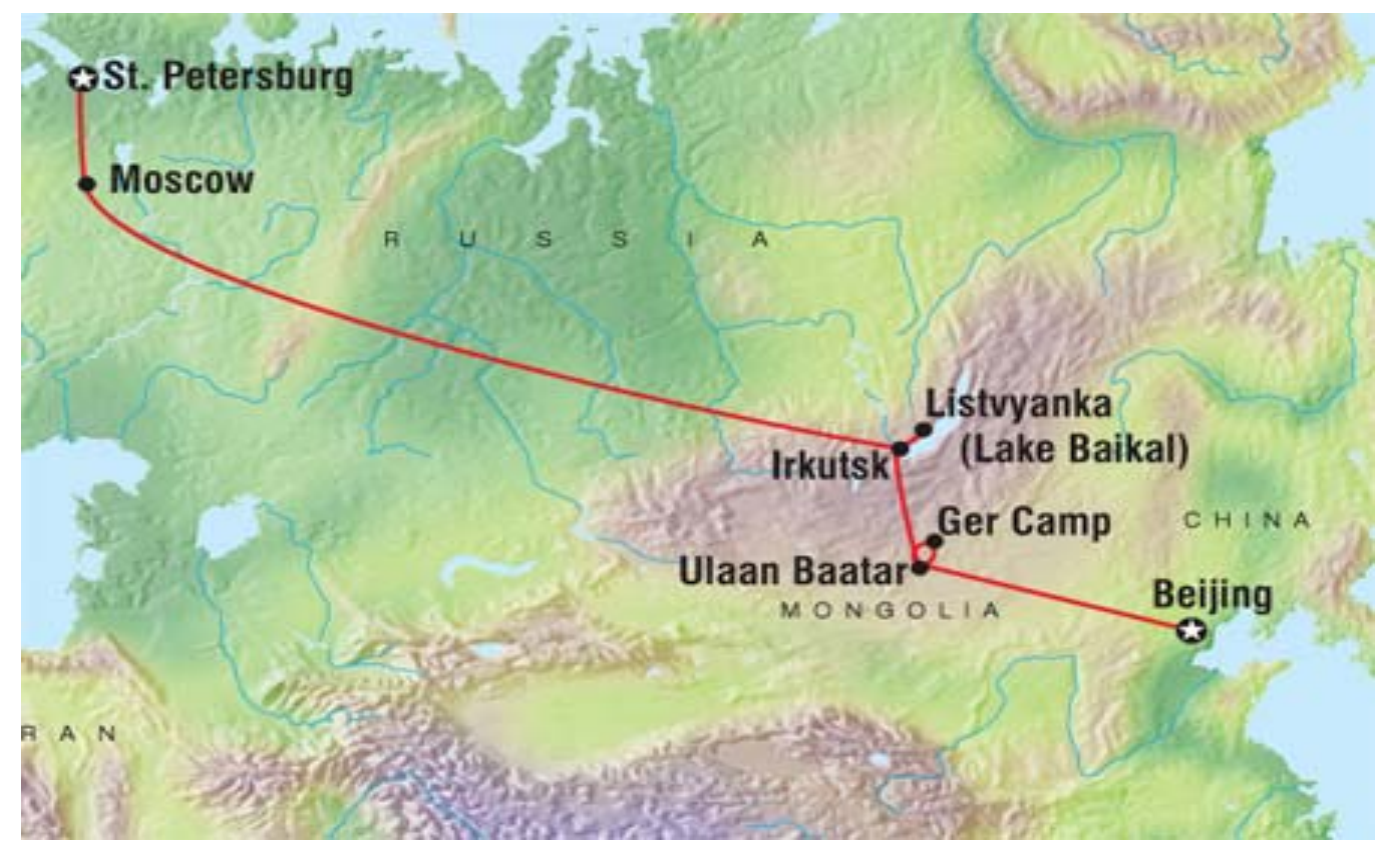

Figure 4. Map of Trans-Siberian route (Source: Global Exploration for Educators Organization)

The C-GEO participants were offered a taste of the complexities, contrasts, and charms of today's Russia, which turned up all of the anticipated stereotypes — from onion domes to nesting dolls, babushkas and bureaucracy, to vodka and borscht. They also experienced one of the most famous train journeys in the world — the TransSiberian Railway. In all, the participants spent over 130 hours on the train alone. The railway took the group across continents and time zones from Moscow to Beijing, but not before traversing the wild steppe lands and encountering some of the nomadic peoples of Mongolia. In Mongolia, they spent a couple of days in the capital city and the cultural, industrial, and financial heart of the country, Ulaanbaatar, and visited a ger camp in Terejl National Park. The rail trip ended in China's capital city, Beijing. The group had a 
local organizer join them on this journey to help arrange for transport and hotel, but for the most part, the trip was self-guided. As this research discovered, the journey provided participants with new perspectives on and knowledge about this vast region with its traditional cultures, stunning natural landscapes and a rich history.

\section{St. Petersburg, Russia (Day 1-2)}

Participants began the trip with three days in St Petersburg, a city with a vibrant, cosmopolitan atmosphere beautiful architecture. St. Petersburg's main thoroughfare is Nevsky Prospekt, a bustling boulevard that features some of the city's best architecture — and great people watching. The C-GEO group took many strolls along this urban artery of St. Petersburg during their visit. Many participants were rather surprised by the large number of American stores (e.g., Apple, Starbucks, Kentucky Fried Chicken, The Hard Rock Cafe). It was also a good place to practice reading Cyrillic signs (Figure 5). Participants quickly realized how essential it is to learn the Cyrillic alphabet in general navigation purposes — and many lamented that they had not done it prior to arrival.
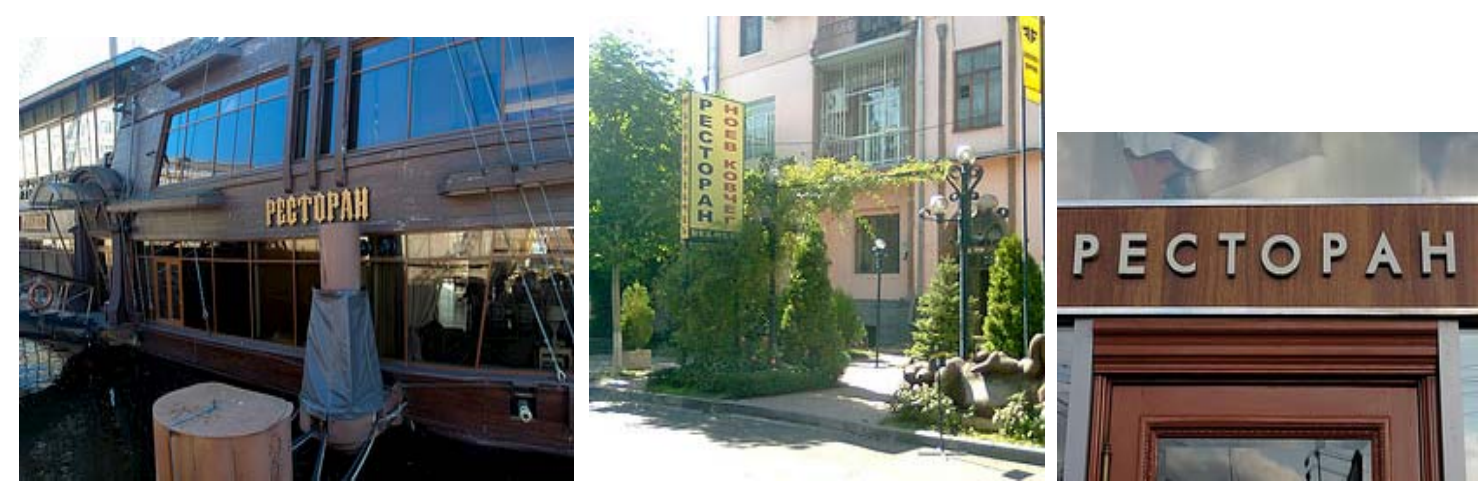

Figure 5. The word "PECTOPAH" is everywhere in Russia. With a rudimentary grasp of Cyrillic, the C-GEO participants soon figured out that it is means "restaurant." (Source: Flickr Hive Mind) 
Parts of St. Petersburg consists of a series of islands separated by canals. The C-GEO teachers took an educational boat ride through the city's concentric canals, under whimsical bridges, and past beautiful mansions and churches, before suddenly popping out onto the Neva — a wide expanse of river — where they were treated to sweeping riverfront vistas of palaces, museums, and fortresses. Participants also began to sample local foods. They were also provided the opportunity to visit one of St. Petersburg largest attractions — the Hermitage Museum, famous as one of the world's best museums with many galleries of old masters, including classic Western artists and treasures from the East.

Participants were also provided with a unique opportunity to visit the historic headquarters of the Russian Geographical Society, which was founded by the Russian Emperor Nicholas I in 1845 with a goal of collecting and disseminating geographical data on Russia (Russian Geographical Society 2013). They received a personal tour of the library, the lecture-hall, and the multi-purpose media studio, which connects the headquarters via videoconference with all of the other 81 of the Society's offices throughout the nation (Russian Geographical Society 2013).

The participants also began their cultural journey of taste by exploring some of the traditional Russian cuisine at their first of several group meals. It included a variety of options, like dumplings, Russian potato salad, pickled vegetables, smoked and salted fish, and wild game. Before leaving for Eurasia, several of the participants expressed curiosity about the region's food so that they could embrace it while there. Food, in fact, is a terrific way to create, develop, or enhance one's sense of place (Denn 2011). This will be discussed later in this paper, but it is also worth mentioning here, as food can have roots 
in a country's political, geographical and demographic histories. Hence, knowing about the foods of Russia, Mongolia and China can help one understand the countries better both past and present.

\section{Moscow, Russia (Days 3-4)}

On Day 3 of the trip, the participants left St. Petersburg for Moscow on a night train. As the C-GEO teachers climbed aboard the first of many trains on this journey, each group of roommates found its compartment and settled in. They locked the doors to keep the train's thieves at bay, and the train chugged southeast. In the morning, the train rattled into Moscow, revealing a very different city than the one the group had left the night before.

Moscow is the most populous city in Europe, with 16.1 million residents (Allianz 2015). The city has the world's second busiest metro system (Allianz 2015), carrying more passengers per day than the London and New York subways combined (Allianz 2015). Many of the C-GEO participants took an opportunity to observe a Metro station at rush hour, where they watched people pour into the entrances and descend down the long, steep escalators. For the uninitiated teachers from Oregon, the Moscow Metro felt like an intricate puzzle. Signs are in the Cyrillic alphabet only, but even more confusing, the name of the station is not prominently posted within view of the arriving train. One just has to "know" the stop. For a tourist, this means keeping eyes glued to a Metro map and counting stops, while at the same time, straining to hear announcements on the crackling loudspeaker (assuming one even knows how the station name is pronounced). Those who rode the Metro spoke highly of the sightseeing value, as many of the stations are designed as if they were ornate underground palaces, with intricate decorations and grand halls. 
For most of the participants, their time in Moscow began on the Red Square -

Moscow's cobbled main square which separates the Kremlin (former royal citadel and current residence of the Russian President) from a historic merchant quarter and religious center. Inextricably linked to all the most important historical and political events in Russia since the 13 th century, the Kremlin is a self-contained city with a multitude of palaces and churches, and has a commanding position on the Moskva River bank next to Red Square. The southern end of the Red Square is crowned by the multi-colored, multipatterned onion domes of St. Basil's Cathedral — perhaps the most famous sight on Red Square (Figure 6).

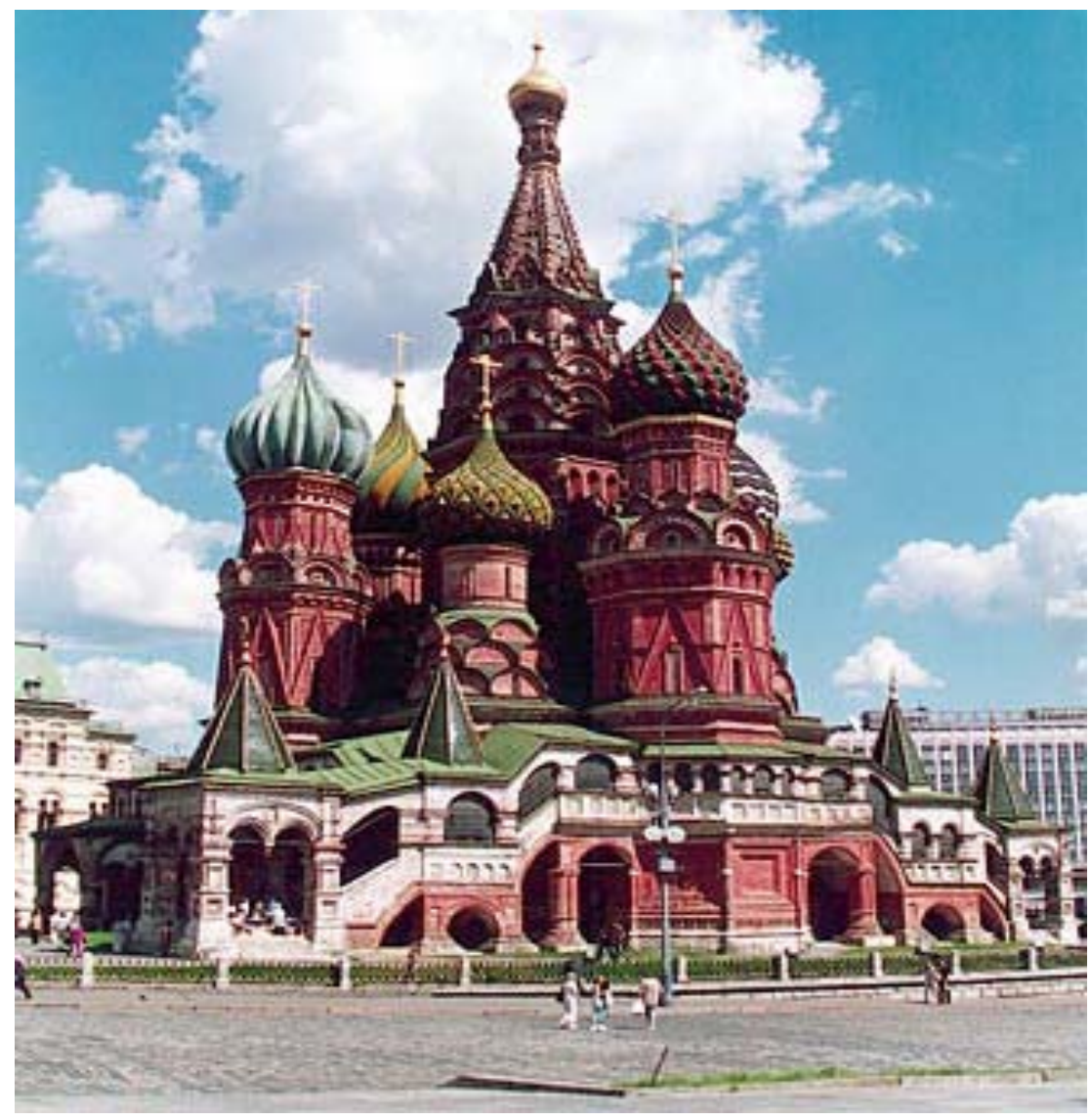

Figure 6. St. Basil's Cathedral, located on the Red Square in Moscow (Source: Moscow.info) 
Enclosing the Red Square from the East is the building that houses Russia's most famous shopping mall — the State Department Store, GUM — an abbreviation of the Russian: Главный универсальный магазин; Glavnyi Universalnyi Magazin; literally "main universal store" (Wikipedia 2015). Prior to the fall of communism, the top floor was home to a secret clothing store only open to the highest echelons of the party (Moscow.Info n.d.).

Much of the interior of the Kremlin is off-limits to outsiders, but two areas allowed tourists - Cathedral Square, a cluster of gold-domed cathedrals in the center of the Kremlin and "The Armoury," a museum of treasury collections and riches of Russian royalty, such as Fabergé eggs, elaborate horse carriages, gowns and crowns.

A boat cruise on the Moskva River provided a glimpse of several key landmarks, including the 16-story-high monument to Peter the Great; the colossal golden-domed Church of Christ the Savior, which was demolished under Stalin, then rebuilt after the fall of communism; the Riverside Towers, a super-modern business district; and some of the "Seven Sisters" - towering skyscrapers including hotels, civic buildings, and apartment complexes built by Stalin in a neo-Gothic style.

Farther afield, several of the participants went to a souvenir market in search of something typically Russian to take home with them. The tradition of open-air markets is still very much alive in Russia and comes with all of the usual trappings: loud and abundant noise, exotic scents, and an overwhelming amount of items to choose from; along with the opportunity to haggle over significantly marked-up products, and the thrill of the chase that often causes tourists to snatch up such items they may not necessarily need. This market offered a wide variety of Russian memorabilia, such as the old 
standard-issue Red Army gear, busts of Lenin, and painted-and-lacquered kitchenware, and the famous Russian fur hats with earflaps, called Ushankas. In fact, one of the teacher participants made the Ushanka her mission that day:

I really want a fur hat! It is the most important thing! That's what I'm looking for right now. (Kelsey)

In addition, there were numerous different styles of matryoshka or nesting dolls — a symbol of Russian folk craft after winning a bronze medal at the 1900 World Exhibition Fair in Paris (teachershelp.ru 2015). The matryoshka dolls are said to symbolize the hope and value of life and the family; traditionally, a matryoshka was given to newborns to wish them a long and prosperous life (teachershelp.ru 2015). Nowadays, one can find numerous variations on the theme, including the classic version depicting smiling babushkas, but also Russian figures and heads of state, infamous terrorists, American politicians, famous musicians, cartoon characters, or various sports stars. The shoppers examined the painted and laquered boxes depicting Russian landscapes or fairy tales. These mass-produced boxes were fairly cheap, compared to the genuine ones made by well-known artists which can cost thousands of dollars. Utensils (e.g., spoons, teapots, elaborate salt and pepper shakers) also seem to occupy a special place among Russian souvenirs. For example, there was a myriad of choices of the famous dishware Gzhel. The name comes from the ancient town where these intricate blue and white ceramics originally came from.

The small subset group of shoppers left the market with bags of goodies on their arms and smiles on their faces and then hurried back to the hotel to pack up their new belongings so they could meet the larger group and collectively embark upon the much anticipated journey along the Trans-Siberian Railway. 


\section{The Trans-Siberian Railway, Russia (Days 5-7)}

Conceived by Tsar Alexander III, the construction of the Trans Siberian railway began in the late $19^{\text {th }}$ century (Babanine 2003). Today, it is still the longest railway line in the world, spanning over 5,700 miles (9,000 kilometers), eight times zones and two continents (Yatskevich 2011). Considered by many as one of the greatest train journeys in the world, the Trans-Siberian railway brings passengers into the heart of Eurasia and its most remote regions. Hence, a particularly unique aspect of this international teacher professional development experience was the amount of time spent on the train. Many of the participants recognized this aspect of the experience as quite meaningful. The train journey alone greatly influenced the physical and cultural environment connections of the participants, as it was essentially a part of everyday life for the travelers. This experience was described in detail by all participants and was often considered to be both demanding and empowering. For instance, Ivan notes that “...the action of being on the train as long as we were, and the process of learning to function together with people from all over the world, was most meaningful and important to me; it was a rite of passage."

For some of the participants, spending numerous days cooped up on a hot train with minimal electricity (and minimal air-conditioning) and plumbing sounded rather unappealing, whereas others had dreamed of taking the Trans-Siberian across Eurasia as a grand adventure. In the end, participants realized both — that the journey can be more arduous than imagined, but at the same time, much more rewarding.

Participants shared four-berth sleeper cabins; there were nine per coach which meant that the entire group was in one coach (Figure 7). By day, they sat on the lower bunks with the upper ones raised. Luggage was stored under the berths or above the door 
to the corridor and all compartments were lockable. Each coach was looked after by a pair of attendants called a provodnik (male) or provodnitsa (female). These attendants checked passenger tickets at the door when the group boarded and shortly after departure, came around to take tickets and supply each person with bedding (two sheets, a pillowcase, and a towel) in sealed packs — the blankets and mattresses were already stacked in each compartment. A samovar (urn) at the end of every train car provided unlimited boiling water free of charge, so the teachers brought items such as instant coffee, cocoa, or noodles, as well as a spoon and mug. They also packed non-perishable snack items, like granola bars, crackers, trail mix, dried meats and fruits. The trains also had a restaurant car - a Russian one in Russia, a Mongolian one in Mongolia and a Chinese one in China — serving drinks, snacks, and full meals. Riders could also buy food from the many vendors or kiosks on station platforms.

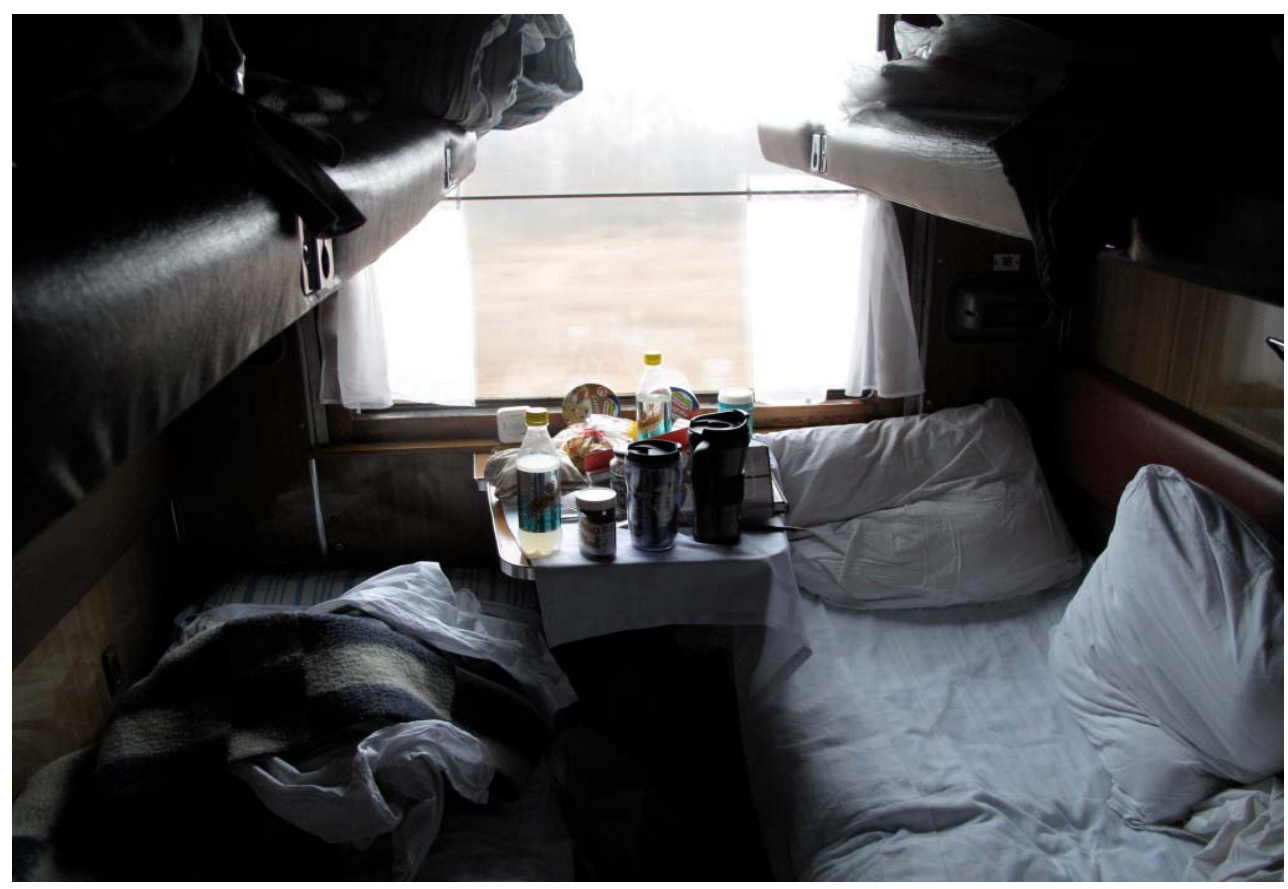

Figure 7. Train compartment on the Trans-Siberian railway — the teachers' home away from home for a large portion of the trip (Source: Holman 2015) 
At each end of the train car there was a washroom with a toilet and a small sink (Figure 8). There were no showers. Generally speaking, these get maintained by the attendants, but the washrooms seemed to get dirty quickly and when the rolls of exceedingly thin toilet paper ran out the attendants were not always amenable to replacing it as quickly as needed. Hence, the teachers learned to provide their own wet wipes for freshening up and a spare roll of toilet paper to better meet their needs. Also, the toilets discharged straight onto the track and for that reason, the washrooms were closed and locked about 20 minutes before arriving at stations until about 20 minutes after departure.

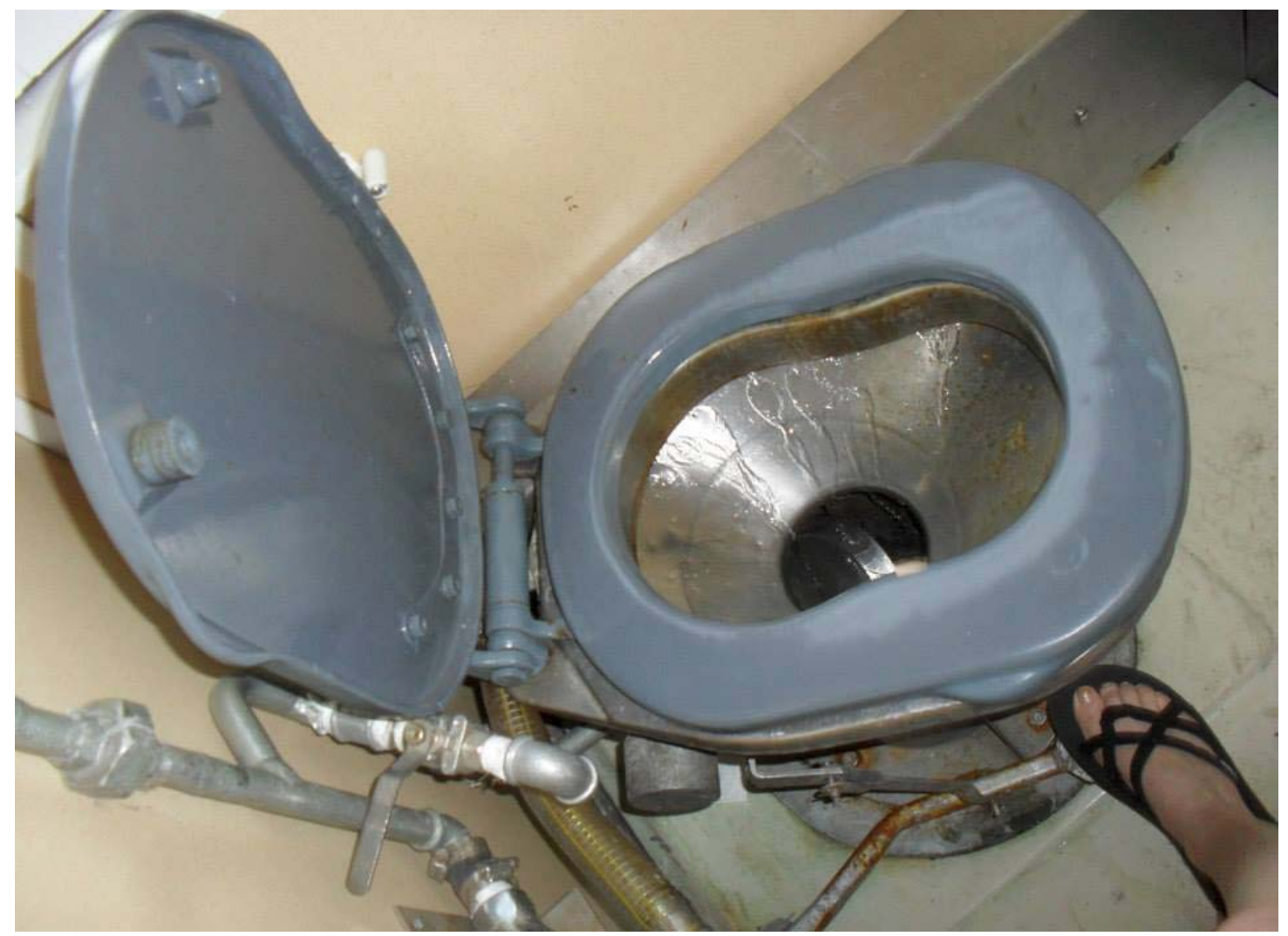

Figure 8. Toilet on the Trans-Siberian train (Source: participant photo) 
The train stopped at a station every few hours, usually for 5-20 minutes — long enough to stretch one's legs, buy something from the station vendors, shops or kiosks (open any time the train was there), and take a few photographs, but not long enough for a tour of the town. For the most part, participants learned rather quickly to remain on the platform during these stops. When getting on and off at stops, attendants typically conducted head counts to make sure no one was being left behind; but again, the group realized that it was best to stay close to the train. Nonetheless, these efforts did not always help and one small group of teachers was abandoned for awhile on the train platform in the middle of the night while the rest of the group remained on board. No one is fully sure why this occurred, but some of the passengers were let off of the train while others were not and within moments of this episode, the train pulled away. Fortunately, it returned about 45 minutes later and the groups were reunited. Participants also had to take into account that within Russia, all Trans-Siberian trains run on Moscow time. In other words, all Russian train timetables quote Moscow time, even though local time can be up to seven hours ahead of Moscow, but the times shown for locations in Mongolia and China are local time, which often caused confusion about actual stop times.

Several participants also mentioned the challenge of dealing with border crossing delays. For example, Ivan said,

When we left Russia [via train, at border of Mongolia], I wondered "did we do something wrong?" We were there forever. (Ivan)

Edith described a contrasting viewpoint of the train experience when she said,

Even though we were on the train so many days - without a shower and with meager accommodations, I was still excited every step of way. I was also nervous at the border crossings - they made me feel really uncomfortable and I did not like it, especially at the Mongolia and China border - the length of time we were there without being allowed to get 
off and it was so hot and we had no access to a bathroom and no control over the situation...I didn't know that ahead of time and am glad I overcame it. I didn"t like the idea of being "trapped" inside while they were lifting up the train and removing the "wheels." I knew we'd be ok, but that was a little challenging. (Edith)

\section{Irkutsk, Russia (Day 8)}

Moscow to Irkutsk was the longest leg of the journey. At the Ural Mountains, the train crossed continents from Asia into Europe; the spot was marked by a white obelisk (Figure 9). Several of the teachers anxiously awaited the photo opportunity.

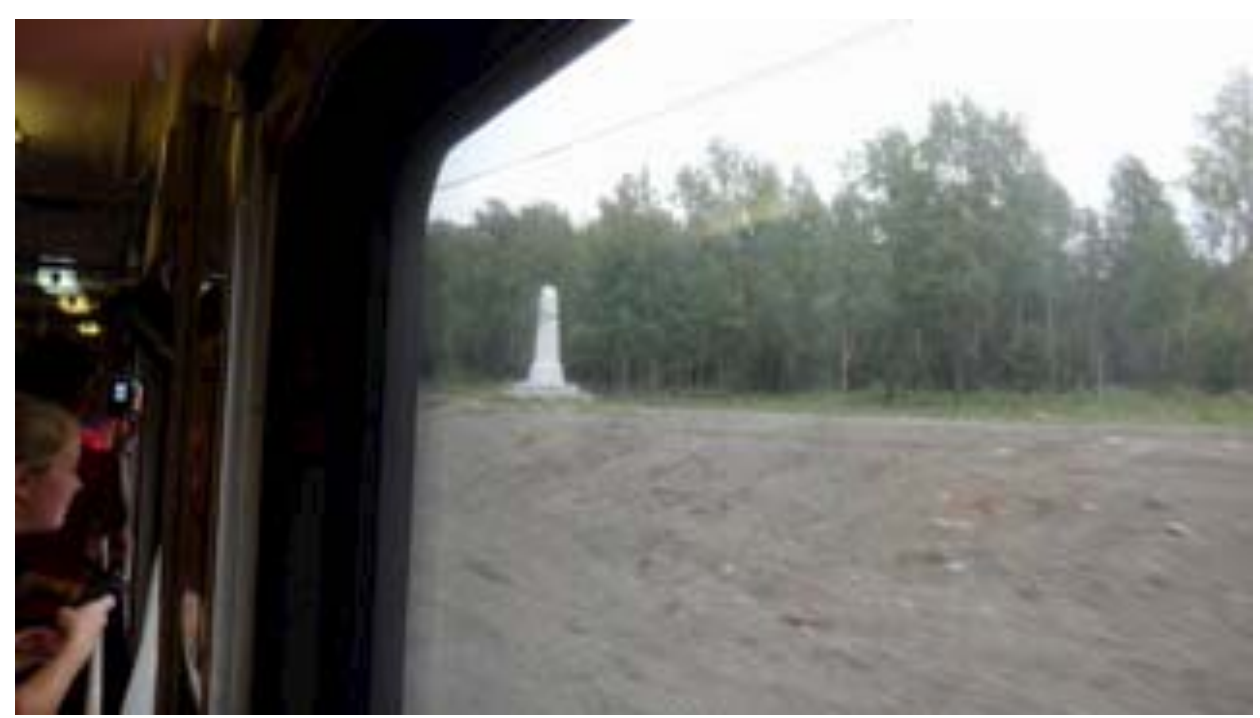

Figure 9. The white obelisk marking the border between Asia and Europe (Source: participant photo)

The group left the Trans-Siberian train behind for awhile in Irkutsk (in order to make a side-trip to Lake Baikal), and explored the "Paris of Siberia" (so called for the wide streets and ornate, continental architecture). In the early nineteenth century, many Russian artists, officers, and nobles were exiled to Siberia for their part in the Decembrist revolt against Tsar Nicholas I and Irkutsk became the major center of intellectual and social life for them (Sputnik n.d.). Much of the city's cultural heritage comes from these 
exiles. For example, it is home to several universities and a major branch of the Russian Academy of Sciences (Sputnik n.d.). In addition, many of their wooden houses, adorned with ornate, hand-carved decorations, survive today surrounded by the standard Sovietera apartment blocks. The C-GEO group spent an afternoon exploring Irkutsk. Many of the participants were particularly impressed by the old, traditional Siberian houses with their bright, carved shutters that were in sharp contrast with the dark wooden exteriors. "Most of them are falling apart, but that's actually part of the allure," one participant suggested. Another participant expressed excitement about the fact that they did not see two homes that were alike. Today, Irkutsk is one of the biggest and one of the most important cities in Siberia, with a growing population of over half a million people (Sputnik n.d.).

\section{Lake Baikal, Russia (Day 9)}

From Irkutsk, the C-GEO group made a side-trip to Lake Baikal, where they spent two days exploring the southwestern lake community. Highlights for participants were a short boat ride on the lake, as well as overnight accommodations and dinner in a local dacha (summer house), as guests of the owners.

This experience was one of the most meaningful to several of the participants. Lake Baikal is the deepest, clearest, and oldest freshwater lake on earth and the largest reservoir of fresh surface water, containing $20 \%$ of the world's unfrozen fresh water supply (World Wildlife Fund 2015). The water is so clean that it can be consumed right out of the lake. And, according to the tour guide, if the rest of the world's fresh water ran out, Lake Baikal could provide every person on earth with enough drinking water for 50 years. It is also famous for the diversity of flora and fauna, which are mostly endemic. 
According to local legend, Lake Baikal's waters have magical powers: if a person completely submerges in the lake, their life will be extended by 25 years - that is, if they are not killed immediately by the frigid water, which at its warmest is only around $50^{\circ} \mathrm{F}\left(10^{\circ} \mathrm{C}\right)$ (Galazy 2015). The cold water temperatures did not stop one brave C-GEO participant from a quick submersion, while the majority of other participants simply dipped their feet into the cold waters. In 1996, Lake Baikal was added to the World Heritage list - a list of places considered to be of special cultural or physical significance by the United Nations Educational, Scientific and Cultural Organization (UNESCO 2015).

Back on the train, rejuvenated participants anxiously awaited the RussianMongolia border crossing, where close to eight hours were spent sitting on the train with no moving air or use of bathrooms - in order to clear immigration. The constant barrage of various uniformed men and women checking travel documents and searching bags, compartments, and personal items, combined with intimidating search dogs and language barriers definitely proved to be a bit unnerving for some.

\section{Ulaanbaatar, Mongolia (Day 10-11 and Day 14)}

Leaving the vast desert landscape behind, the train finally pulled into Ulaanbaatar, the capital city of Mongolia. In Ulaanbaatar, participants seized the opportunity to exchange currency, shop for unique Mongolian merchandise, and eat at least one exotic Mongolian meal. The group also visited a local school where they had a tour and an hour or so discussion with several of the Mongolian teachers. The teachers exchanged classroom stories and information on teaching practices, with a specific focus on geoliteracy. It seemed to come as a surprise to many of the C-GEO teachers that the 
Mongolian students received a significantly larger amount of geography education in their schools and there was a sense of frustration that this was not the case back home. The teachers from the local school were incredibly kind and generous with their time and their insights (they also provided each of the C-GEO's teachers with a one-of-a-kind student drawing depicting a Mongolian animal). The C-GEO teachers were left with special memories and much to ponder about their own education systems and personal teaching practices as they waved goodbye, moving on to their next stop — the Gandan Monastery, one of the only Buddhist monasteries to survive the communist regime, which lasted until 1990. It has since been restored and revitalized with numerous monks in residence. It also features an 86 feet (26.5-meter) high statue of Buddha. The teachers also enjoyed a cultural show with all types of Mongolian music and cultural acts. In addition, the participants visited a memorial on a hill overlooking the city. The majority of the group climbed the hundreds of steps to the top and were rewarded with a panoramic view of the city. The monument itself was also quite impressive consisting of a circular mural depicting scenes of friendship between the peoples of the Soviet Union and Mongolia, ostensibly built by Russians to honor Soviet soldiers in World War II (Wikipedia 2013).

\section{Ger Camp in Terelj National Park, Mongolia (Day 12-13)}

The participants also enjoyed an overnight experience in a traditional Mongolian ger camp, which was nestled in a secluded valley of Terelj National Park, just a short distance from Ulaanbaatar (Figure 10). Terelj, named after the Terelj River, is a scenic landscape of pine covered cliffs, grassy steppe, and giant granite rocks which have been eroded by the elements into bizarre shapes. Participants embraced opportunities for 
outdoor pursuits, including hiking or exploring the region on horseback, in addition to visiting with a local family and enjoying free time to simply relax.

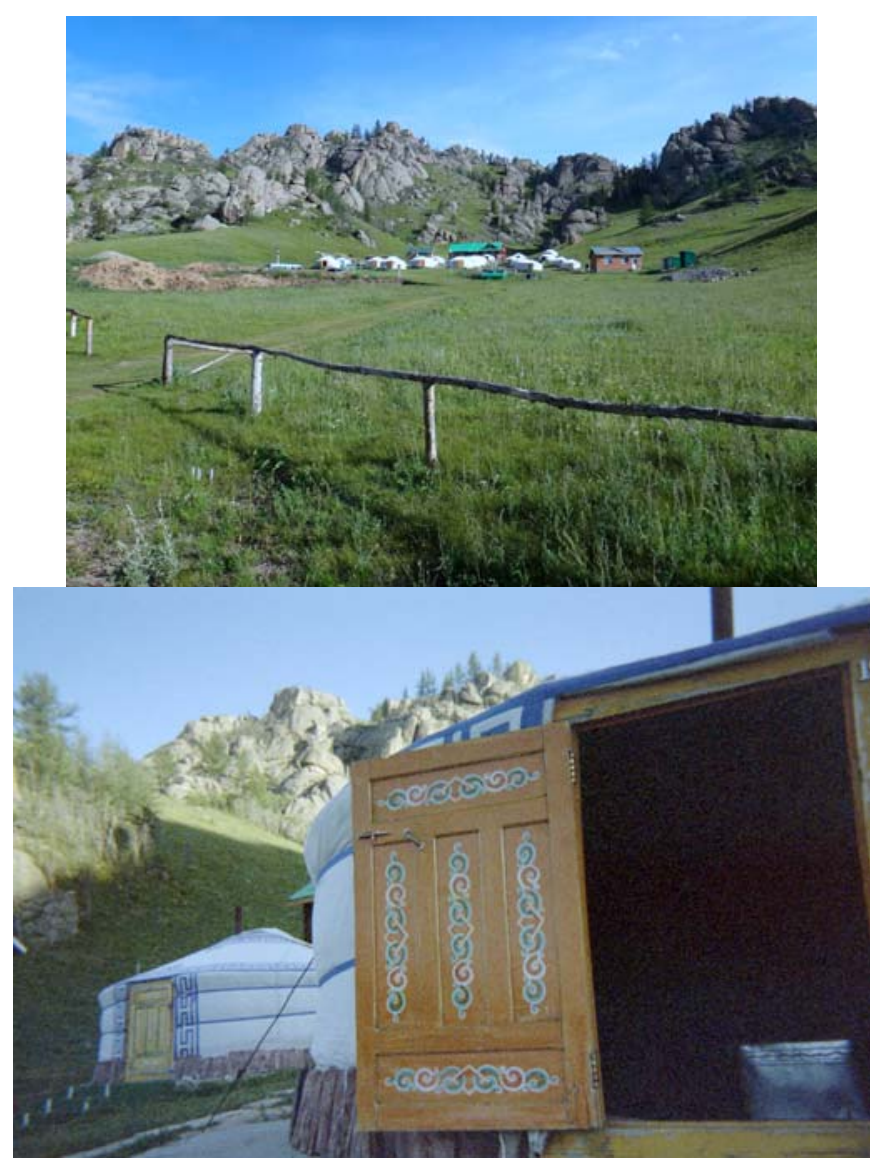

Figure 10. Photos of ger camp in Terelj National Park (Source: participant photos)

On the way to the ger camp, the group visited an enormous (over 130 feet tall) statue of Chinggis Khaan (Genghis Khan) riding on horseback. The statue commemorates the site where Chinggis Khaan allegedly found a golden whip (which he is holding in his right hand). The teachers had the opportunity to walk to the head of the horse, passing through its chest and neck, where they took in a panoramic view of the region. Inside the two-story base of the statue was a museum where participants were able to see a replica of the legendary golden whip, a very large replica 
of a traditional Mongolian boot made for horse riding, ancient tools and everyday utensils, belt buckles, knives, sacred animals, and more from the $13^{\text {th }}$ and $14^{\text {th }}$ centuries. Leaving the grand memorial, the teachers expressed great enthusiasm over the gigantic tribute to Chinggis Khaan (Figure 11). And, before reaching the park entrance the group encountered a man along the side of the road with a large Golden Eagle, which he allowed tourists to hold and photograph for a small fee. Several of the participants enthusiastically took a turn. Western Mongolia is famous for golden eagles. Eagle hunters from that region preserve ancient traditional practices passed on from their ancestors. They begin taming and training eagles at an early age and use them for sport and hunting small prey (e.g., foxes or marmots) on the steppe. The Mongolian eagle hunters are some of the last people on earth to do this and it is a way of life to them (Mahboob 2012).

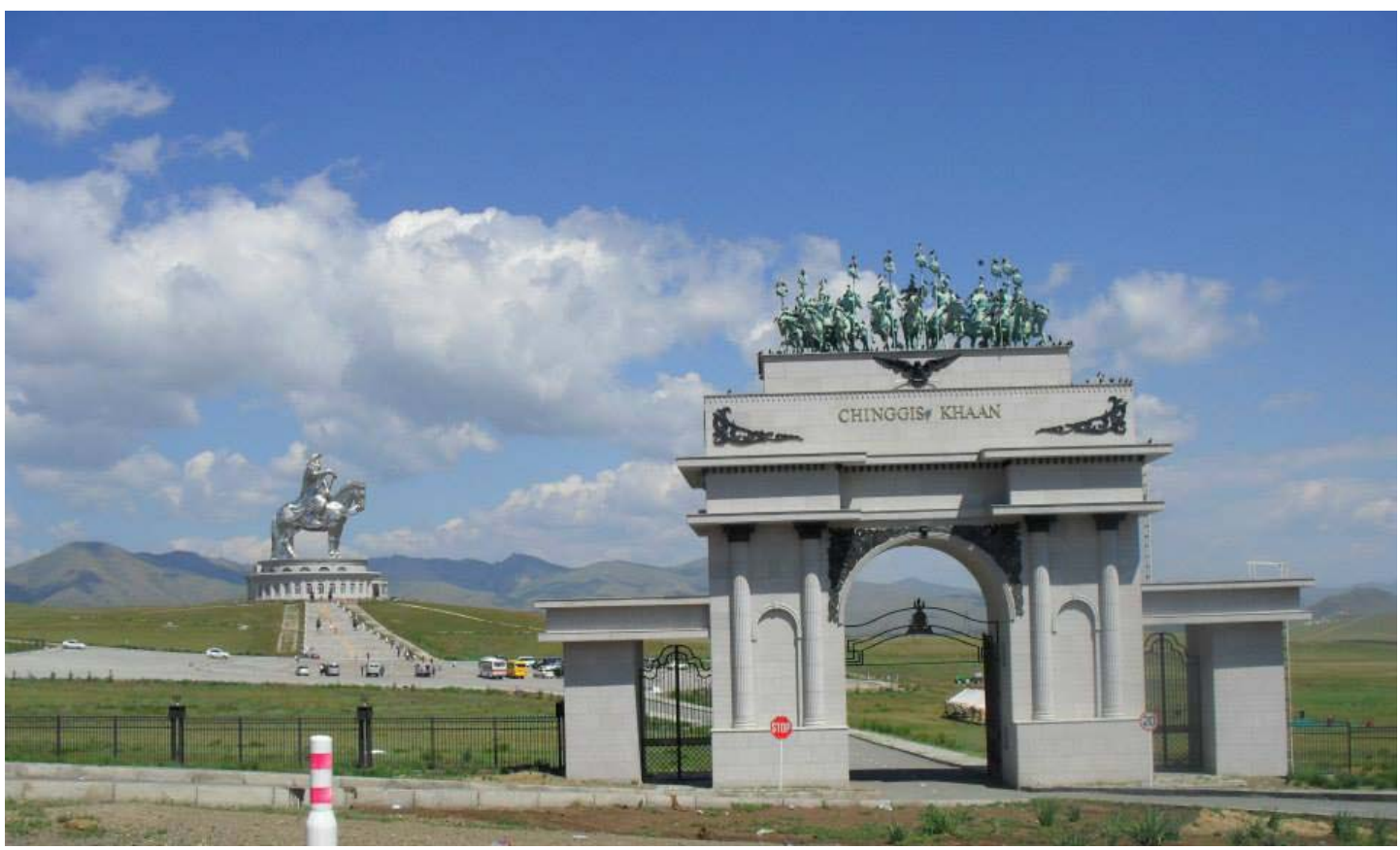

Figure 11. Chinggis Khaan memorial in Mongolia (Source: participant photo) 


\section{The Trans-Siberian Railway, Mongolia and China (Day 15)}

From Ulaanbaatar, it was a 30-hour journey to Beijing, but after only 13 hours the train arrived at Erlian on the Chinese-Mongolian border. Here, the train had to make a long stop to change its undercarriage. Since the Chinese tracks are not compatible with the narrower Mongolian and Russian tracks, the entire train was lifted up by a large hydraulic system, the undercarriage wheel system was swapped out for a larger gauge one, and then the carriage was lowered. All of the passengers remained on the train as it was raised and lowered for the over three-hour process. Once again the toilets were all locked.

\section{Beijing and The Great Wall, China (Days 16-17)}

From Erlian, the train slowly made its way through China's mountainous terrain to Beijing, where the group was greeted by skyscrapers, smog, and other symbols of China's roaring economy and rapid development, including a massive number of people to maneuver around at the train station. Beijing is the political center of China and has a clear strategic history, indicated by the numerous walls built around it, including the

Great Wall (Figure 12). The Great Wall was built during the Ming Dynasty (1368-1644) and runs over 13,000 miles (21,000 km) (Gardner 2012). With the Great Wall being so close, those participants who had not yet experienced it (all but one), felt it a mandatory sightseeing endeavor and chartered a bus to enjoy the culture and beauty, while meandering along the bricks in small groups for several hours. 


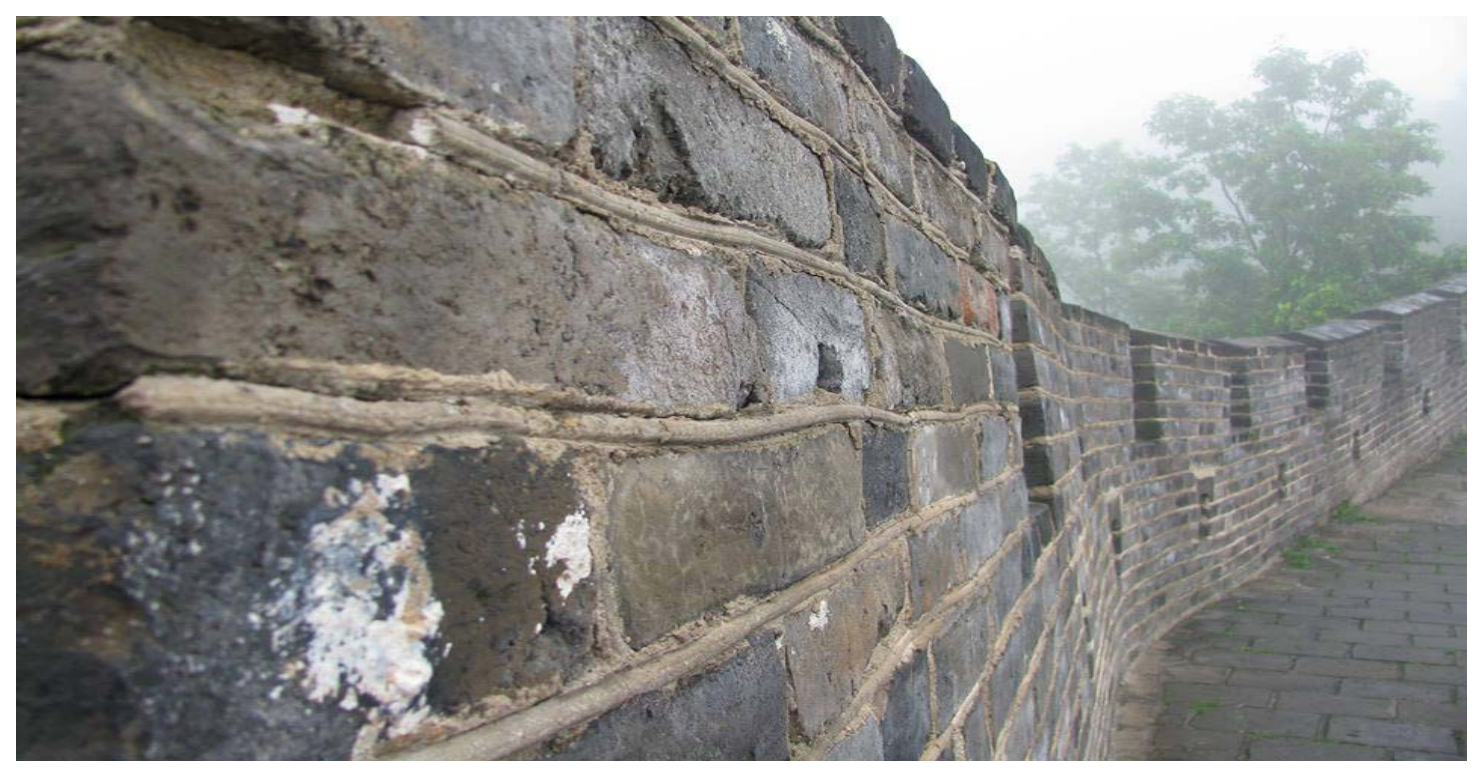

Figure 12. The Great Wall of China (Source: participant photo)

On the only full day in China, teachers had the option of visiting a variety of cultural landmarks; the majority of them chose to visit Tiananmen Square, the Forbidden City, and/or the historic Silk Market. Ivan reflected upon his experience in Tiananmen Square during the interview approximately one year later, saying,

Standing in Tiananmen Square, I thought about the 1989 massacre when tanks came in to suppress a student-led pro-democracy demonstration. There were so many people left for dead in the streets and my students typically know nothing about it. Our textbooks don't mention it. (Ivan)

Another participant recalled walking through the Chairman Mao burial chamber with hundreds of reverent viewers, and then being led directly to a gift shop. She chuckles and says, “...it was a collision of communism and capitalism!” In the evening, the C-GEO teachers were provided a guided tour of the meandering back alleys of the city (the hutongs) — a rich cultural side of China that few people know much about and a glimpse into the old way of life in Beijing — where middle-aged men and women play 
fierce card and board games or buy and sell exotic food products and other goods, while others simply pass the time chatting with friends and family.

While the visit to China was extremely brief, the teachers expressed a much deeper understanding of the people and the culture as a result of this international learning opportunity. Many posited a sincere appreciation of China's nuanced growing pains and contrasts. It was, in fact, the everyday differences that seemed to impact them most. They animatedly described their shopping experiences with aggressive vendors at the Great Wall and Silk Market. Many were also fascinated with the extremely large department store next to the hotel, where a significant amount of space was devoted to exotic groceries, including live fish, eels, scorpions, horse, and dog meat. At the same time, they lamented about how politically closed China felt when they discovered (or were reminded of) this fact: when searching the Internet at the hotel, many U.S. media (e.g., Facebook) and government websites were blocked.

From Beijing the group headed off in the early morning to the airport and prepared for the long journey home. They all seemed eager for the comforts of home, while at the same time relishing in what a remarkable trip they had taken over the last few weeks. And, as they boarded the plane, perhaps a few of the participants longed to be back on the train.

\section{E. Trains as Liminal Spaces}

The idea of liminal space as a way to understand and make connections to place is explored as part of this research. Liminal space is defined as the threshold between two places, states of being, or eras (van Gennep 1909), and the Trans-Siberian railway experience provides a classic example of liminal space — one of crossing thresholds over 
an extended temporal duration. The conscious act of separation from the "real world" and the transition into a liminal time and space was recollected as transformative in most of the participant's accounts of the Trans-Siberian railway experience (Figure 13).

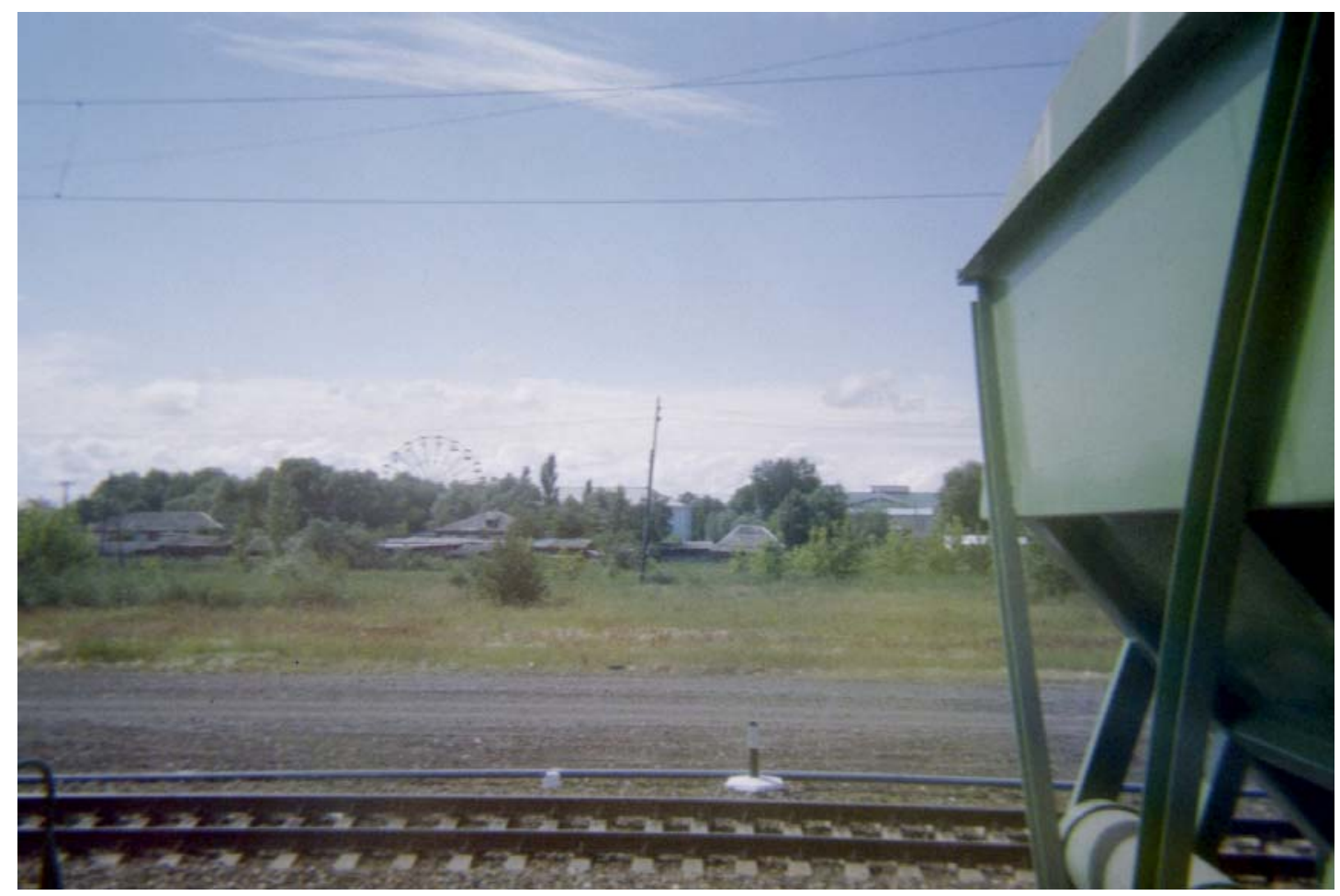

Figure 13. Train crossing through liminal space (Source: participant photo)

While the participants typically found the destination locations to be most meaningful (for instance St. Petersburg's history and beautiful architecture or Beijing, the flashy, pulsing heart of capitalist China) they also seemed to appreciate what lay in the liminal space between the cities. As Esther described: “...the train was zipping past almost every landscape on Earth, from mountains to deserts to forests and rivers, and I was snapping photo after photo out the window trying to capture all of the amazing places between the cities." They also appreciated the time and space to think and reflect on their experiences, as Edith described: "Looking at the ever-changing scenery outside 
of the train windows was one of my favorite things about traveling by train and at the same time, random thoughts and images drifted on and on in my mind." Another participant, Maria, said, "The farmlands and villages among flat grasslands reminded me of paintings I had seen at the Portland Art Museum and made me wonder what life must be like in such remote areas." Igor expresses the idea of traveling through liminal space when he states that "the train was not a great memory but we were moving along and were somewhere new each time we stepped off." And Marie admits that "riding the train itself was an experience which I would not have done on my own." Yet, when asked what her most significant memories from this experience were, she provides this quote:

Riding the train and getting to see the country that way - and surviving the train. It is a different way of traveling and there are not a lot of Americans doing it anymore. (Marie)

These participant narratives exemplify the psychological, social, and physical space that was unfolding along the journey — the literal crossing through spaces of liminality that train travel allows. Traveling long distances by train also frames the passing landscape in a way that encourages interaction among those with perceived differences. The riders were sharing physical space apart from the outside world and for an extended period of time. This aspect appeared to facilitate communication with strangers, despite the language barriers. On train rides, the researcher observed participants sharing dialogue, gestures, and other forms of basic communication with people they may not have connected with in other circumstances. For example, Kelsey offered the following description:

While our train climbed the Ural Mountains, I began talking with a young Asian girl. We laughed and shared stories and I gave her a coloring book. She was so happy and it was one of my most meaningful experiences of the trip. (Kelsey) 
Edith recalled:

I enjoyed sharing stories with other passengers on the train. I felt that the people from Russia were very stoic and not like Americans, but I really wanted to make connections with actual people. There was a Russian guy on the train and in other circumstances we might have disregarded each other, thinking we had nothing in common, but I was determined to make a connection and eventually I got through to him with a picture of my dog. The effect of our cultural connections was in a positive way and any preconceived ideas diminished even though I tried not to have any. I'm very happy that rather than ignoring or accepting that there was a cultural difference, I kept at it until we came to common ground. This really helped me make meaningful connections. (Edith)

Indeed, numerous long days on a train taught the participants lessons that they indicated have already been applied in their daily lives. For instance, based on the teachers' feedback, it appears that the train journey fostered a sense of appreciation and curiosity about the landscapes through which they passed, which in turn helped the participants develop a deeper connection to place. They also greatly appreciated the time to reflect, be creative, meet strangers, and better connect with the other Oregon teachers. One participant summed up this experience when she said,

I actually miss the trains and the peaceful, reflective state of mind that they brought me. Sure, there were some hours of restlessness, but for the most part I stared out the window at the countryside for hours and became deep in thought. It is, by far, one of my favorite adventures.

Overall, it is important to note that all of the participants allude to the train experience as deeply meaningful, despite — or perhaps at some level because of — the challenges that it brought with it. Nell explained that this new experience brought with it new emotions for her:

I thought the train ride would be... I've never ridden a train long distance or much short distance and I remember thinking the train would be frustrating, crowded, uncomfortable, but it was no problem; I really enjoyed it, except the border crossings. I enjoyed chatting and taking it 
easy; I liked it as way of traveling. I thought it would be more taxing. (Nell)

Amber briefly recounted the time-space and cultural connection that she felt as part of the train experience:

...riding on the train was meaningful. It narrowed the experience minutes went into hours and all the while I was learning to spend a lot of time with other people. (Amber)

Susan mentioned an important learning outcome for her when she said, "I appreciated the time to reflect on the train; it was a great time to talk about teaching and reflect with each other, to develop ideas and bounce them off someone else." 


\section{ANALYSIS AND RESULTS}

C-GEO works with an increasing number of teachers from Oregon who are interested in teaching more geography in their classrooms. One way that the C-GEO serves these teachers is by providing international professional development opportunities, which it has been offering for two decades. Previous evaluations of the teachers' experiences, however, have been limited in scope and often only anecdotal in nature. This study provides more detailed, structured research into the professional and personal learning outcomes for the eleven teachers who completed the Eurasia professional development program in 2013. All of the teachers fully participated in the research by completing pre and post surveys, allowing in-situ observations, and semistructured photo-elicitation interviews. The responses are detailed and discussed more fully in this chapter.

Based on a critical examination of and reflection on existing research literature, the following research questions were examined:

- Does the international teacher professional development experience impact participants' sense of place in meaningful ways?

- How does the experience of place influence the individuals' knowledge and attitudes about that place?

- Does the international teacher professional development experience improve teachers' geo-literacy?

The first research question seeks to describe the places that were important to the participants, the meanings and experiences that gave rise to that importance, and the ways in which those places and meanings came together to contribute to the creation and maintenance of each one's sense of place. The second research question examines the C-GEO international professional development program goal of building learners' 
understanding about wide-ranging topics in geography. More specifically, the program aims to educate participants about the interconnections among Earth's systems at local to global scales, as well as relationships to different cultures — past, present, and future. In addition, this part of the research examines whether new teaching techniques were developed and if the teachers felt better prepared and more committed to teaching geography in their schools.

As described in the Methodology chapter, all recorded interviews and supporting photos, observations, and surveys were analyzed to search for themes embedded in the participants' experiences. And, all of these themes were further analyzed to assess meanings associated with those experiences, and to unearth teachers' personal and professional insights. This chapter highlights these identified themes using teachers' quotes and images in order to provide a nuanced understanding of the C-GEO Eurasia experience and to illustrate and clarify the findings related to sense of place and geoliteracy.

\section{A. Sense of Place}

The term "sense of place" describes a relationship to place based on how a person associates significance, meanings, values, and feelings with a particular location. Understanding how sense of place develops and changes is important to understanding how and why people interact with particular environments. There is a considerable amount of research dedicated to defining what makes a place meaningful enough for such place attachment to occur. For instance, certain localities may project a sense of wellbeing and become places a person wants to return to time and time again — or, perhaps, even establish a residency there. Other settings, especially dramatic landscapes or 
locations of intense experiences, can cause an almost-immediate, intimate, and emotional association. One's sense of place may also be strongly enhanced by the place being written about by poets, novelists, and historians, or portrayed in art, music, or cinema. Different forms of designation (e.g., Conservation Areas, World Heritage Sites, National Parks, or National Historic Landmarks and Monuments) may be created by cultural groups or governments in an attempt to protect, preserve, or enhance special natural and historical places felt to be of value.

Clearly, a sense of place emerges through experience and knowledge of a particular area, its flora and fauna, its legends, and a growing sense of the land and its history. At the same time, it is important to recognize that while every place has its own influence on how one relates to it, one's relationship with and attachments to places are multi-faceted and complex and how an individual feels in one place is influenced by the positive and negative feelings that the person has for other places (Cross 2001). Each individual experiences the world uniquely. One's brain gives meaning to events and stimuli encountered as determined by physical brain function, memories, beliefs, and attitudes about oneself and others, and a "lifeworld" shaped by family, religion, school, culture, and past and present experiences. These influences are often below conscious awareness yet help determine how a person responds to the world, interacts in relationships, and thinks of and talks about himself or herself. While this processing of information uses one's intellect, memories, or biases, it is one's senses (e.g., sight, touch, smell) that give individuals experiences that are personally meaningful and memorable and that connect them with places. 
While it is not fully understood how and why perceptions of events may vary from one human to another, the process by which humans process inputs to their senses is well understood. Sensory systems are responsible for collecting, analyzing, and converting inputs into messages to the brain and, in turn, trigger different responses (Morin 2009). Hence, making sense of the world and its events is merely an individual brain's interpretation of the signals it receives while interacting with various environments. For instance, smell is widely recognized as a memory stimulant, and color is nothing more than cone cells in the retina being stimulated by light waves within a certain range of the visible light spectrum (Elert 2015). Because everyone's brains are different, individual perceptions of color are also different. Hence, a multi-sensory learning experience with combinations of visual, auditory, and other sensory functions takes full advantage of the natural connectivity of the brain.

Person-place relationships can occur at a variety of scales, whether they are tied to a specific point on a map, a geographic region, a thematically-focused area (e.g., political or eco-based region), a country, or even a continent. These scales are an important aspect to consider when dealing with sense of place research. In this study, participants had relationships to places as small as a whimsically decorated gate in St. Petersburg, or as large as an entire country. For example, it was evident when examining meaningful places at a large, country-level scale, Mongolia was the place that consistently resonated with the participants. Of the three countries they visited, Mongolia was consistently identified as having the most impact on the teachers. When asked which place was the most meaningful to them, six of the eleven teachers answered "Mongolia." Responses included: 
Mongolia was mostly unknown beforehand. I made more personal contacts there and feel closer to it and could go back and find places to revisit. (Amber)

Mongolia is the place I have spoken about most with people since our return. I've shared those memories with a lot of people (Nell)

I really enjoyed Mongolia a lot; not just Ulaanbaatar or the ger camp, but just the place itself.... They are on the verge of wanting to develop, but are culturally not there. I loved that struggle and found it interesting. (Kelsey)

At a smaller scale, the cultural use of gers and the participants' visit to a ger camp in Mongolia had meaning to the eight of the eleven participants. It is difficult to separate this more specific aspect from the overall connection to Mongolia, as there seems to be a clear association between the two. Based on the final photos selected by participants for this sense of place research, all but one of the participants included at least one of their three sense of place images from Mongolia (in a couple of cases, all three of the participants' sense of place photos were from Mongolia) and of those, nine of the total thirty-three sense of place photos were directly or indirectly represented by gers or the ger camp experience. In one instance, a participant including all three of the sense of place photos from the ger camp.

Two examples of participant's sense of place photos and supporting interview comments representing a strong connection to Mongolia and the ger camp experience are illustrated below (Figure 14 and Figure 15): 


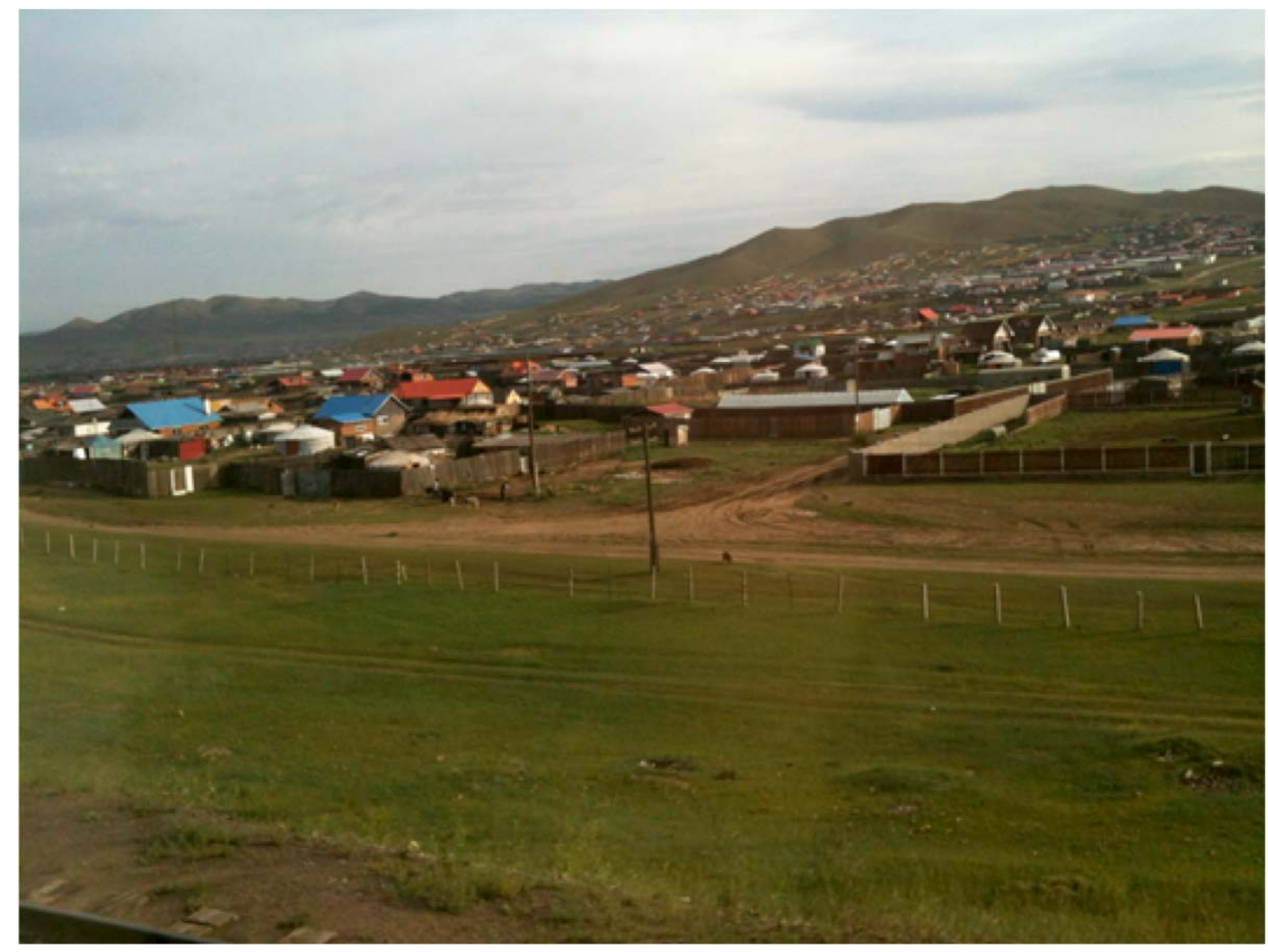

Figure 14. Mongolia (Source: participant photo)

Interestingly enough all my photos are from Mongolia. I believe in this photo we are in the train and there's some grass and cement fence posts and buildings and then people's houses and an expanse of gers going clear up the hills and all the colors of houses and gers are scattered out there....the word adventure comes to mind. It's expansive, like you can breath in the spirit of the people and it is reflected, I think, in the picture - the interpretation of this picture speaks of the fierceness and spirit of Mongolians and Ghengis Kahn...I think it's beautiful. The expanse and the colors remind me of a people who are still wild and free — in a good way. (Esther) 


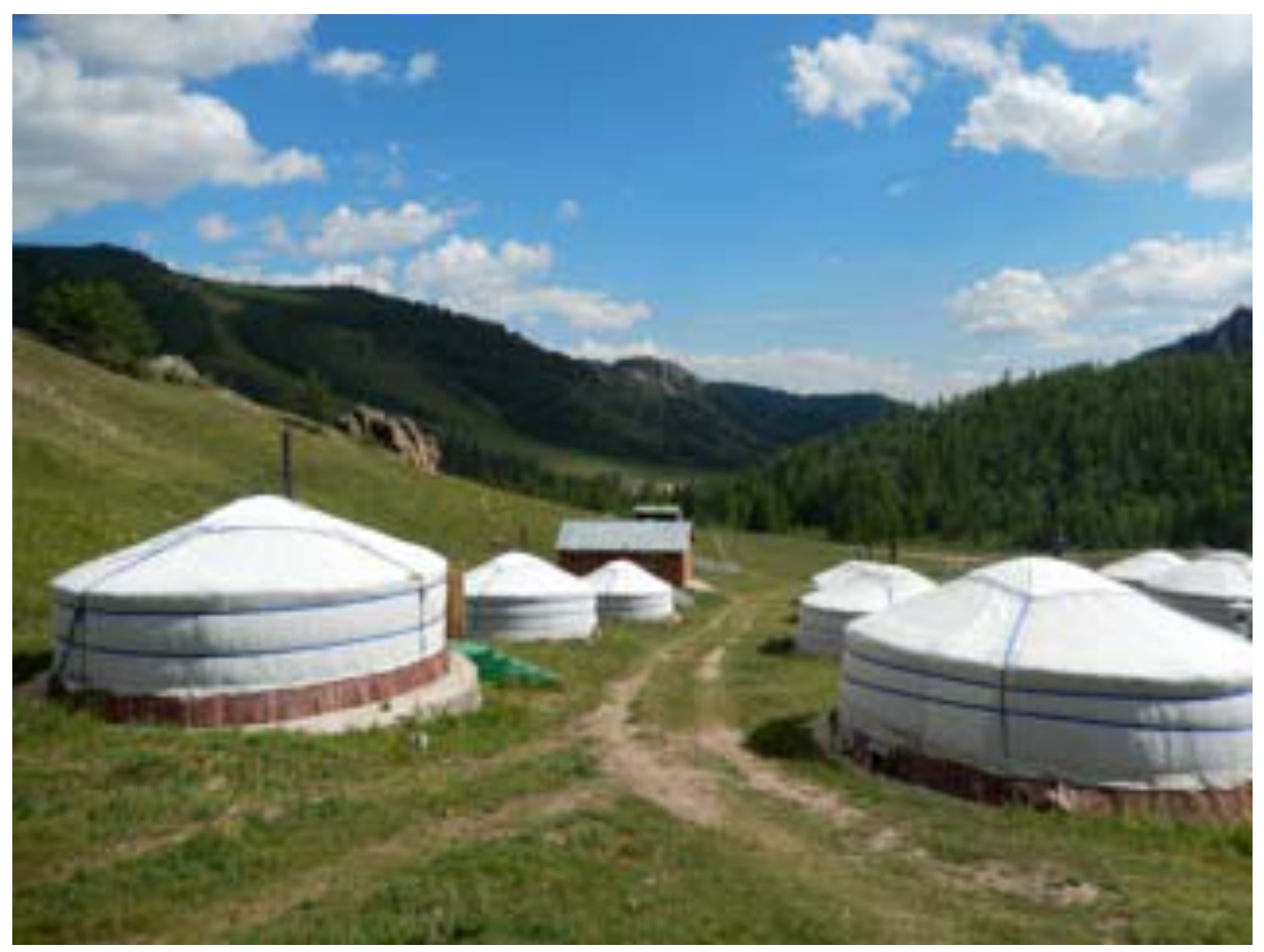

Figure 15. Ger camp in Mongolia (Source: participant photo)

This shows the traditional culture of Mongolia - the yurts and how people have lived but yet they are also finding a way to financially benefit from showcasing their traditional culture. It reminds me of the peace and tranquility of what we experienced there. I loved being outside of the city, in nature. We could see the sky. It was peaceful. Because of how it made me feel and the memories... I enjoyed our time up there. Traveling is so much go, go, go and this felt relaxed. And, even though there was a lot of downtime on the train, we were still in motion, moving. (Marie)

More generally, the teacher participants described several different types of relationships with place, including connections to the land and the people and other special factors (e.g., natural beauty, uniqueness, history, familiarity, or serenity of a place). These have been categorized into four types of relationships to better facilitate understanding and to characterize what the participants described as the fundamental ways they related to places. They were chosen because two addressed the geographical 
connections (i.e., physical and cultural aspects), while the other two identified personal and professional connections to place. The categories are not intended to be seen as descriptions of individual people; in fact, many of the participants had more than one connection with a single place and in some cases their sense of place may have changed over the course of this research. The four place-based relationships include:

- natural environments (e.g., climate; landscape features);

- culture and history (e.g., customs; design and architectural elements; artistic and cultural exhibits and events);

- personal connections (e.g., familiarity with hometown or residence; individual interests, such as a sense of adventure; spiritual similarities and differences); and

- professional and intellectual connections (e.g., teacher affiliation, new knowledge).

\section{Natural Environments}

Natural environmental influences help to define a place. They are also considered an important aspect of one's self-identity. The natural environment can make a place beautiful and livable or hostile and uninhabitable. Humans place particular value on the different aspects of an environment in a way that best fits one's personal history, needs, and desires. For instance, the health benefits of an environment (e.g., fresh water or clean air) may be of particularly high value to one person, whereas access to one or more natural areas (e.g., green spaces, mountains, or water bodies) may be what is most important to another. Climate also contributes to one's sense of place. The climate plays a large role in people's lives impacting such things as hobbies and contributing to mental health. An avid skier may prefer to live in a climate that has long, snowy winters, whereas an active golfer may prefer a drier, warmer climate. And, while some people have a preference for the more stable temperatures and lush, green foliage that comes 
with a humid climate, others may prefer drier, desert-like climates, with larger differences between day and night temperatures and sparse vegetation. At the same time, the frequency of extreme events such as hurricanes or earthquakes might influence a person's well being, and in turn, their sense of place.

In the end, each individual defines a particular place in their own way. One common approach that participants used to recall and describe the various places they visited was by examining its physical characteristics or special natural features. And, while aspects of physical landscape are tangible, the meanings they give rise to, which are less tangible, are equally significant in terms of personal experiences and affective attachments. During the interviews participants were asked to describe two to three of the physical environments in Eurasia that were most meaningful to them. Table 2 highlights these influential physical geography dimensions of the Eurasia experience for each participant.

Table 2. Key Natural Environment Influences by Participant

\begin{tabular}{|l|l|}
\hline \multicolumn{1}{|c|}{ Participant } & \multicolumn{1}{c|}{ Physical } \\
\hline Marie & $\begin{array}{l}\text { Variety of environment/transitional zones; } \\
\text { Lake Baikal }\end{array}$ \\
\hline Esther & $\begin{array}{l}\text { Arduousness; Expansiveness; The Ural } \\
\text { Mountains; Lake Baikal }\end{array}$ \\
\hline Alice & Mongolia; The western part of Russia \\
\hline Nell & $\begin{array}{l}\text { The Urals; The steppe lands of Mongolia; } \\
\text { Mongolia-China border }\end{array}$ \\
\hline Amber & Vastness of Siberia; Mongolia \\
\hline
\end{tabular}

Continues on next page 
Table 2, continued. Key Natural Environment Influences by Participant

\begin{tabular}{|l|l|}
\hline \multicolumn{1}{|c|}{ Participant } & \multicolumn{1}{c|}{ Physical } \\
\hline Kelsey & The variety of forests in Russia; Lake Baikal \\
\hline Susan & $\begin{array}{l}\text { Lake Baikal; The rolling hills and steppes of } \\
\text { Mongolia; The Gobi Desert }\end{array}$ \\
\hline Ivan & Urals; Siberia; China \\
\hline Igor & $\begin{array}{l}\text { Mongolia; The mountains in Russia; St. } \\
\text { Petersburg }\end{array}$ \\
\hline Edith & $\begin{array}{l}\text { The landscape was so diverse and vast; Two- } \\
\text { humped camels; Gobi desert }\end{array}$ \\
\hline Maria & The mountains in China; The Gobi Desert \\
\hline
\end{tabular}

It is clear from this list that there are some distinct similarities in terms of physical geography impacts on participants (e.g., the general variety and vastness of the landscapes; Lake Baikal; the Ural Mountains). But why were these places or particular aspects of the land so important to participants? The following first-hand accounts of natural environments that held meaning to the participants help to better reveal the significance behind these environmental connections:

The Gobi desert surprised me. It was so hot. I'm not accustomed to it nor would I normally do it but I appreciated seeing the camels and the vegetation and other stuff. (Maria)

I liked the transitions - from the Urals...to the [Gobi] desert and into China where it was lush green again — seeing the varieties of the physical environment and Lake Baikal was gorgeous, especially being able to see into the water. (Marie)

Lake Baikal was pretty special. You can look at the smallest map possible and can still see Lake Baikal because it is so significant. (Kelsey)

I liked the arduousness of everything and the expansiveness was awesome and resonated with me. Being outside is my thing. I equate it with being free and a sense of adventure. (Esther) 
Definitely, the Mongolian mountains were just my favorite! I can't even describe it very well; it's just my favorite. I loved it so much - there were both similarities and differences of landscapes to my home but I was half across the world. And, I love the outdoors; being out of city. (Alice)

It becomes clear from these accounts that in the formation of a strong sense of place, natural environments contribute with a variety of positive effects. Often people accept these qualities as parts of their individual identities. Esther and Alice, for example, described how their affinity towards outdoors directly influenced their most meaningful experiences from the trip. At the same time, since sense of place is an individual notion, multiple meanings of place are possible within the same geographical area. Hence, it is not suggested that all participants experience nature uniformly; Esther is drawn to Mongolia for its expansive landscapes and sense of adventure that it creates for her, whereas Alice loves the mountains of Mongolia.

When examining the connections between landscape preferences and place attachment, this study found that natural environments were no more favorable than sites with greater human influences, generally. However, several individuals did show a particularly strong preference for natural landscapes. While not closely examined in this research, one theory which may help explain human affinity for natural environments is Attention Restoration Theory (ART). According to ART — the theory suggests that the experience of personal restoration, which occurs in natural places accounts, at least in part, for the positive sentiments associated with them (Herzog et al. 2003; Ulrich et al. 1991). It follows then, that place attachment would be higher for natural environments (and specific types of natural environments especially) among people with certain restoration motivations, such as solitude, relaxation, or spiritual development. 
One way that social and environmental scientists are measuring people's cognitive connection to the natural world is through a Connectedness to Nature Scale (CNS). Nature connectedness is the degree to which individuals include nature and all that it is made up of, including the negative aspects - as part of their identity (Schultz 2002; Nisbet, Zelenski, and Murphy 2009). According to Nisbet, Zelenski, and Murphy (2009), the characteristics of nature connectedness are similar to those of a personality trait in that it is stable over time and across different situations. The CNS is being used to test the effects of situational factors and personality characteristics which might impact connection to the natural world and to assess one's belief that this connection is an important part of one's sense of self. Several research studies have found that contact with nature (and feeling connected to nature) can provide numerous psychological benefits (e.g., improvements in mood and vitality, lower stress). Studies have also shown that people who score high on the CNS report greater concern for the environment as well as greater satisfaction in life (Nisbet, Zelenski, and Murphy 2009). At the same time, however, a recent study published in the Journal of Environmental Psychology (Zhang et al. 2014) suggests that high connectedness to nature predicts greater life satisfaction only for those who have a greater perception of nature's beauty (Figure 16). 


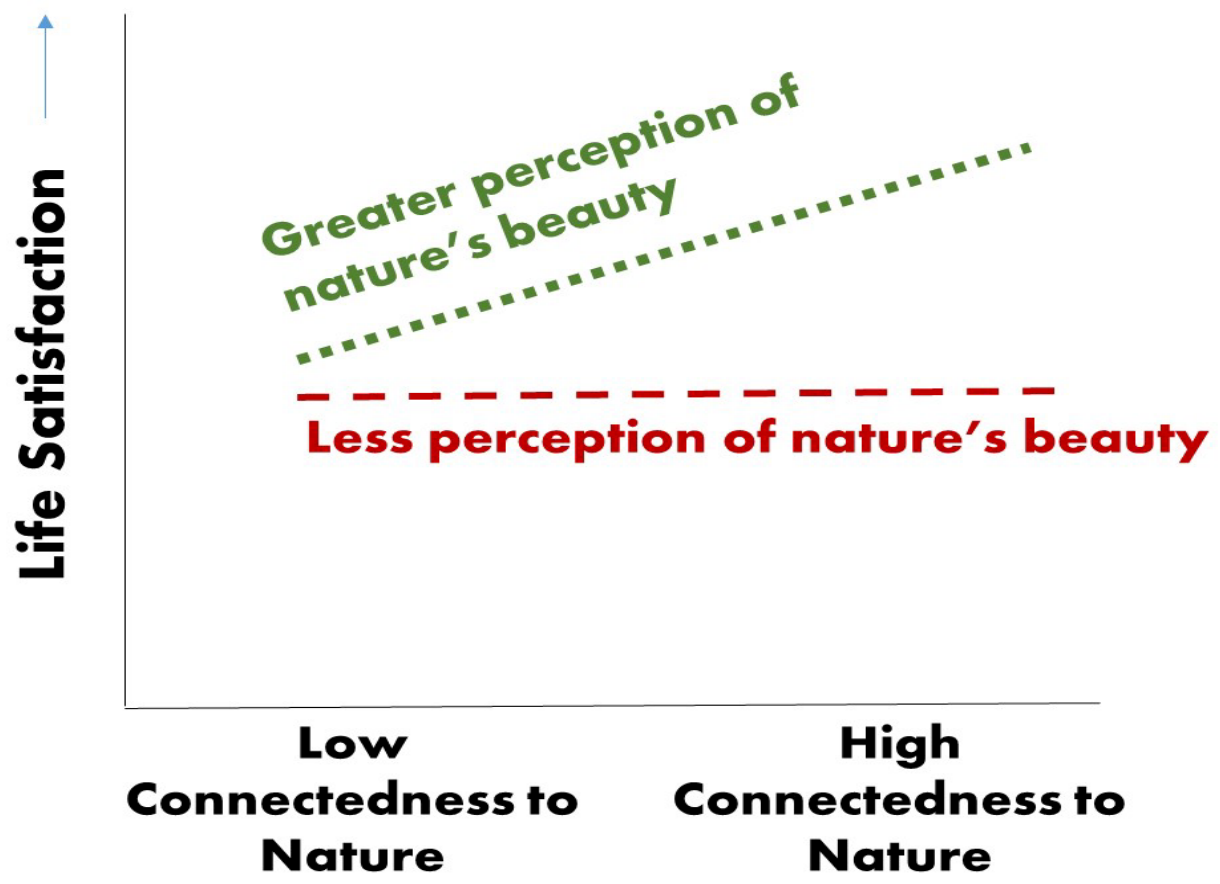

Figure 16. Correlation between perception of nature's beauty and life satisfaction (Source: Zhang et al.)

Although this scale was not used in this study, this research supports the idea that those with an affinity toward nature (e.g., Edith and Alice) find more of a connection to the natural environment and in turn, their sense of place is related to the experiences which took place in more natural settings (e.g., mountain and lake environments). On the other hand, some of the participants — especially those with less outdoor experience indicated a dislike of more remote natural areas and some trepidation about visiting them and expressed an affinity for the urban settings (see next section for more details).

\section{Culture and History}

When a place is capable of leaving an impact, on body or mind, it can enhance a person's attachment or sense of place. A place becomes special when such things as the views, sounds, local people, tastes, and smells mean something to the visitors or the inhabitants of that place; when those who use it can identify themselves with it. The 
importance of the stimulation of the senses in creating a meaningful experience of place has already been extensively discussed, but not yet with a focus on how incorporating popular and traditional culture in an experience can impact one's sense of place. Culture is an important factor in shaping one's identity, as it links people to the place, its history and traditions. Findings from this research show that historical and cultural contexts of a place, as well as opportunities for participation in historical and cultural experiences, helped reflect the identity of a particular place and provided an essential foundation for developing and building sense of place. During the interviews participants were asked to describe the cultural and historical aspects about their experience that most affected them. Table 3 summarizes their responses.

Table 3. Key Cultural Influences by Participant

\begin{tabular}{|l|l|}
\hline Participant & Historical/Cultural \\
\hline Marie & The Great Wall; the people \\
\hline Esther & $\begin{array}{l}\text { Exposure to tour guide's culture (from Azerbijan); exposure to } \\
\text { tour group culture }\end{array}$ \\
\hline Alice & Language barrier; the Great Wall \\
\hline Nell & The Great Wall; monastery in Ulaanbaatar \\
\hline Amber & Monastery in Ulaanbaatar \\
\hline Kelsey & Monastery in Ulaanbaatar \\
\hline Susan & $\begin{array}{l}\text { Monastery in Ulaanbaatar; the schools and teachers; the } \\
\text { countryside; eating local foods }\end{array}$ \\
\hline Ivan & $\begin{array}{l}\text { The number of people in China; the money (wealth) in China; } \\
\text { Orthodox churches in Russia }\end{array}$ \\
\hline Igor & Weddings; Russia; the Great Wall \\
\hline Edith & Russia; making meaningful connections with local people \\
\hline
\end{tabular}




\section{a. The Great Wall}

It is clear from this list that there were some distinct similarities in terms of cultural and historical impacts on participants. One place that was consistently recognized as "meaningful" was The Great Wall in China. The Great Wall, with its numerous walls, towers, and fortifications, has been synonymous with China since travelers and adventurers first spoke of the region to the rest of the world. In fact, few cultural landmarks symbolize a nation's long and vivid history more powerfully than the Great Wall of China. Originally conceived by Emperor Qin Shi Huang in the third century B.C. as a means of keeping invaders out of the Chinese Empire, the wall is one of the most extensive construction projects ever completed (History.com Staff 2010). At the height of its importance during the Ming dynasty (1368-1644), the Great Wall is believed to have extended some 4,000 miles (Larmer 2008). Though the Great Wall never effectively prevented invaders from entering China, it came to function more as a psychological barrier between Chinese civilization and the rest of the world. Today, there are some who regard the Wall as an aspect of China's strength; while others perceive it as a sign of weakness. Nonetheless, the Great Wall remains a powerful symbol of both China and its people, and is generally recognized as one of the most impressive architectural feats in history. In 1987, UNESCO designated the Great Wall a World Heritage site and in 2007, it was named one of the Seven Wonders of the World (UNESCO 2015). As such, the outside world's fascination with it has never abated and today, the Great Wall of China welcomes approximately 10 million visitors a year (Discovery News 2013).

When examining how a specific cultural and/or historical location is transcribed into a global sense of place, it is important to examine how tourists' viewpoints of the 
place differ from local people and governments (e.g., what kind of restrictions or limitations may put upon tourists). In the case of the Great Wall, military defense is generally considered to have been the aim of the Great Wall, but it is touted by the Chinese government to serve a peaceful rather than warlike function (Rucai 2008). At the same time, construction of the Great Wall was also a means of restoring order to China's nomadic and farming economies (Rucai 2008). More recently, the local peoples surrounding the Great Wall help to produce a global sense of place by interacting with tourism, while local governments and other influences work to preserve the site. In fact, the very livelihood of local small business operators at the Great Wall are highly dependent on tourism and, at the same time, they are directly impacted by any site development decisions introduced by the government (Tummala 2014). This example illustrates just how individual, and yet inevitably intertwined, the development of a global sense of place is and how international initiatives can converge with local priorities. It is these various viewpoints, altering opinions, and lifeworld differences which truly signify how a global sense of place arises. Globalization promotes and thrives on differences while at the same time, provides a sense of synchronicity and interconnection — the idea that events and decisions made in far-off places can have consequences for many others a world away. As Anna Tsing claims in her essay The Global Situation (2001, 107), "Globalization draws our enthusiasm because it helps us imagine interconnection, travel, and sudden transformation." Although many tourists are from far countries they are able to feel connected to the history surrounding places like the Great Wall through both roots and routes. According to Massey (1994), a global sense of place can provide stability and 
a source of identity; a single sense of place which everyone shares. The Great Wall of China serves as a strong exemplar for this global sense of place.

Several of the teachers describe the importance of this experience with the following photos and quotes (Figures 17-20):

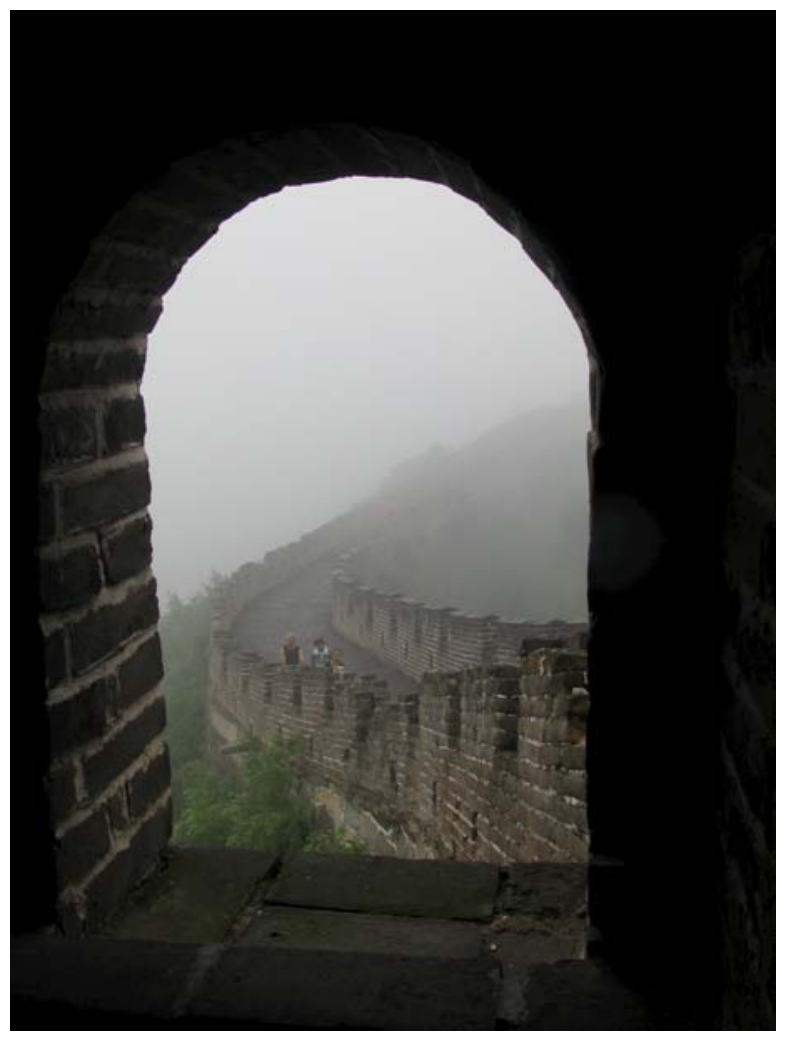

Figure 17. The Great Wall of China (Source: participant photo)

The Great Wall is probably the most important historical thing we saw and it is very important culturally....it represents the concept of movement in that it was used to both stop it and protect it, and yet people can walk along the wall, as well. (Igor) 


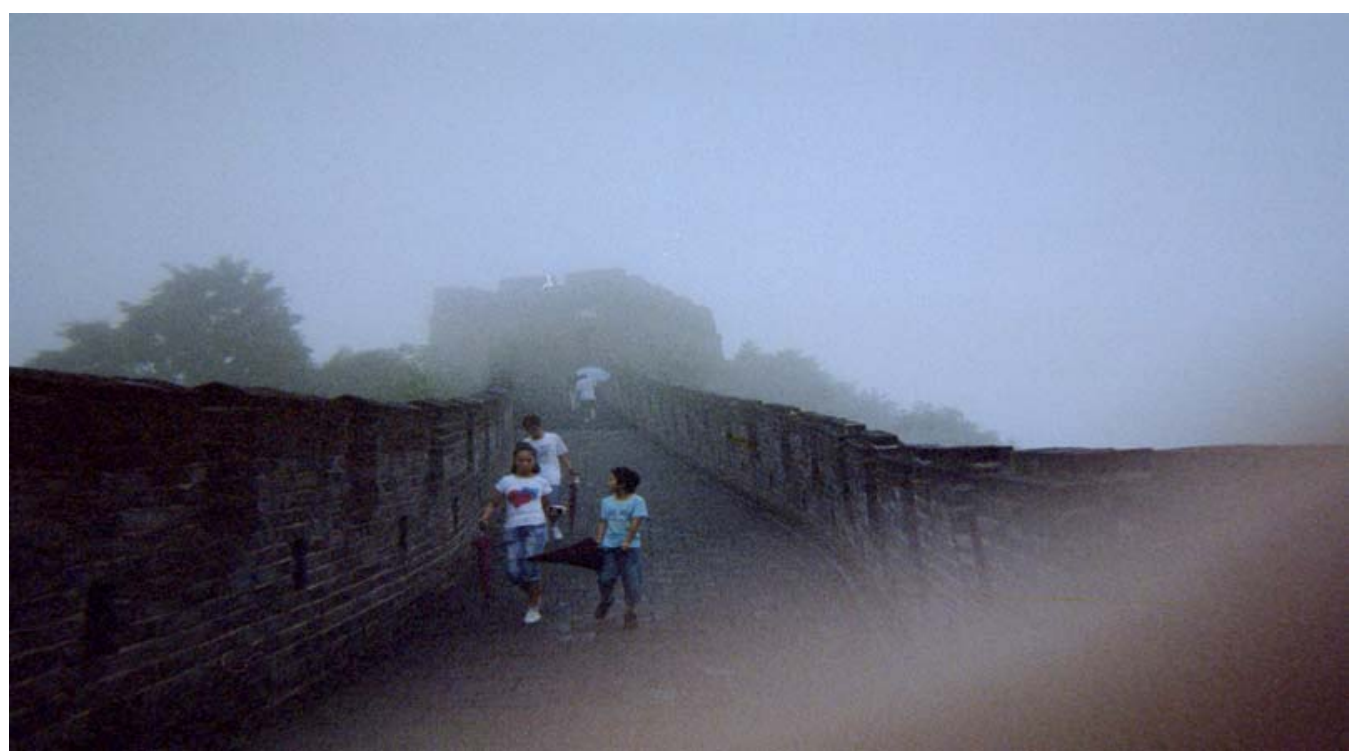

Figure 18. The Great Wall of China (Source: participant photo)

It feels surreal that I actually walked along the Great Wall. It's something you learn about all the time and you can see it from space and I knew about it since I was in middle school but I never thought I'd walk on it. I often think "Wow, I've actually been there and when people talk about it, I know that place; I've experienced it." (Nell)

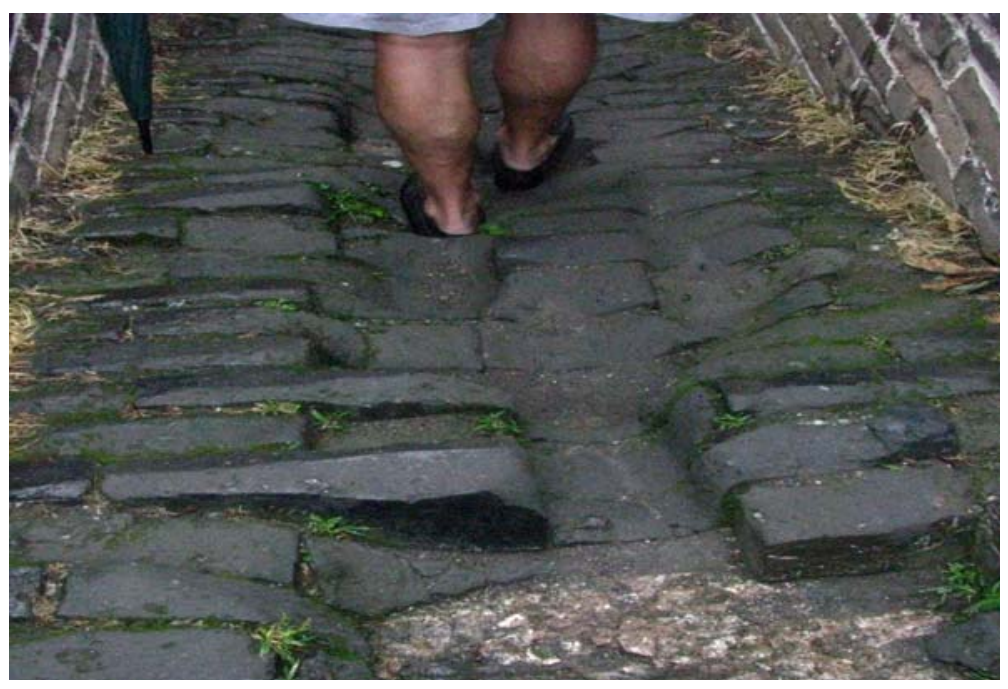

Figure 19. The Great Wall of China (Source: participant photo)

The Great Wall really had a huge impact in terms of thinking about history; it is one of the seven wonders of world and is so well known and I actually got to be there. I've heard about it so much growing up....these foot holds were worn into the rocks and that struck me. "How many years 
had it taken for these to be worn away to this point?" The whole experience I was just in awe, thinking "I'm in this place, on this wall that is so many years old and with so much history and so many people walking on it." The wall has so much meaning. (Alice)

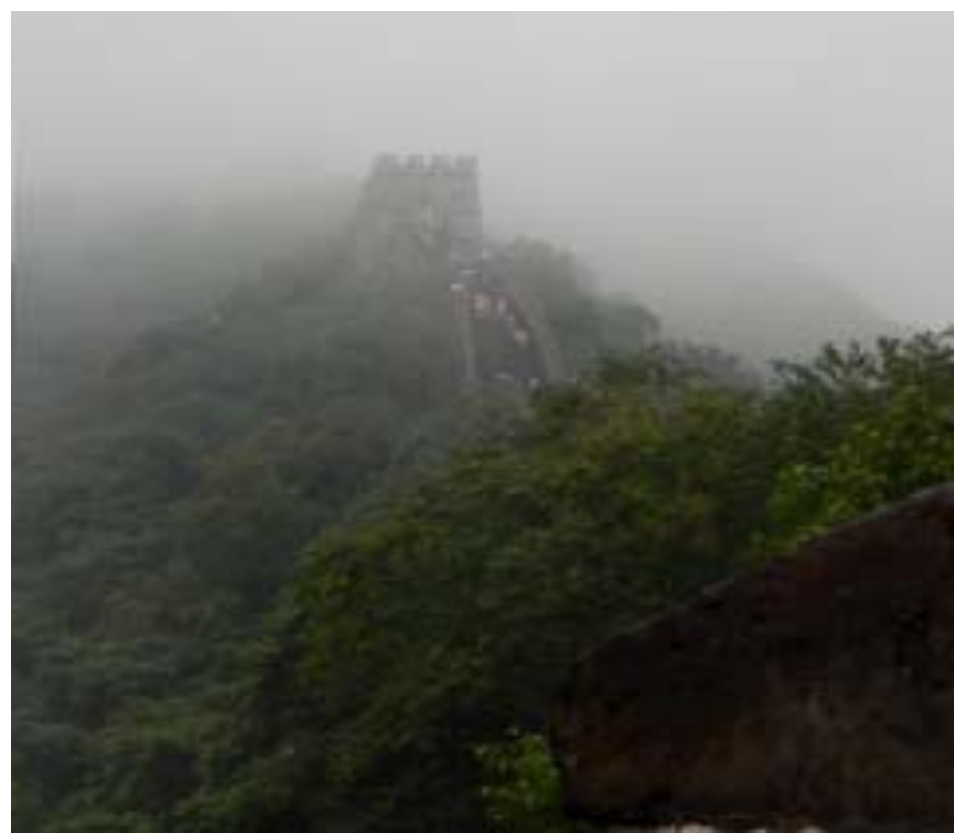

Figure 20. The Great Wall of China (Source: participant photo)

This [image] shows beauty and history. It's inspiring because I think about the amount of work it took to build and the effort it took to walk and climb it. It's just beautiful and sometimes when I think of China, it's not about beauty, but rather the communist controlled government and a lot of poverty. But, it is a diverse country with beauty. We should not be quick to judge....that's one of my best memories... and it was a nice way to end the trip. (Marie)

For many of the participants, the opportunity to see and walk the Great Wall of China was on their "bucket list." In fact, today's image of the Great Wall of China as a major tourist attraction motivates mass visits by both domestic and international travelers. So, for the final hours of the train journey, as it approached Beijing, many of the teachers were staring out of the window to get a sense of context for the setting of the wall. The teachers were clearly attracted to the site not only for the history behind it but also for its 
beauty, as indicated by Marie's quote above. Another participant connected the experience to sense of place with the following thought:

It really makes me think about identity and sense of place and the need for communities and a sense of belonging; [The Great Wall] symbolizes power and defines boundaries.

And yet another participant described their initial reaction to the Wall: "It is an incredibly impressive piece of architecture... and an amazing symbol of China's identity." These combined photos and quotes suggest how modern tourism can have a direct contribution to a global sense of place.

Another place that many of the participants identified as having a cultural connection to was the Gandan Monastery in Ulaanbaatar. The Gandan Monastery flourished as a center of religious and philosophical studies from 1835-1938, at which time the communist regime closed the monastery in an attempt to eradicate religion from Mongolia (Mongoluls.net 2007).

Gandan monastery was allowed to reopen in 1944; it operated with minimal staff, yet it was seen as a token of homage to traditional Mongolian culture and religious heritage. Today, Gandan is the most important monastery in Mongolia with over 400 Buddhist monks (Mongoluls.net 2007) and consisting of three temples and five centers of Buddhist learning. Inside the temple resides a large statue of a god who looks in every direction and is adorned with precious stones and gold leaf. Outside, in front of the main temple, there is a big pair of golden feet. The guide explained that the Mongols were attempting to build the world's largest human structure, a Buddha even bigger than the Statue of Liberty. The place was clearly fascinating to many of the participants, who were impressed with the various structures described here but the interviews identified that 
those who were most compelled by the monastery were so for personal reasons and spiritual connections. Hence, this will be discussed further in the "Personal Connections" section of this paper.

\section{b. Designing a Sense of Place}

Architecture and the way in which cities are built within their environments are important factors in creating sense of place, in that they contribute to making one's experience memorable (Brown 1981). In the paper "Neuroscience and Architecture: Seeking Common Ground," Sternberg and Wilson (2006) describe how both memory and sense of place prominently involve the same part of the brain — the hippocampus. Psychologists and neuroscientists generally agree that the hippocampus plays an important role in the formation of new memories about experienced events and in the detection of new surroundings, occurrences and stimuli. Experts also agree that the hippocampus plays a role in learning and storing information referring to portions of space, in the form of cognitive maps (Mandal 2014). As such, one's memory of events may depend upon a strong sense of place, and by extension, one's sense of place may be influenced by the integrity of the memories formed there (Sternberg and Wilson 2006).

As indicated in the Literature Review, a key factor in distinguishing place from space is the ability of humans to interact and make meaning. In the article entitled “Designing a sense of place: don't forget memory!" (Lehman, 2009), the author writes about how the ability to interact in space with other users, as well as with the space itself, gives a feeling of belonging rather than just passing through it. Lehman (2009) also mentions that the incorporation of certain architectural elements can help a space to be remembered as they become signals that guide and help orient the users. Of course, sense 
of place greatly depends on the interpretation given by each user of the space, which in turn depends on social, cultural, and economical factors, separate from the architect's intention. When the architecture is experienced, and the experience is memorable, it becomes personal and it stops belonging to the architect. In turn, it becomes about what one perceives as they make the space their own through personal experience, and so when the person leaves the space and tells other people about it, it is that experience, as well as personal perceptions and interpretations, that are shared. As landmarks and other architectural features come together in one's mental map, a person's sense of place becomes stronger.

Moscow serves as a showcase of Russia's rich historic, architectural, and artistic heritage: the colorful onion domes of Saint Basil's Cathedral, and the Kremlin, Moscow's historic fortress and the center of the Russian government. The vast rectangular stretch of cobblestones and buildings on the Red Square evoke a sense of awe, for many, as they explore a place where so much of Russian history unfolded. An important public marketplace and meeting place for centuries, Red Square is home to not only the familiar Saint Basil's, but also the State Historical Museum, the enormous GUM State Department Store, Russia's most famous shopping mall; and a pyramid mausoleum for the revolutionary leader Vladimir Lenin (Figure 21). 


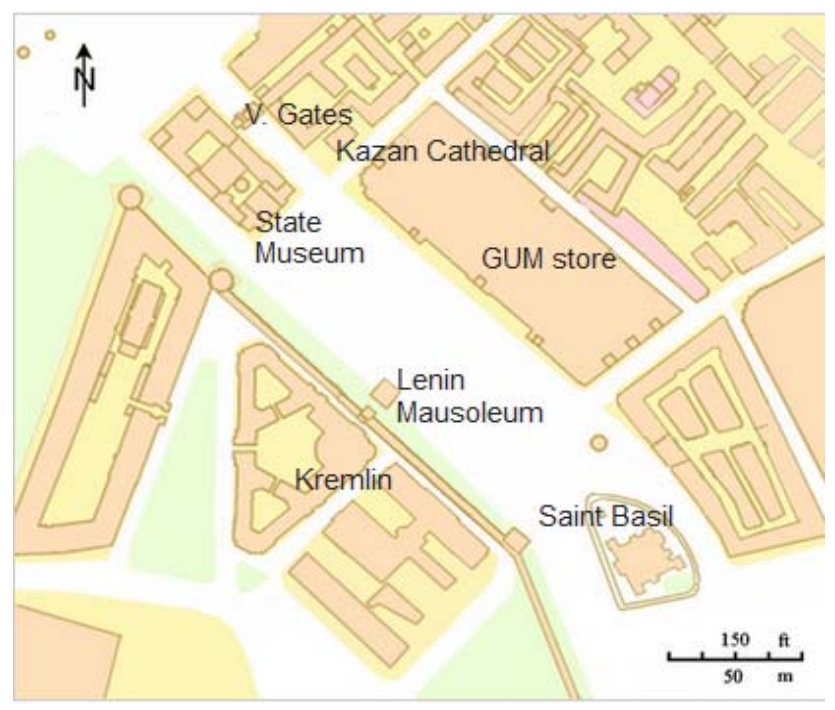

Figure 21. Layout of Moscow's Red Square (Source: Wikipedia 2015)

Taken together, Moscow's Red Square and Kremlin, with their inextricable links to Russia's most important historical and political events since the $13^{\text {th }}$ century, serve as a rich symbols of the heart and soul of Russia. As such, many of the participants described how these historic and architecturally dynamic sites impacted their sense of place, as indicated by the images and quotes below (Figures 22-24):

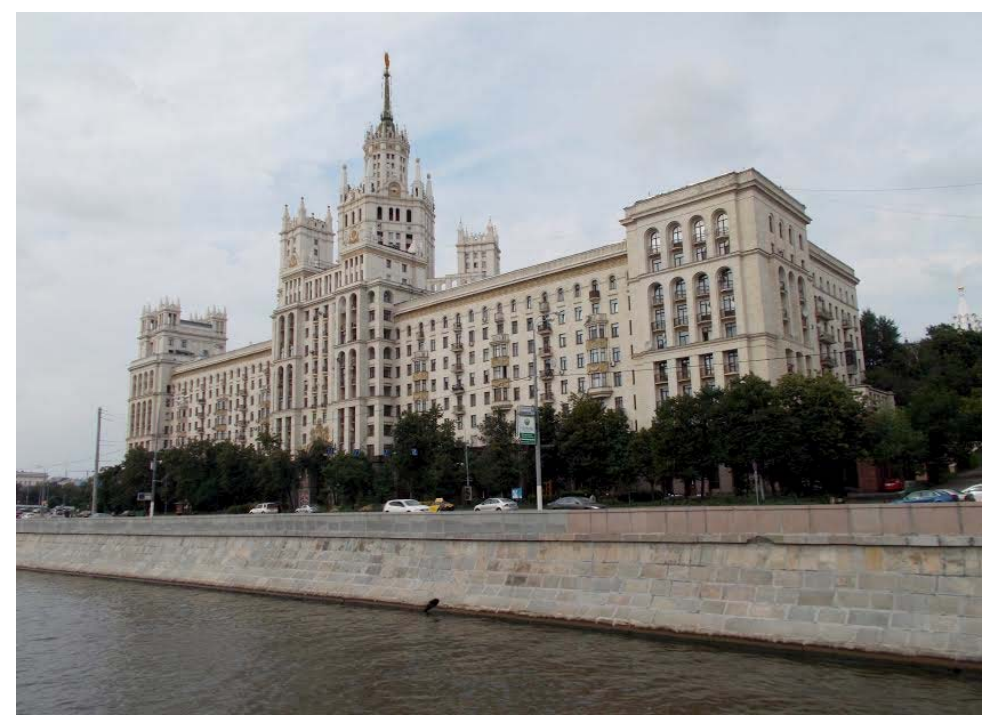

Figure 22. Koteinicheskaya Embankment Building of the Seven Sisters Buildings in Moscow (Source: participant photo) 
I saw [this building] on a river cruise. It wowed me that we saw this structure and it's impressive that we still have structures like this. It stood out and is representative of the massive architecture and buildings we saw in Russia. When I think of Russia now this was a big take away. (Susan)

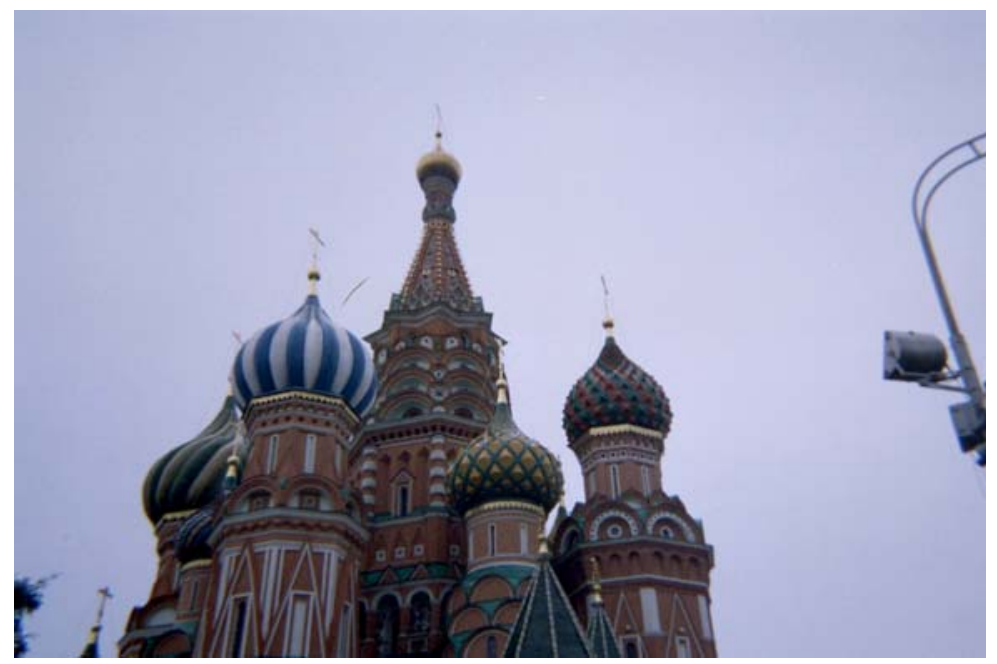

Figure 23. St. Basil's Cathedral in Moscow's Red Square (Source: participant photo)

I particularly remember the day we went to Moscow and the Red Square and saw the Kremlin...St. Basil's Cathedral was really special. I felt like I was in the midst of history; it was so unique, with such different architecture...It was a really special place. (Nell)

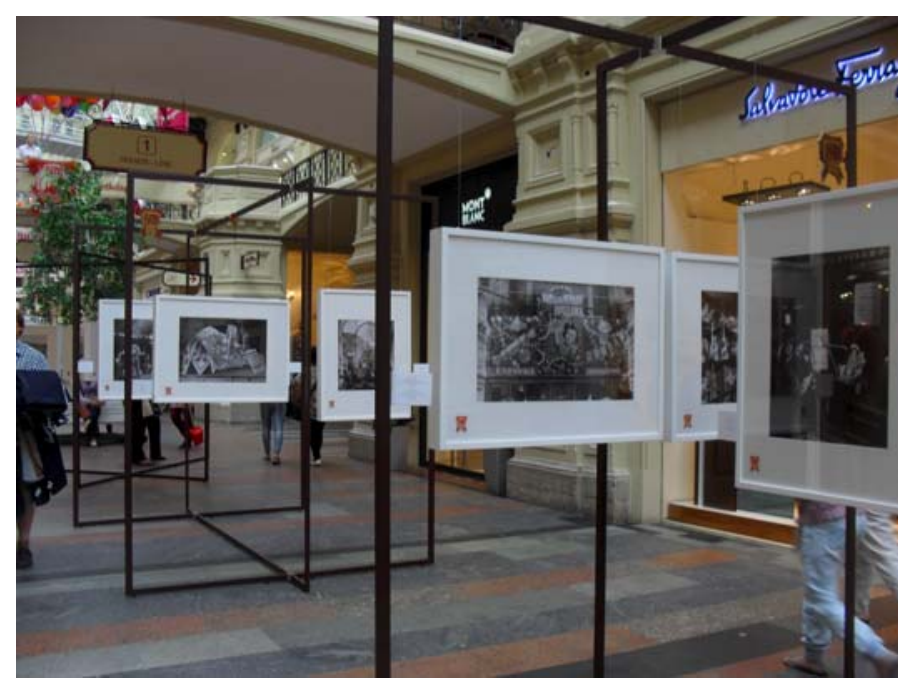

Figure 24. Photo exhibit at GUM Department Store on Red Square in Moscow (Source: participant photo) 
This is a photo exhibit of a Dior fashion show that took place in this mall in the 1950s or 60s. The mall is in the middle of the Red Square. I didn't go into the walls of the Kremlin...Our guide showed us this mall. It was just outside of the Kremlin and has been there forever. There were very expensive clothing and handbag stores. Everything was more than we could afford and I found this juxtaposition of the Kremlin and the mall interesting. The mall was so beautiful and this photo exhibit is in all black and white. You can see the babushkas watching the models; it made me realize that no one else [from CGEO group] but us saw this. It was awesome. It reminds you that Russia is not all about communism; this mall has always been there. It really made me think. I like the originality that this photo represents. This was not a tourist attraction; it was real life, at their [local Russians] mall and they can afford to shop there. (Maria)

From onion domes to opulent department stores, the Russian art and architecture — for many of the C-GEO participants — seemed to bring to life the culture and personality of the country. The Russian people also made a great impact on the participants and were a fairly common topic of discussion while visiting the country and a year later during the sense of place interviews.

\section{c. The Russian Personality}

The Russian personality has many faces, making it difficult to define. Many of the C-GEO participants found the Russian people to be an enigma, with some particular behavior patterns unique. Several of the teachers referred to having difficulty making small talk with Russians (compared to how they would with other Americans). In some cases, the Russian people were described as appearing "rude," "blunt," "serious," and, "not very friendly" — particularly in public situations. For example, public drunkenness was seen in the cities, which at times caused a few of the participants to feel a bit concerned for their personal safety. The Russians also appeared to have a very different concept of what it means to stand in a line. "They were pushy while getting onto the Moscow metro," says Esther. "They kept trying to get on while others were still trying to 
get off." The same seemed to apply to lines at such places as supermarkets and banks. “...it was difficult to figure out where the line started or who was there first," recalls Maria. She goes on to say, "Actually, there were no lines, just an unstructured mass of customers heading to the open cashier in no particular order." At the same time, the Russians stood very close to each other in conversation, leading to a feeling that they did not want outsiders to hear what they were talking about. A couple of the C-GEO teachers found this uncomfortable.

On the other hand, most of the teachers indicated that they took advantage of opportunities to speak one on one with local Russians about their lives when possible, providing a glimpse into their world. They also took the time to reflect upon the dramatic contrasts between Americas and Russian history and cultural roots, which ultimately led them to a better understanding of the Russian personalities they encountered, as indicated by the participant comments below:

I think many people are dissuaded from visiting Russia because they perceive the people as rigid, aggressive, and unfriendly, but my understanding is that their toughness is a result of their environment and their history. If you're turned off by their rough exterior, then you might miss out on an opportunity to get to know their softer, kinder side. (Esther)

I think it is important to understand Russian's historical context, and the decades of enduring and suffering these people have faced. Sure, some of the Russians came across as stern and cold, but I encountered many friendly and very helpful people. (Ivan)

At first, I was a little afraid of going to Russia because of all the propaganda I had heard about, but I wanted to know more about it. I found the Russians interesting and I have respect for all they have been through...Russia was nothing like what I had been told or seen on television. (Edith)

Despite the various patterns and processes of globalization, cultural differences between Russia and America still remain. The societal and cultural norms that an 
individual is most familiar with will significantly influence worldviews. An example experienced by the C-GEO teachers related to appropriate levels of personal space, which commonly varies across cultures. Americans rarely stand closely face to face with others and often feel that people from other cultures who cross their personal space threshold are pushy and aggressive, and make them feel uncomfortable. As the C-GEO teachers readily recognized, these types of cultural differences can lead to misperceptions and misunderstandings, which, in turn, can inhibit the learning process and lead to negative associations for a place and its people. In this new, globalized world, it is critically important that teachers, in general, recognize their own ethnocentric behaviors and attitudes so they can instill in the next generation of global citizens the ability to embrace cultural differences and to be understanding of other people. This is especially important as U.S. classrooms are becoming increasingly more diverse.

\section{d. Taste of Place}

It is clear that exploring local culture plays a substantial role in developing one's perception and understanding of a place. While not mentioned in significant detail during the participant interviews, observations indicate that trying traditional foods was an essential part of their cultural experience. As the teachers passed from one country to another, they often sought meals that were akin to what the locals ate. When in Russia, pirozhkis, blini, borscht, and vodka were on the menu; in Mongolia, participants were anxious to try Mongolian barbeque, as well as horsemeat and the popular fermented mare milk, airag; and, in China, the teachers sought Beijing roast duck, kung po chicken, and jiaozi (dumplings). 
Different places create different and unique tastes. Trying traditional foods is a way to taste a part of what makes that particular place (and culture) unique. As with all sensory faculties, taste and sense of place are intimately related. Taste and place come together for example, in the concept of terroir. Terroir is a French term that, like sense of place, attempts to capture the myriad environmental (e.g., soil, plants, climate) and cultural influences (e.g., traditions, tools, and recipes) of a certain place, but with express focus on agricultural products (Michalski 2015). The term is most commonly used in winemaking, but has more recently spread to a variety of regions and food products (e.g., coffee, cheese, chocolate, tea) (Szanto 2013).

The majority of participants appeared to recognize that eating at local establishments outside of the tourist areas and pursuing the experience of authentic flavors helped them to better make sense of the place. In St. Petersburg, Ivan confirms this when he stops at a street vendor in a residential neighborhood and says, "This is where we'll find the cheapest and usually most delicious food out there." Others fully embraced the idea of visiting traditional restaurants and expressed continued enthusiasm for the opportunity interact with local people and try the foods that they typically eat.

Not only does food provide a taste of place and a time for connecting with other people, but it has been suggested that food is one of the few remaining ways in which we engage all of our senses (Boynton 2002). Igor, Edith, and Kesley all mentioned that food was an essential element to their cultural experience in Eurasia; it was also clear from observational data that at times during the journey eating was one of the few full experiences which truly did engage all of the senses. A great example of this was when the participants were served homemade local fare from their Mongolian host family at the 
ger camp. Upon arrival at the ger camp the participants "checked in" and got oriented, many by following their nose to the communal ger and introducing themselves to the local hosts who were preparing dinner using locally grown products and recipes passed down through generations. Even with a minimal ability to exchange words - and with some translation help — the group quickly learned that their meal would consist of dumplings and a soup of meatballs and fresh vegetables. When the group later convened to enjoy this communal affair, the travelers had ample opportunity to visit with the local family, share a cup of milky tea with them, and learn about their customs and traditions. There was an overwhelming consensus that the food was "delicious." One participant, exclaimed, "This is some of the best food I have had on this trip." After dinner, a long evening was spent enjoying the atmosphere and sharing stories with the family members from the ger camp, as well as with other participants of the C-GEO program. Kelsey and Edith played cards with two of the Mongolian children while the adults played a simple mystery game and drank Mongolian vodka or tea. This example shows that in addition to trying traditional foods, participating in the rituals surrounding the meals was helpful in understanding a particular country's culture; and, as such, provides a powerful sense of place experience for travelers who take part.

These findings suggest that sense of place is developed and enhanced, at least in part, by cultural and historical aspects of place. Cultural and historical experiences help to define a place and, in turn, may anchor one in it and give the place special meaning. More specifically, this research indicates that the particularly unique aspects of a place, like architecture and food, are capable of creating a truly memorable experience for visitors, which in turn, makes an important contribution toward providing them with a 
sense of place. This case study also suggests that the most impactful places for participants were often derived from the fact that each location focused on a distinct mixture of wider and more local social relations. Ultimately, it becomes clear that while the concept of heritage, which has multiple, complex, and socially constructed meanings, also plays a role in helping individuals, communities, and nations define who they are, both to themselves and to outsiders, and in turn provides a sense of place and belonging.

\section{Personal Connections}

Traveling exposes visitors to new landscapes, ideas about people, politics, heritage, food, and so much more. This study asked participants to explore their personal connections to the places they visited on the trip. The participants especially related to and described the similarities and differences of navigating other cultures, new cities and modes of transportation, and various physical landscapes.

An important finding is that, in many cases, what made places meaningful had a direct relationship to one's familiarity with the setting. In fact, some of the strongest relationships described by the interviewees are characterized by a strong sense of identification with place and a familiarity to one's home community. Kelsey sums this up well when she said,

My favorite thing about geography is place. I have a very strong attachment to the place I grew up. I love the idea the people and place are so intertwined. My hometown greatly influences my lived experiences and the activities I identify with now. (Kelsey)

Kelsey, who was born and raised in Oregon, goes on to say,

I liked to see how similar the landscapes were, especially across Russia where I imagined myself in the Willamette Valley [Oregon] and there were a lot of other places like where we're from. I felt like the Siberian part of Russia takes the Willamette Valley back 100 years with dirt roads 
instead of freeways, but you could transplant the physical landscape. (Kelsey)

It makes sense that familiarity with an environment would have a direct effect on how individuals respond to and perceive other locations and cultures. Most people live and work in places, and around people, that are familiar. In these relationships, place is an integral part of people's lifeworld. One noteworthy finding indicates that there is an important link between exposure to natural environments in one's childhood and environmental preferences later in life. According to Measham (2007), hometown landscapes form part of people's identity and constitute a key point of comparison for considering subsequent places later in life. One example of this comes from Susan, who was born and raised in Oregon, and says,

The Mongolian steppes reminded me of where I am from - sheep ranching territory and a valley full of rolling hills. This is where I grew up and when I got home, I found myself commenting on how beautiful and interesting it was to be in Mongolia and see the rolling hills that went on and on and on; it reminded me of southern Oregon. (Susan)

Alice included a unique sense of place photo which cuts out the bottom to show only the mountains which had significant meaning to her (Figure 25), as described below:

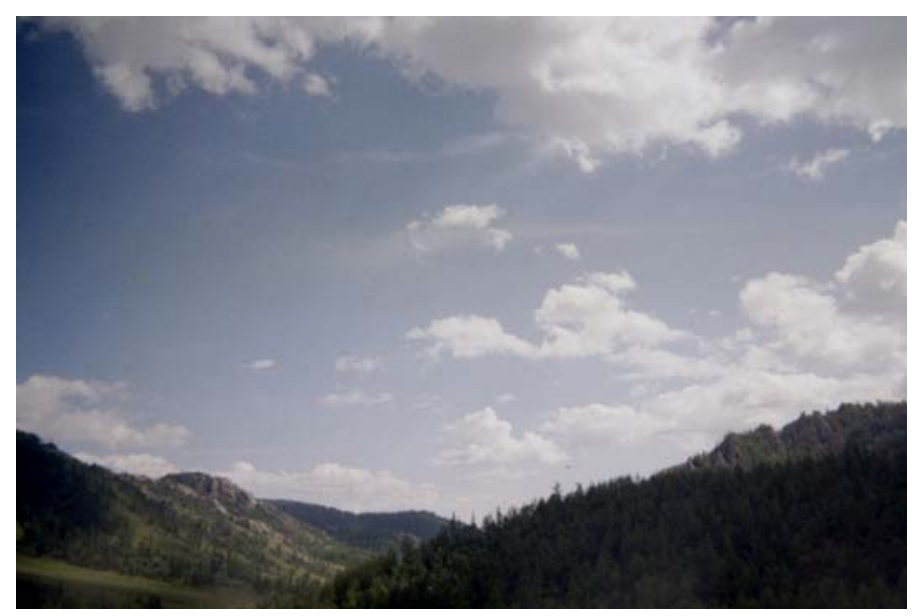

Figure 25. Mountains and sky above ger camp in Mongolia (Source: participant photo) 
This [photo] is in Mongolia when we were out in the gers and it was just...the mountains are so similar to home. I cut the bottom of the photo cause I just wanted the mountains; our camp was at the bottom of the scene. I felt at home out there and probably the biggest thing — I could have picked any of the photos from there - was the connection to the mountains at home. This represents finding home in another country and it was my favorite experience of the trip, being out there. I could've been happy with any photo taken from there. (Alice)

The C-GEO participants often described their relationships in terms of the emotional connections, memories, meanings, and contextual implications of feelings that they associated with places of attachment. Another case in point is made by Edith below (Figure 26):

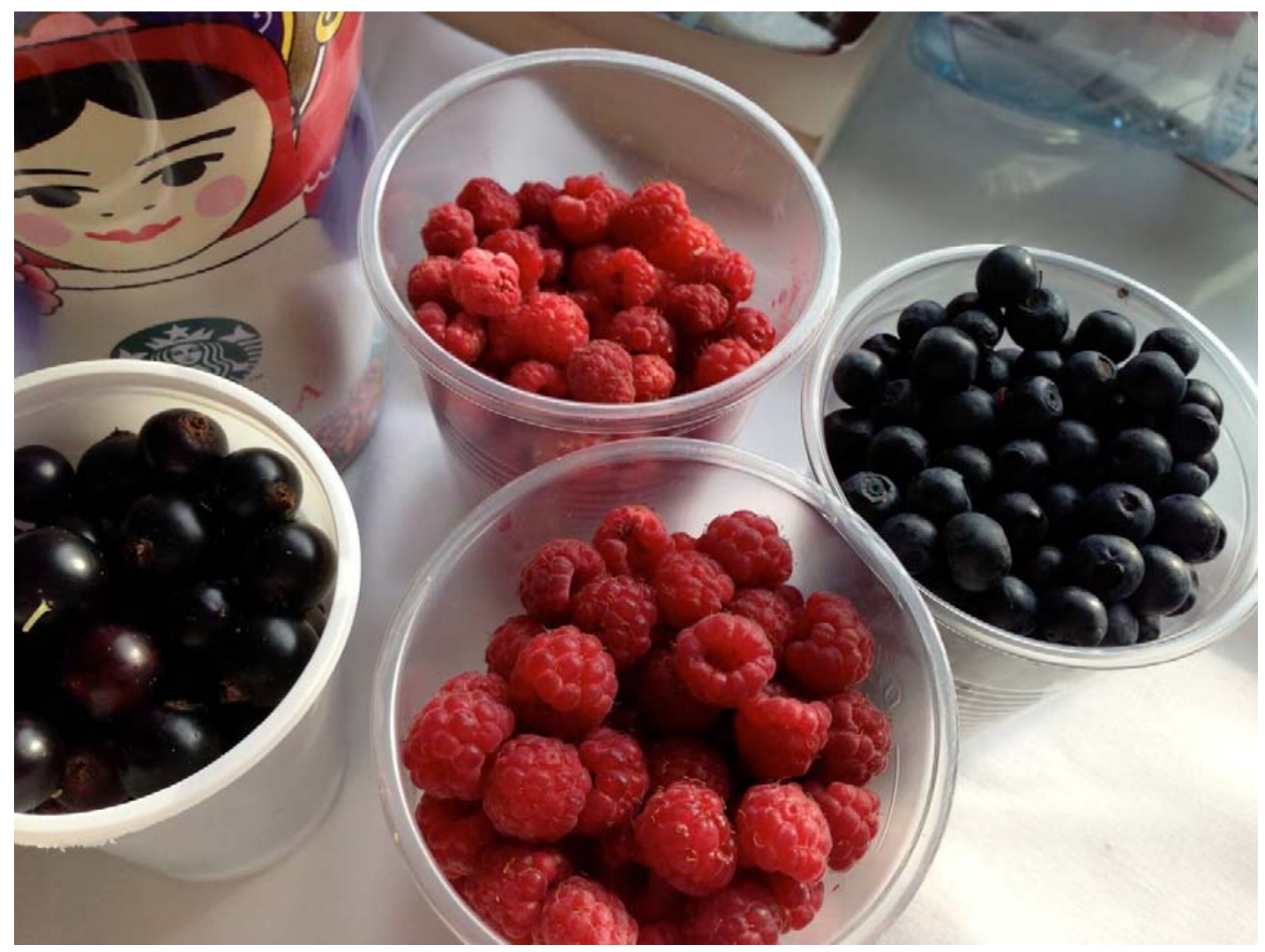

Figure 26. Local berries from Russia (Source: participant photo)

This photo is a picture of four cups of wild berries from the local woods, I imagine, and a Babushka doll coffee cup that I bought in Moscow. I bought the berries at a train stop. [This image] makes me feel relaxed and 
smile. It makes me hungry. I like it because it reminds me of home. In the Northwest, we love berries and it's a great connection to be in Russia and get off the train and buy berries from a babushka. And, I collect babushka dolls so the doll represents me. I love huckleberries and fresh berries and the connection to home makes me happy. There's also a piece of home represented by Starbucks - that makes me feel that our world is connected more and at many levels. I also have a grandma and it's fun to see them [babushkas] out there. My grandma loves to garden...I chose [this photo] because of how it made me feel - the experience of buying fresh berries and eating them - I did this a couple of times and it helped me feel connected to home. (Edith)

According to Othman et al. (2013), over time memories collectively allow an individual to develop feelings of familiarity that comprise a sense of place. When an interactive experience does not match developed expectations, an individual adapts his or her understanding of place through learning and sensory input. For this reason, places are frequently associated with memories that can evoke physical senses (Othman et al. 2013). For example, Alice describes her favorite place (ger camp, Mongolia) as being similar to the physical landscape of her homeland, when she says that

...it was so much like home and yet half-way across the world. It was really nice and made me feel like "wow, this landscape feels like home but it's so far away." It made me wonder if we are at the same latitude because of the similar physical aspects and I wondered if the world might create physical landscapes so far apart. (Alice)

It seems inevitable that when traveling, visitors will find themselves drawing comparisons to their homelands. The C-GEO teachers participating in this researcher were no exception. In fact, this study finds that travel actually heightened many of the participants' appreciation of their hometowns and in ways that they might not have considered at the onset. The following quotes give detailed information on how the C-GEO teachers made meaning of the professional development experience in relation to their feelings toward Oregon: 
Edith, who grew up in the Pacific Northwest region of the United States says, “...travel away helps me appreciate the Northwest even more."

Maria, who was born and raised in Oregon, describes her connection this way: "Every place I go, this trip included, reminds me how special Oregon is and how lucky I am to live here."

Maria, also from Oregon, explains,

I love Oregon and the diversity here. I love to travel but I also love my home and appreciate what I have. (Maria)

Esther, who has lived in Oregon for 15 years, suggests,

It's like we're friends — Oregon and Mongolia - we are "two peas in pod." There's a resonance rather than a dissonance. This experience just made my bond with Oregon stronger. (Edith)

Alice has lived in Oregon since she was 5 years old and explains the impact of this experience in these words:

Partly, it made me love Oregon so much more; it's home, it's known and comfortable. As much as I love traveling, coming home is such a nice feeling and I appreciate it more. (Alice)

Travel across cultures also offers the excitement of new experiences, and the freshness of being in unfamiliar places and as such, serves as a meaningful distraction from one's "normal" day-to-day routine. In some cases, the places that had the most effect on participants were the most unique or unfamiliar to them. For instance, Nell states,

What most changed my mind set, was the most eye opening - when we went to the temple in Ulaanbaatar and I saw all the people spinning the prayer wheels and there was the big pole to walk around, and the big feet, and a wedding going on. It was unlike any wedding I've ever seen anywhere, including on TV or in the movies. They were dressed so differently, with different stories, traditions, and rules on how things work. It was such a different culture from anyone I know and my own. (Nell) 
Yet, as it relates to the temple in Ulaanbaatar, there was a clear dichotomy in the responses — some felt a connection to the familiarity of it based on their lifeworld experiences, while others found an association because it was so unfamiliar to them. Nonetheless, the temple itself, for whatever reason, had a significant impact on many of the participants. Amber describes it as "the temple with big feet" and includes the following image as one of her three sense of place photos, along with the following description (Figure 27):

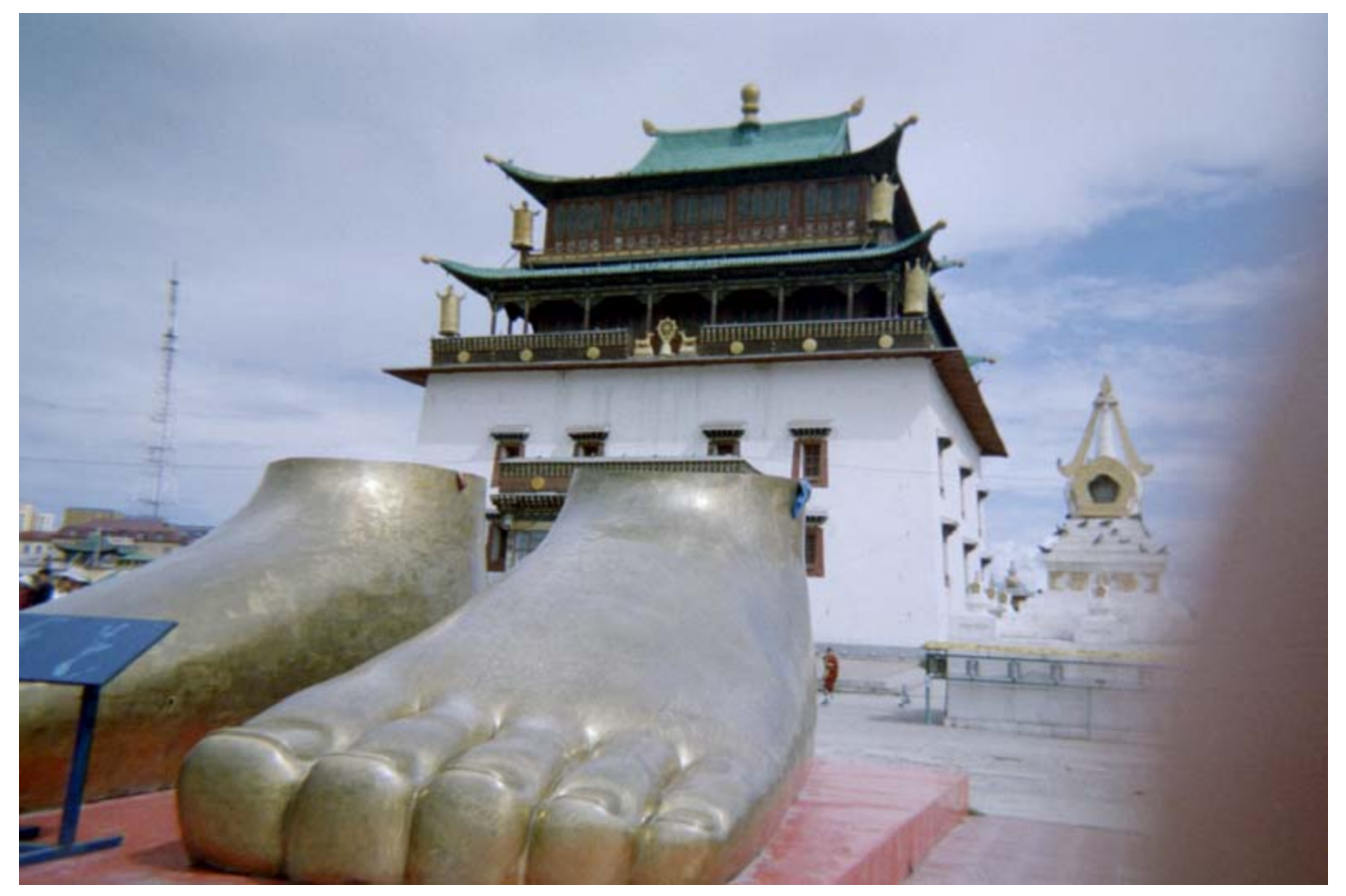

Figure 27. Temple in Ulaanbaatar (Source: participant photo)

...when we went inside there were a whole bunch of local people in there. When we were leaving, an older women was coming in and she turned me around and showed me how to walk out backwards. (Alice)

Kelsey discovered personal connections during the visit to the temple in Mongolia, which she describes this way: 
I couldn't help but draw many connections to my own religion, which is very western, but the temple services are more eastern. The symbolism connected me with my own culture. (Kelsey)

Susan also appreciates a connection based on her lifeworld experiences, when she states,

I really enjoyed the Buddhist temple. I felt connected through my prior knowledge of Tibetan Buddhism based on a trip to Nepal; it was interesting to see how it manifested in different places but it is still the same practice. That was really striking and has given me a broader perspective when I'm teaching. (Susan)

The affective approach to contact with new and different cultures is sometimes referred to as "culture shock." The term is attributed to the anthropologist Kalervo Oberg, who in an article in 1960 used it to illustrate how people who are suddenly exposed to strange or unfamiliar places may become overwhelmed by it - a phenomenon particularly possible in the age of globalization (Oberg 1960). Today, people tend to take the expression too literally, however, and the phenomenon of culture shock is often characterized in a negative connotation to describe, such feelings as confusion, anxiety, disorientation, suspicion, or even grief due to a sense of loss of familiar physical objects and social relationships (Bochner 2003). There is no doubt that this reflects some of the feelings and experiences of travelers who suddenly find themselves in new, strange, or unfamiliar places, as demonstrated by some of the C-GEO participants. However, the use of the word "shock" seems to put too much emphasis on the threatening circumstances of contact with new situations, without acknowledging that such experiences all too often have beneficial consequences for the participants, as well, and particularly over time. While being comforted by what is familiar when traveling to far away destinations is a more common way of connecting to place, some of the participants seemed to thrive on what were for them exotic locations or experiences. It was also apparent that personal 
connections can change over time, particularly as one takes time to reflect on their experiences and relate them back to more recent experiences. An example of this comes from Ivan, who says,

I left St. Petersburg for Moscow without any feelings of connection. But after some time, I've realized how much I really enjoyed St. Petersburg to just walk on the streets and visit amazing places. Now, I'd like to go back there one day. (Ivan)

Teachers have a direct influence on student learning. Previous studies, along with the results from this research, substantiate that a holistic range of personal and professional teacher experiences can lend to the credibility and trust necessary for meaningful dialogue in the classroom, and has the potential to lead to increased student achievement (Tucker and Stronge 2005). For example, a teachers' firsthand experience with a place that is being taught about in the classroom can affirm the value and legitimacy of the teacher's knowledge, by way of cultural context, stories, and intellectual connections. This, in turn, may enable students to better relate to the course content. In addition, based on the data collected from this study, the influence of a teacher who has learned in an international setting, results in a more positive response towards their culturally diverse students.

\section{Professional and Intellectual Connections}

Participants were interviewed approximately one year after they returned from the trip to Eurasia. Hence, they had ample time to transition back into their day-to-day activities, assimilate and reflect on their travels, and return to the classroom. The year gave them time to reflect, and then in the interview, to discuss the impact of the experience on their professional life. 
All of the teachers noted that the C-GEO Eurasia program excited and motivated them professionally, and they were able to use their firsthand experiences to excite their students. Susan describes how her experience made for richer discussions:

Being able to provide personal explanations and my own photos, which I use a lot in class, and to talk about those experiences which I had in person — it's just more authentic for the students; not just textbook examples. I use my own photos and personal descriptions related to my perspective. I also use artifacts, like currency. (Susan)

Maria argues that students appreciate having a teacher that can say what a place is like:

...when I tell my stories, students pay attention. I'll tell them

St. Petersburg is like this and it is different from Portland in these ways. I navigate the classroom differently by making connections and sharing my feelings for a place. I do this by sharing my experience. (Maria)

Ivan agrees when he says,

When kids ask, I can give real information based on experience and not just based on assumptions.... what I've learned has been transferred to my students, not in a life changing way, but it has added to my repertoire - I can tell them that last summer I went to Russia, Mongolia and Beijing; I stood on the Great Wall and their ears perk up. It gives me more clout. (Ivan)

Igor reinforced this sentiment when he stated,

My teaching style is to give examples based on my own experiences (e.g. migration and people move thru railroad). I can now give real examples versus simply relying on textbook. (Igor)

Following these thoughts, several of the teachers also shared that the experience changed their worldview and, as discussed earlier, gave them a much greater understanding of the region. For example, Maria stated,

I think that this trip has given me a different perspective; I am better able to relate to students from that region. I realize that these countries are so large and we cannot generalize about them. I pay attention more and understand politics more. (Maria) 
And, Marie agreed when she said,

I have more of a global perspective and can talk first-hand about when I was there and what I saw there. Sharing my experiences gets them thinking beyond their small world; most of my students have not been outside of Salem, let alone Oregon. (Marie)

Esther concurred and noted,

I learned anchor points for what I teach — world geography covers Asia, Siberia and China. I can now explain the physical geography impacts on these places and their economics and I can say these things with more clarity and experience than simply using a book. (Esther)

She goes on to suggest that her students may be more interested in traveling based on her experience:

...when we teach, it makes a life change in kids; it's especially important when you can see it. My students have really been intrigued by traveling because I was there and can show and tell them about it and they realize that they can do it too. (Esther)

When asked if their involvement in the C-GEO Eurasia program supported specific objectives or needs at their school, the majority said simply that no it did not, but a few notable responses include the following:

My school has an Advanced Placement (AP) focus and this experience makes me a better AP teacher as I am better able to give real world examples and in turn, the students do better on exams. Hence, the school benefits. (Igor)

OGA [C-GEO] itself provides materials and professional connections that I bring into what I do. (Maria)

Esther, a middle school teacher from rural Oregon, brought back ideas to create space for change in a culturally isolated education setting. Using cultural artifacts, videos, and maps of Eurasia as a medium for understanding, Esther is getting her students more deeply interested in global issues and conversations about global citizenship. "I'm 
starting to see students think beyond their bubbles," she said. At the same time, she seems to be making a big impact on her teaching colleagues, as well.

I think it has also intrigued other teachers about traveling. It has elevated the teaching of geography...they realize "Oh my! You can do all this with geography...?" (Esther)

Esther goes on to say,

I'm working on taking the global education conversation to local districts, national conferences [and] board meetings. I want to have more conversations about globalizing culturally isolated classrooms. (Esther)

Middle school Language Arts teacher Ivan decided to focus on the writing process and had his class address cultural similarities and differences among students in Oregon and abroad, with a specific focus on Russia and Mongolia:

[Global education is] essential for [the] growing interconnectedness of our world. The types of problems that we're facing today, and will continue to face in the future, cannot be solved by individual countries. They have to be solved by multiple countries working together. For teenagers, [global education is] really important because it takes them outside of themselves. They need connections to the world, not just to a 15-block radius. It is disconcerting that my students are not more aware of the world around them. (Ivan)

The strength of connections tied to the group's profession as teachers is strong. An example of how the participants' profession as teachers influenced their sense of place is demonstrated in the story behind the image below taken of local teachers waving outside of a school in Mongolia (Figure 28): 


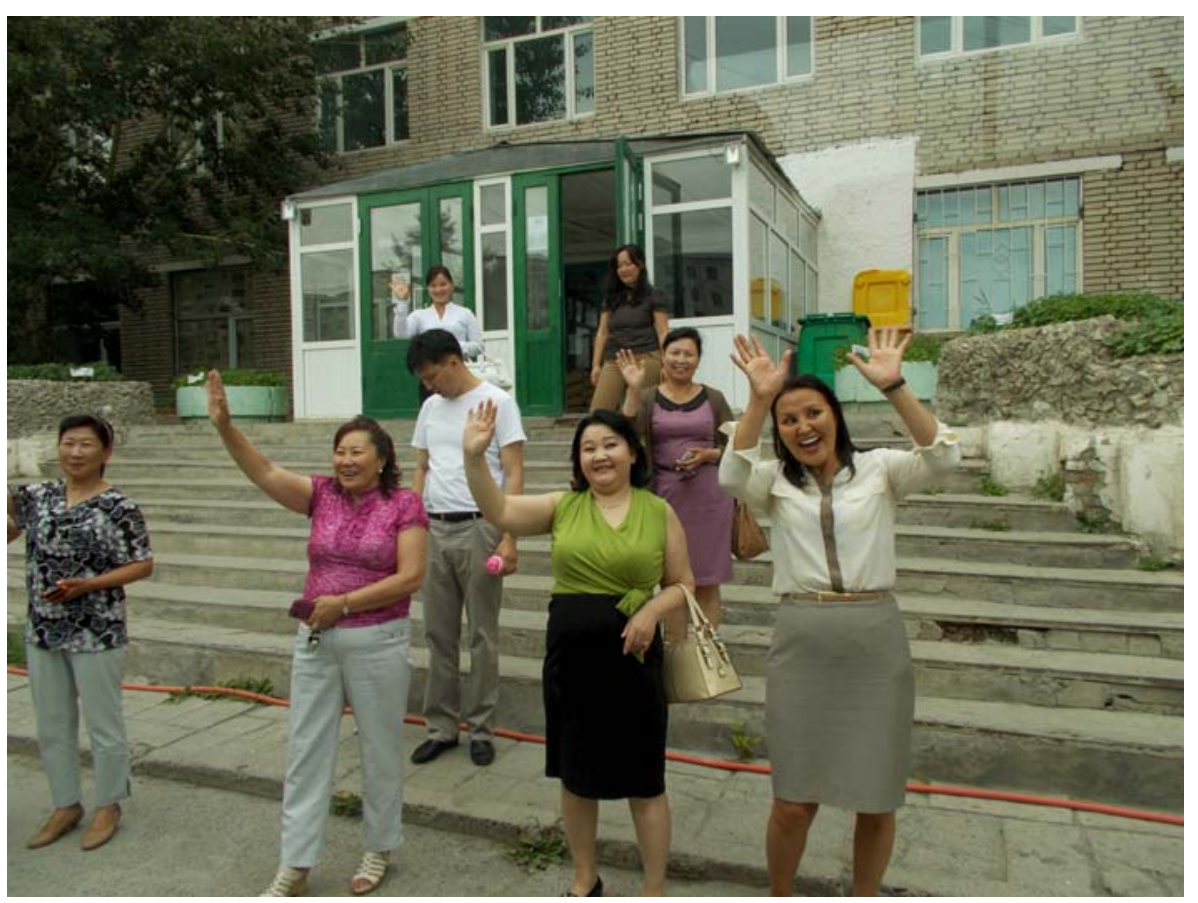

Figure 28. Mongolian teachers waving goodbye after school visit (Source: participant photo)

It's so easy to connect to people who do what I do - there is a kinship, a connection, just by the nature of our profession. Teaching is a calling for most; not just a job and it becomes who you are. It is easy to be in the presence of people who must feel the same calling and give their lives to try to make world better place. This picture makes me feel great. It's energizing to see people who do what I do and are enthusiastic. Teachers and kids are the same all around the world and they face the same challenges. It was uplifting that [these teachers] were excited to see us and gave their own time to do so. I can't help but feel this wasn't about tourism and this was not paid time for them. It was rewarding. (Susan)

The primary goal of this type of field study is to provide teachers real-time experiences they can utilize and integrate into the curriculum. When one of those "teachable moments" occurs in their classroom they can reflect on personal knowledge and experience to better inform their students. By simplifying the complex ideas of global education and cultural understanding through in-situ, international experiences and a collaborative network, C-GEO teachers have clearly enhanced their own learning and, in 
many cases, helped their students grow to foster an international perspective in the classroom. As such, this research supports the idea that well-planned, content-driven overseas immersion experiences are of significant professional benefit. The teachers clearly gained a well developed level of what Cushner and Brennan $(2007,10)$ refer to as "global cultural competence, an essential and integral part of what it means to be an effective teacher." Another major finding from this study is the participants' belief that learning in another cultural setting significantly enhanced and extended their professional experience. For instance, during the school visits, they observed and experienced differences in the way schools organized both themselves and their students' learning. They also realized that teaching methodologies, lesson planning, managing behavior and assessing students were shared issues in a variety of schools around the world.

This research also found that participants made gains in understanding cultural differences and developed a greater awareness of the different ways of seeing and reflecting on global issues. This, in turn, challenged their pre-existing views, beliefs, and assumptions about people, cultures, and systems outside of the United States. The results from these participants suggest that individuals who spend time outside the comfort zone of their home society for an extended period can gain a valuable understanding of what it means to be perceived as "other" when part of an ethnic minority. Participants confirmed that their experiences in the different Eurasian countries gave them first-hand insights into the difficulties faced by many of their own students who are from other cultures. This research also identifies benefits of cross-cultural experiences, including a gain in pedagogical skills and a deeper understanding of the needs of culturally diverse learners. More specifically, exposure to a wider world-view resulted in increased professional 
competence. Experiencing other cultures for an extended period of time (three weeks) helped the teachers refine their personal beliefs and practices. The full and critically reflective responses of the participants all identified a growing sense of professionalism and understanding of cultural differences. Participants were also able to incorporate what they had learned from their overseas experiences into their professional philosophy and subsequent classroom practices and became more creative in their choice of curriculum, lesson planning and delivery.

\section{Photo-Elicitation}

A major emphasis in this project focused on respondent generated photographs, in order to better understand sense of place. Since the participants were allowed to narrate their photos, both abstract and concrete aspects of place attachment were revealed, including the rationale for why they chose a particular photo and the feelings it evoked. This narrative feedback was an invaluable addition to the sense of place images. A good example comes from Maria who submitted a picture of a globe taken at the Russian Geographic Society. The globe itself was particularly unique in that it was a handmade, topographical (showing elevations) globe, yet it was the narrative context that Maria provided which gives meaning and potency to the image. She recalled the story about the local teacher who, in the $19^{\text {th }}$ century, made the globe for his students, and then went on to say,

This teacher has gone through all this work to educate students and that is what teaching is all about. Teachers will go through almost anything to help students understand something; that is the essence of teaching and learning. And, in this case, the effort is focused on geography. It makes me feel good as a teacher and that I chose the right profession. I can feel what that teacher who made this globe felt. (Maria) 
The use of photography also provided advantages related to participant reflections on the experience. Reflection, the practice of critical thought or consideration, is an important part of the learning process and creates a greater understanding of self. People can go through life viewing their experiences as isolated, unrelated events. As learners and teachers, it is imperative to view these happenings as opportunities for learning. In today's education context, teachers are expected to help their students develop the habit of linking and constructing meaning from their experiences. Such work requires reflection, which fosters new insights and self-growth by drawing forth both cognitive and emotional information from as many of our senses as possible and then processing, synthesizing, and evaluating the data.

In this study, reflection was applied by all of the teachers by nature of the longitudinal photo-elicitation interviews. It clearly aided the teachers in processing the experience a year later. For instance, Edith suggested that

the narrowing [of photos] process brought back memories and emotions; the reflective way of having to go through them was a good experience that helped me remember the trip and having to do so made the experience even richer; anything to help me reflect adds to my experience. (Edith)

Alice reinforced this idea when she said,

I think the narrowing down a year later was good because I haven't thought about the trip much because I've been so busy and it was so nice to think about it again. I went back to see which 12 photos I had actually chosen; I had different ones in my head; they were similar pictures of the areas but different in my head, which I thought was really interesting. The final three photos were based on the three experiences that were most impactful for me. (Alice)

Kelsey also shared this sentiment:

I liked to be able to choose from all the photos I took and it was a much more valid representation of what was meaningful to me. I didn't feel constrained then when I was reflecting a year later on narrowing it down 
to three. I loved that a year later I could really internalize and reflect. That part was really neat. (Kelsey)

In the end, the use of photography enhanced the participant voices and

participation in the research. The use of photographs aided in their learning — about themselves and their worldviews. Photo elicitation, as a methodological approach to understanding place, should be considered more often. The photographs offer more than

just a source of information, of details that can be interpreted by the interviewee; instead, they are part of a collaborative interaction between the interviewer and interviewee in the production of analysis and data. As such, they provide much greater detail and insights for all parties involved in the study.

\section{B. Geo-Literacy}

A high-quality geography education should inspire in students a curiosity and fascination about the world and its people — one that will, hopefully, remain with them for the rest of their lives. Geo-literacy includes knowledge about diverse places, people, resources, and natural and human environments, together with a deep understanding of the Earth's key physical and human processes. The need for our K-12 students to be globally connected, informed and active has never been more important. Yet, today's educators rarely begin their careers with the deep knowledge and robust skills necessary to bring the world into their classrooms. As discussed in the Literature Review, geography education imparts an essential perspective for the next generation of global citizens. That said, in order to teach today's students more geography, most teachers need to learn it themselves, especially since teacher education programs require little to no specific content knowledge. 
This research aims to understand how the C-GEO international teacher professional development experience improves participants' geo-literacy. The primary methodology used to analyze geo-literacy learning outcomes was the pre- and postsurveys. However, the in-situ observations and longitudinal interviews also provided important insights. The C-GEO Eurasia case study demonstrates how geography education has the potential to contribute to the following three capabilities:

1. geographic skills and knowledge;

2. ability to teach and use more geography concepts and skills in classrooms; and

3. new understanding and appreciation for other cultures.

\section{Geographic Skills and Knowledge}

It is difficult to separate the learning outcomes related to a professional development program focused on geography from an international experience which provides geographic learning by its very nature. However, the C-GEO program leaders made concerted efforts to incorporate and highlight important geographic concepts, promote geography learning exchanges (via visits to geographic societies in Russia and Mongolia and group discussions), and teach about geographic ideas and theories throughout the experience, including significant time spent on establishing a geographic foundation during the two pre-trip orientations. Based on the results of this study, it is clear that this program achieved its goal of improving the geographic skills and knowledge of teacher participants. Susan does a nice job of summarizing what were, for her, the most influential components of the C-GEO Eurasia program:

When we were able to spend time in a particular place -- for instance Mongolia was the place I connected to most. It was easy to soak everything in because we had time to spend there and reflect. It's hard for me to separate myself personally from being a teacher. This time was valuable for me; I also focused ahead of time on the geography concepts it helped me to think about the trip along with the geography concepts. 
That provided structure. I am not a trained geographer but rather am trained in social studies and I never learned the foundational geography concepts (e.g., continentality). I felt like it allowed me to connect a lot of experience with structure, which best fits my personality. I appreciated the time to reflect on the train; it was a great time to talk about teaching and reflect with each other, to develop ideas and bounce them off someone else. (Susan)

Other participants discussed how they have incorporated more geography — and the tools that represent geography — into their classrooms. Maria, a new teacher, explains that "prior to this experience, I never thought it was crucial to have maps in my classroom." Esther, a more veteran teacher, makes a similar connection when she says that "just being sure to show maps as part of political progression is important." Several of the participants referred to the fact that they came away from this experience with a better understanding of core geographic concepts. They also indicated that this learning opportunity exposed them to geographic content not typically available to them in their teacher education classes. Susan describes how new knowledge has enriched her teaching practices when she says that

we learned about [relevant geographic concepts] ahead of time; I kept coming back to them, looking at the trip through that lens. I also incorporated them specifically into my classroom....I am also able to use my new knowledge to teach my students more geography beyond just place names and maps. (Susan)

Nell and her students also benefited from learning some new geographic concepts as part of this professional development program: "I have taught about the five topic areas that we were asked to focus on beforehand (e.g. transhumance, continentality, etc.)."

Additional results from this study also indicate that the international learning experience provided a new perspective on the field of geography through exposure to the 
discipline based in different cultural frames of reference. Susan described how she benefited as a teacher by learning in a contextualized environment linked to local realities and related global dimensions when she says,

I learned anchor points for what I teach - world geography covers Asia, Siberia and China. I can now explain the physical geography impacts on these places and their economics and I can say these things with more clarity and experience than simply using a book. (Susan)

A major subset of the goal to improve geographic skills and knowledge was to educate participants about the geography of the places they visited. When asked specifically if they felt a personal connection to Eurasia after their experience, the results indicate a significant association for all participants. Kelsey described this connection simply: "Once you visit a place you automatically grow connected to it." Edith explained that the mode of travel allowed for more connections when she answered,

Yes, because we visited and experienced so much versus just flying into a few places - we covered a vast amount of land and for that reason, I feel more connected than other places I've been. (Edith)

The participants had opportunities to study the physical and cultural geographical similarities and differences throughout areas of Eurasia, which enhanced many of the teachers' country, region, and culture specific learning. Maria explained how she increased her understanding of Eurasia with the following comment:

I also grew in regards to my geographic knowledge. I had a vague understanding of Eurasia - its borders and the continental divide. Geographically and visually, it was very instrumental and I can describe the region better now. (Maria)

Ivan also better understands the region:

Siberia was much wetter than I envisioned; even though I'm not sure what I envisioned... There was way more water and I could not have learned those things as well from a book as much as being there - in the moment and in the place; the actual setting. (Ivan) 
Igor also discussed his improved knowledge of the region: "I have a greater understanding of the region and it broke some of my preconceived ideas such as the thought that Mongolia is just a vast desert, but it is green and has a large city (Ulaanbaatar)." He went on to explain how this new found knowledge has provided him with legitimacy in the classroom regarding his understanding of the places he visited:

I now understand the importance of the railway system there and have used this information in class; it's also helped me with my understanding of the region. When kids ask, I can give real information based on experience and not just based on assumptions. (Ivan)

Edith also described this concept of a new legitimacy in the classroom:

I'm a reading teacher so we've been reading about China and trains and I've been there, so I'm able to bring my real life experience to everyday teaching. I don't teach geography but can share more relevant information with them and share pictures. (Edith)

The C-GEO program provided opportunities at the pre-trip orientations and on-site in Eurasia for teachers to reflect on skills learned and knowledge gained from their involvement in the program. And, the unique research component offered through this study provided guided reflection during, and one-year after, the trip. The research also introduced different ways of getting to know a place (i.e., photo-elicitation). These structured opportunities for comparative analysis, critical and creative thinking, and problem solving proved to be effective in providing teachers' insights that might not otherwise have been considered. For example, Esther explained how the photo-elicitation process of narrowing photos for the interview helped with her reflection and overall learning when she says,

[The process of selecting the final three photos for the interview] gave me the opportunity to reflect back and find some that are actually good quality and really spoke to me. Sometimes I took a picture to cooperate but now I ended up with these being more meaningful. If you hadn't asked us to use 
your cameras, though, I wouldn't have reflected so much during the trip. The process of narrowing down was really easy for me; I knew immediately where my focal point would be and interestingly enough I learned more after I came back — I researched about things that were points of interest and to put captions on pictures so I could give meaning to them. (Esther)

Another outcome identified by teacher participants is how the C-GEO program provided them with a network of local geography-minded teachers for future connections and programming. Many described the benefits of forming meaningful relationships and friendships with the other Oregon teachers. This ability to learn from the other teachers is illustrated in the following quote from Edith:

I learned a lot actually and it might have come in a different way than for most because I had just graduated and was getting ready to start my first teaching job, but because I was with other teachers, it helped me prepare for teaching and the beginning of the school year as new teacher. I took lots of notes from veteran teachers. (Edith)

When asked what the most meaningful part of the experience was for her, Kelsey also described the importance of connecting with local teachers, in addition to learning about other cultures: "I would say the networking with other people on the trip and then the observations of different cultures; it was such a large region with differences between the cultures and I can now identify what they are.”

The answers highlight that the teachers gained geographic skills and knowledge as a result of this program. In addition, they learned a vast amount about the locations they visited and they are incorporating their learning outcomes from the Eurasia experience into their classrooms. 


\section{Ability to Teach and Use More Geography Concepts and Skills in Classrooms}

Participation in this program influenced the teacher's perception of how geography can be incorporated into their classrooms. Prior to this professional development opportunity, many of the teachers were not very familiar with geographic principles or tools, nor how to include geography in their curriculum — regardless of the subject they teach. When asked if they were more apt to teach geography content as a result of participating in this experience, nearly all respondents presented an emphatic "yes" response. And, while some responded with a negative response, in each case there was a caveat that helped to explain their thinking and indicated that they either are, in fact, teaching more geography or their school environment simply does not allow for more at this time. For example, Igor's response was:

Not really because I already teach it. This simply adds to what I'm already doing. Although, I did add more to my European history class related to my more personal geography experience. (Igor)

While his answer was negative, he added more explanation that shows that he is actually teaching more European geography based on his Eurasia experience. Marie described her school situation as a reason she is not able to teach more geography:

I try when I can. I was asked to teach geography this term but it didn't happen. Next year I will teach a different class since it's an election year; I'll teach government and then I'll go back to geography. (Marie)

With this response, she is clearly willing to teach more geography and will likely be able to in future school years when her class schedule changes. It is also important to note that many teachers who are not specifically identified as geography teachers have found ways to incorporate geography into their classes, regardless of their academic focus. Igor describes this in his comment above. Another example comes from Esther: 
Oh yeah! It also seeps out into other things that I'm teaching, like English, I'm able to tie in my personal experiences as more of a natural segue way because of my experience; it's not just something we read about. (Esther)

It is also noteworthy to highlight responses that addressed a new confidence in

teaching geography as a result of this program. Alice suggested,

I've always been interested in geography so would've taught it anyway, but this experience opened my eyes to the fact that I know so little and after coming back and talking to people about it, I understand how lacking others are in terms of their understanding of geography. I want my students to have a good understanding. (Alice)

Another example comes from Nell, who said,

I feel like the opportunity itself, along with my involvement in C-GEO, have made me feel more confident teaching geography. I infuse it into all of the standards and I have a broader perspective because of C-GEO. (Alice)

This program clearly motivated teachers to begin or continue teaching geography in their classrooms. It also provided opportunities for teachers to give presentations about their international professional development experiences upon return to their home communities and/or at meetings of professional associations.

\section{New Understanding and Appreciation for Other Cultures}

The C-GEO international professional development program in Eurasia facilitated intercultural learning by stimulating teachers' sense of place through engagement with the local culture. For example, the program provided opportunities for meeting culturally different geography professionals and educators, which Susan described as one of her most meaningful activities:

One of the best activities, the one I enjoyed most was visiting the Mongolian school and the teachers. When I travel to different places it is hard for me not to think about teaching and connecting to other teachers - only thing better would be students. I enjoyed their enthusiasm and candidness. (Susan) 
Several of the teachers also mentioned that they greatly appreciated time for structured and unstructured encounters with local people and customs in a variety of contexts. Ample free time enabled them to engage more freely and intimately with the local community. The participants also took advantage of opportunities for exposure to, interaction with, and reflection on the everyday aspects of the different cultures through such activities as home stays and participation in local customs (e.g., cultural show, observation of weddings, etc.). In addition, the teachers prepared for the intercultural experience through participation in two pre-departure orientations, assigned and elected readings, and other preliminary research (e.g., television and radio shows, blogs, movies). They were also required to attend regularly scheduled on-site reflection sessions during which encounters with the host culture were analyzed and geographic concepts revisited. These meetings helped the teachers make connections among such things as the host country's culture, society, history, politics, and arts. Finally, the post-program interviews conducted as part of this research helped the participants realize and articulate their intercultural learning and sense of place development through reflection.

The participants consistently described how they learned to better appreciate the values and attitudes of others. A common response was that they were introduced to new ways of seeing and thinking, which challenged old assumptions and beliefs. Kelsey explained, "I discovered that I am a lot more at ease not knowing the language and cultures; I learned I can be an observer and a participant simultaneously." Marie described how this experience provided her with a more global outlook on life:

It makes me think differently. I have a new perspective.....As Americans we get our information from what the media gives us; it's a specific viewpoint and we need to go beyond that tunnel vision; we are ethnocentric. Everyone should be given a chance to talk to others about 
their view of the world and to get a different perspective and not always take what the media tells us at face value. Those interactions can make quite an impact. I did tell my students about how in Beijing we had no access to Facebook because it is communist China....Personally, taking these trips expands my horizons and opens my eyes to how other people live beyond our own insular world. Seeing different things and different cultures changes my ways of thinking and makes me rethink how I look at world and gives me more of a global perspective. (Marie)

Edith explained how she now has a heightened sense of engagement with, and

increased awareness and appreciation of, different cultures as a result of the program:

It made me think of the people and teachers and kids and culture more sensitively and made me more open-minded. It was a really good experience and I have a more positive view of the place, and in light of what's going on there now, it makes me more aware of the people and how they view their government - I remember the elementary school we visited with Putin picture and how they said he had made their lives better; it makes me question what I see on the news; which feels alarmist, yet my experience shows otherwise....I think in general it helped me to be more understanding of different cultures in school, and that's true with both teachers and students. My school has more Native American students than I have ever worked with before so I have more interactions with elders and people in the community. This trip has made me a better communicator and I have a stronger connection with families because of geography night; I incorporated parents and other family members in how they wanted to participate and built relationships with them. (Edith)

Igor provided another example of the cultural impact on him:

I have a better appreciation of Russia, China, and Mongolia's unique cultures. I guess this better appreciation may have changed my mindset a bit. One example is a student of mine that was born in China and was adopted; I feel I have a better connection with that student because of this experience. (Igor)

Finally, Alice described how her appreciation of cultural diversity has been reinforced based on this experience:

I've had a lot of classes and some experience with student teaching and have worked with students from different cultures and language backgrounds. This refreshed me and gave me a deeper understanding and as a result I want to make sure that my teaching allows for differences that 
the students have and that I'm respecting different cultures and languages and bring that to celebrating in the classroom. (Alice)

It is clear from these accounts that this international professional development program led to a greater global mindedness. At the same time, this experience enhanced the teachers' self-awareness and understanding of their own culture by providing opportunities to compare and contrast the different Eurasian countries' customs, values, and traditions with their own. Participants reported that the international experience required them to confront personal anxieties and challenge limitations, which helped them to develop a range of qualities including increased self-confidence, adaptability, resourcefulness and ability to take risks. For example, Alice referred to a personal goal of "becoming fearless" as part of her growth from participation in this program when she said,

I understand myself and think differently. I am still in process of learning to be fearless and jumping onto a plane to a country half-way across the world with people I barely know, taught me I can do these things. I want to be fearless. (Alice)

She went on to explain how being from a small town has, perhaps, limited her worldview and this experience has broadened it:

I came from a small rural community, which is not a super open-minded community, so this experience brought my worldview and perspective away from my tiny town to across Eurasia. It opened my eyes to similarities and differences of people across the world. (Alice)

Nell, an American teacher who is currently teaching in Brazil gave an interesting perspective on how this trip helped her to understand both America and Brazil differently:

Many teachers come to Brazil who have never lived elsewhere. They can be more critical. Teaching and living here is not like it is in the USA, there is lots of bureaucracy and the infrastructure and systems can be frustrating. 
I've felt it too; we are so privileged in the U.S. and we take it for granted. Now, when I hear people complain I think about how we were stuck in traffic and there was that bulldozer in the roundabout; I mean there was no attention to roads and it was pure chaos in Mongolia; now the traffic appears mild in Brazil. Mongolia, specifically Ulaanbaatar, was crazy to me and when we exited the train station in Beijing, everywhere you looked was a crush of people. Rush hour here is nothing in comparison, yet people complain it's congested, that we need more lanes...It is interesting to see different cultural impressions and I like to make comparisons to Brazil. Brazilians are rude, not forgiving. Americans too. They can be abrupt and harsh, but compared to Russia, Brazilians are mild. Russians were severe, I kept wondering "am I being yelled at?" It makes me think about how I first felt in Brazil, compared to the Eurasia countries. I went to the market in Beijing and did some bartering. I would ask "How much?" And, they would respond "How much will you give me?" I would wonder "am I being cheated or being too generous?" I had no sense of what the price should be. And, I compare it to a bazaar in Brazil. People always say Americans pay more, but not here because there are prices; not like in China, where you just call out a number. Then they reply "you're being stingy or I have to feed my family." It's interesting to see other cultural contexts and China makes me feel blessed to live in Brazil and the U.S. (Nell)

This research suggests that it is precisely the difficulties and frustrations that participants encounter in adjusting to an international environment which appear to facilitate their personal growth. This study also finds that for the novice teachers, in particular, stepping outside their comfort zone was a significant milestone in their professional and personal growth. It is important to note that there was a common feeling among the teachers that their personal development underpinned their ability to work more successfully in their classrooms; professional and personal gains were often intertwined. Several respondents commented that the resourcefulness acquired in their overseas experience enabled them to handle challenges in their subsequent teaching practice and with a greater sense of ease than some of their peers who had not had this type of opportunity. 
The interview and survey responses, as well as observational data, reveal that the teachers have a positive opinion about their experience with the C-GEO international professional development program. In fact, the positive impact of learning in another country was fairly profound; participants returned home with enhanced intercultural understandings, sharpened self-awareness, and emerging leadership skills. The teachers progressively developed knowledge, skills, and behaviors that have and will continue to support them in developing students who are active and informed global citizens. For example, the majority of teachers are using more geography in their classrooms and selfreported a better understanding of core geographic concepts. In addition, involvement in the program helped the teachers to build their personal and social competences and intercultural understanding. In addition to the sense of place and geo-literacy related outcomes, the teachers also indicated that they came away with an enhanced sense of self and personal identity; increased independence, maturity, confidence and self-awareness, in addition to an enhanced social competence, more generally, through confronting challenges beyond their familiar environment and comfort zone. Amber does a nice job of summarizing some of these outcomes:

You're more about others than yourself when you come home....You're more of a leader because of the skills you gain from the experience. (Amber) 


\section{DISCUSSION}

Previous research studies related to international education programs have primarily focused on student study abroad, as opposed to teacher professional development. This research provides a longitudinal (one-year), in-depth study of eleven teachers participating in the 2013 Center for Geography Education in Oregon (C-GEO) Advanced Summer Institute in Eurasia. It considers first-hand, personal experiences, and reflective responses from participants in order to provide a rich narrative related to sense of place and geo-literacy learning outcomes. The detailed information that the teachers provided offers insights into how they gained both professionally and personally. There is substantial evidence from the data collected in this study that international teacher development programs, with a focus on geography education, can help participants develop the qualities they need to become more flexible, more knowledgeable, and more culturally aware. At the same time, they returned home with an enhanced sense of place for both the countries visited, and for their home communities, as well as an improved understanding of the geography discipline as a whole (e.g., a broader global view and a better understanding of how to incorporate geography in their classrooms).

\section{A. Key Findings}

This research reveals which aspects of a successful international professional learning experience most improve teachers' geo-literacy and sense of place and, potentially, their teaching practice and student learning. Among the findings:

\section{Stronger Connection to Home}

A unique outcome of this research is that learning in an international context can foster a new commitment to ones past or present home location, by providing a retooled 
sense of place and new community connections. In general, the research revealed that participants felt more at ease in the type of landscape they were most familiar with (e.g., place they grew up in, settings where they feel most at home). Similarity to the familiar stirs an emotional bond and the new place inherits the meaning of the old. Some of the participants reflected that being in these foreign places helped them to a more balanced understanding of their home country by reflecting on its politics, culture and lifestyles in turn. This point is well illustrated by Igor, who suggests, "Sometimes you need to go far away to see where you're from."

\section{Photo-Elicitation as a Successful Method for Sense of Place Research}

The use of photography adds value to the study of people-place relations. This study provides an example of how a successful application of the photo-elicitation methodology can be conducted. Photo-elicitation interviews are a relatively underutilized research method for geography and education disciplines, yet they provide exceptional advantages for exploring people-place relations. While interviews alone have the ability to reveal abstract aspects of places (i.e. social and cultural aspects, opinions, and memories), the incorporation of more creative and interactive field methods allow the respondents to use more of their senses in generating knowledge and communicating about a place. To that end, the participant-led photo data collection used in conjunction with interviews appears to be particularly successful for gathering information about emotions connected to places and gaining a better "feel" for places. Photo-elicitation also empowers participants to take some aspect of control of the research process. This results in richer and more meaningful data on sense of palace construction. The incorporation of this creative and interactive method allowed participants to generate knowledge and 
communicate about a place using more of a lifeworld perspective and visual sense. In so doing, they revealed emotions triggered by direct contact with the object, place, or event being photographed. In addition, the teachers returned with numerous photos for classroom use.

If well executed, photo elicitation can add validity and reliability to word-based surveys and interviews. It also provides a richer perspective into a different part of human consciousness over other methodologies. This is due, in part, to the fact that reflecting upon the experience is enhanced by the photographs, but also because the use of photographs leads to deeper and more interesting conversations about the experiences. Hence, photo-elicitation is an ideal method for sense of place and other cultural geography and international education based research.

\section{Increased Teaching of Geography and Geo-Literacy Skills}

Learning in other countries and meeting with colleagues from the local communities gave the teachers the opportunity to develop a wider global perspective which underpinned their subsequent educational philosophy. Several of the teachers described how the experience changed their worldview and gave them a much greater understanding of the region. In addition, their participation excited and motivated them as teachers, and they were able to use their firsthand experiences to better engage their students. They have incorporated more geography — and the tools that represent geography (e.g., cultural artifacts, videos, and maps) - into their classrooms. In turn, several of the teachers indicated that their students are more interested in global issues and international perspectives. Nearly all of the participants referred to the fact that they came away from this experience with a better understanding of core geographic 
concepts, skills, and content which, for the most part, was not available to them in their teacher education classes. Other significant outcomes identified by teacher participants is how the C-GEO program provided them a new confidence in their teaching and a network of local geography-minded teachers for future connections and programming.

\section{Greater Acceptance of Cultural Diversity}

Many participants felt that the rich cultural experiences enhanced and extended their professional and personal development and gave them the confidence to work with a range of ethnically and culturally diverse learners on their return to their home classrooms. While some found the experience initially uncomfortable, most teachers adapted quickly and were eager to understand the local cultures. In most cases, it was relatively small things which they found hard to adapt to such as lack of air conditioning or limited food options on the trains. In the end, the teachers acquired a heightened sense of professional confidence when dealing with the diverse range of students in their classrooms. When reflecting on their experience, they came to recognize the importance of learning about and better understanding of different cultures. Traveling takes this kind of learning deeper by helping to reveal and enhance the underlying identity — the unique meaning, value, and character — of a place and its people. This identity is reflected through one's sense of place as the traveler begins to develop a story or narrative of the place.

\section{It Is Important to Focus on Individuality When Studying Sense of Place}

Sense of place is a complex interaction arising primarily from uniquely individual factors. The results of this research show that personal experience molds the specificity of place meanings. Participants became more attached to a place if their sense of self 
(e.g., the roles, attributes, behaviors, and associations that they consider most important about themselves) were linked to that place. Each of the participants' sense of place development, in relation to this Eurasia trip, appears to be specifically connected to their particular interests and personality style. For instance, the self-described active "outdoorsy" participants seemed to connect more with the physical landscape. The more artistic or creative participants related more to the cathedrals, temples, museums and art. The adventuresome individuals appeared to identify more with activities like horse back riding, train rides, and "getting off the beaten path;" and those more focused on their profession as a teacher, in this instance, gravitated to the educational culture and interaction with local teachers. All, in turn, gained a different sense of place from the experience, which perhaps affected the focus of what and how they teach back in their classrooms. On the other hand, since all of the members of this group felt a strong affiliation with their occupational role as teachers, the ability to travel with and learn from other teachers was a powerful addition to their learning, more generally, and should be considered when planning international teacher professional development programs.

Participants' senses of place also seemed more enhanced to the extent that their experience was similar or at least somewhat familiar to their life and landscape back home. Esther pondered this idea during her interview when she said,

I wonder if where people live or grow up makes a difference to how they perceive a place. Like, if you grew up in a big city you might rarely have the opportunity to connect with nature and so never really think about it. But, if you grew up in the country, or near mountains, you might feel a strong connection and appreciation of that kind of beauty. (Esther)

This connection to home environment was a strong outcome from this research in that it came up repeatedly in the interviews, surveys, and observations. In the same 
vein, what is unfamiliar also has the potential to enhance one's sense of place, but can also weaken it. This study found that cultural barriers for some seemed to disrupt their sense of place and/or well being on the trip. This too might be expected at the outset, but the point of an international professional learning experience is to build sense of place and cultural connections so further examination into this phenomenon and ways to mitigate or improve learning outcomes as a result of the cultural barriers should also be considered.

What is clear from this research is that no one person's sense of place was identical to any of the others. This suggests that the very concept is a fluid, individualistic experience. As such, these findings suggest that teacher professional development programs include an individualistic approach to the management and outcomes of such programs. For example, these programs should better address and investigate the roles that individual perceptions, motivations, and senses of place have on teacher participants. As most geographers recognize, it is often at the interface of physical and cultural environments where the most diverse experiences occur. In order to understand people and place relationships, there is a need to more fully understand how people experience these environments. This coincides with the existing research examined in the literature review.

In addition to these primary outcomes, participants described a newly developed range of personal attributes, such as confidence, flexibility and resilience, which helped their ability to work with challenging situations. The exchange of ideas and experience with colleagues from other countries, as well as those from their own state, was also an invaluable source of learning, and an effective instrument in establishing professional 
contacts and networks. According to pre- and post-survey feedback, the effects of the C-GEO program go far beyond individual and professional development. Its benefits, in many cases, also include an impact on the participants' schools and their respective stakeholders.

\section{B. Areas for Further Research}

The literature review conducted for this research suggests that there is a need for disciplinary content development in teacher professional development, in particular in the field of geography, where little to no funding is provided (National Geographic Education 2013). The previous research also validates the important role of teachers in inspiring and motivating their students to learn about the world. However, when teachers personally lack international experience this can be difficult. According to Hoffa (2005), many American educators have not taken any international courses and comparatively few participate in international education programs.

Collaboration and support is critically needed among the various stakeholders who have a direct or indirect role in teacher and student learning of geography and global studies. It is well documented that many teacher education administrators are unlikely to support international experiences for teachers. Hyser (2005) suggests that the reluctant attitudes of some administrators may actually be generated by their own lack of international experience, a view supported by Briggs and Burn (1985). In addition, Raby (2011) cites the 2008 global economic crisis and resulting widespread recession as having a negative impact on the overall support of international education. She observes that from 2009-2011, significant budget constraints meant that very few education programs were able to develop their learning abroad components (Raby 2011). 
This research examined the reasons and motivations leading teachers to participate in the C-GEO international teacher professional development program in Eurasia. Only three of the eleven participants said that they had been encouraged by administrators about the possibilities of going abroad to improve their geography teaching. Yet, all of participants showed a very positive attitude toward going overseas prior to the actual experience - six of the teachers expressed a desire to do something completely different and five felt it was a chance to broaden their career opportunities. These results indicate that the teachers who participated did so without direct support from their school administrators and that they were more independently driven by either personal or professional goals. Ideally, a more solid integration among school administrators, funders, and the staff responsible for developing and delivering the professional development programs would occur. Enhancing teachers' knowledge and understanding of the world around them through international experiences requires significant coordination, collaboration, and determination at all levels of teacher preparation. These programs need to be seen as a priority within existing workload and budget levels.

Increased strategic research on effective design and delivery of geography and international professional development programs — those that remove the teachers from their presumptions about other cultures and take them out of their comfort zone and provide opportunities for learning in a multicultural context and in a collaborative fashion — is a key starting point toward informing professional development providers and education administrators and, in turn, helping to secure funding sources for these important efforts. This view is supported by Roberts $(2007,23)$, who concludes that "the 
sustained success of international student teaching programming is dependent on professional development of faculty and institutional support. Teacher educators require a knowledge base and experience in international practices before they can impart it to their students." Additional research on various aspects and effectiveness of these programs, similar to what this study offers, would offer more evidence about the impact of international learning programs on teacher participants, and potentially on their students.

This study shows that learning abroad provides both an intellectual and critical point of access where teachers, distanced from the insulation of home, are exposed to and challenged by their own practices and beliefs. According to the teacher participants in this case study, they were able to translate their lived experience into classroom practice by examining their multi-cultural awareness and sensitivity of the educational, social, and political relationships between their own lives, as well as other cultures. At the same time, they were learning important life-skills that helped to bridge and strengthen the gap between their student populations and aid in better understanding the rapidly diversifying classrooms in which they teach. The teachers also felt that negotiating cultural differences within a global context, outside their personal comfort levels, had a greater impact on their multicultural understandings and global competencies over traditional classroom learning. Another result of this research shows that if teacher professional development programs are steeped in course work and field experiences that are grounded in a geographic framework, the participants enhance their ability to teach diverse learners about cultures and countries. They are also better able to teach about the increasingly important patterns and networks of interdependence among different 
countries around the world and to provide vital knowledge about the international dimensions of current trends and issues which are critical to their lives and livelihoods. In turn, they are more effectively helping to create young citizens who are able to understand and do something about some of these major issues. These realizations indicate that effective professional development programs have the ability to help education professionals meet a key challenge in teacher education - the development of global perspectives in teachers.

Professional learning in international environments should be based on teachers' needs and supported throughout a teacher's career, and can be best fostered by using exemplary programs when designing and supporting professional development plans. The case study presented in this research highlights one unique way that a geography education organization is creating international professional development opportunities for teachers. The C-GEO program serves as a helpful model for other global education programs interested in leading teachers toward meaningful changes in their understanding of geography content and context, with an aim toward teaching using a global perspective. Interview and survey responses from this case study revealed that the teachers have a similar, positive opinion about their experience with the C-GEO international professional development program. Using the C-GEO educational approach as a model for international professional development experiences, these types of programs should typically include an extensive pre-departure orientation (approximately ten contact hours) and a field or on-site program built on the following mutually reinforcing parts: 
- the academic learning aspect (e.g., geography as a discipline);

- the geography of place (i.e., study of physical features in relation to the people and cultures and vice versa);

- the "life experience" facet, which includes unique or targeted experiential learning opportunities within the communities where participants are visiting (e.g., homestays, visits to geographical societies and schools);

- reflective components (e.g., use of photography to explore sense of place); and

- integration into classroom upon return (e.g., new and shared lesson plans, use of artifacts from place, etc.).

At the same time, each of these elements should inform the others as participants interact and communicate within new contexts for learning and teaching.

In terms of professional growth, one of the most influential components of the C-GEO Eurasia program was that the teachers returned from the experience better prepared for the classroom and with a new, local network of other geography-focused teachers to learn from. Nell provides an example of this when she discussed how she shared related resources with others: "During our "International Day [at school]," I used some family geography activities created by other Eurasia teachers." Edith shares a similar outcome:

I learned a lot actually and it might have come in a different way than for most because I had just graduated and was getting ready to start my first teaching job. But, because I was with other teachers, it helped me prepare for teaching and the beginning of the school year as new teacher. I took lots of notes from veteran teachers. (Edith)

Organizations like the C-GEO not only provide important geography-based professional development opportunities for teachers, but also connect educators in Oregon by providing a network of other like-minded teachers and a platform for interacting with each other to share ideas and views about their practice and how it might be improved. These types of teacher networks enhance the quality of teaching by 
enabling teachers to expand their capacity in a wide range of dimensions, spanning from subject matter knowledge to general pedagogy, but also about learners' individual characteristics, like values and lifeworld influences. However, there appears to be a lack of empirical evidence showing the actual impact of teachers' networks on the above dimensions so further research is recommended. What is clear though is that teachers require support from multiple arenas if they are to effectively grow, teach, and perform to the best of their abilities. For many, a great way of obtaining this support is by connecting with local and national professional education organizations and networks.

Given that professional development is important in scaffolding and assisting teacher learning, in any analysis of how teachers are developing professionally it is important to assess how these styles of learning impact the personal and professional growth of teachers and their ability to provide high quality learning in their schools. While this research does not examine program assessment, the research itself proved to serve, informally, as an assessment model through the methodologies presented. As such, an interesting follow-up research project would be to look at a consistent assessment paradigm for evaluating international professional development programs. Examples might include a focus on student learning outcomes, the amount and impact of support by schools for such training, or a more detailed study of the effect this learning abroad opportunity had on the teachers' personal assumptions, beliefs, values and attitudes.

Professional development program leaders of geography and international education must also strive to build capacity and should consider incorporating new, innovative approaches toward educating teachers, and in turn students, as global citizens. Participants should be encouraged to develop their individual sense of place and to build 
new relationships with the physical and cultural aspects of places in an intensely personal way. For example, the fact that an individual's home environment is tied to one's sense of place is a finding that would benefit from further research, as not many studies exist about the familiarity of landscapes and how that enhances sense of place when in foreign environments. While it was not a primary question in this study, it soon became an important outcome.

These programs should also incorporate or improve upon reflection practices related to content and critical thinking. This study illustrates the importance of incorporating intentional reflective practices in teacher education programs in an attempt to deliberately engage teachers in meaningful thinking about their learning. Critical thinking is foundational to the effective teaching of any subject or discipline. Teacher professional development facilitators often assume that reflection is occurring and that it is occurring effectively for everyone. This assumption may not be valid, however. Encouraging reflection needs to be a conscious effort on the part of the facilitator and should be a series of planned activities throughout the program.

As indicated in the Literature Review, the need for reflection in teacher professional development encourages participants to examine their values and beliefs and to use their new knowledge to construct change in their practice (Association for Experiential Education 2013; Beavers 2009; Dewey 1933). This study provides unique insights into how teachers may develop the skills necessary for purposeful reflective during and after their field experiences. For example, the use of photo-elicitation and peer-group discussions were indicated as useful tools, which helped the teachers reflect upon and improve their practices. Furthermore, the research results indicate that these 
critical reflection methods also encouraged teachers to challenge their own existing theories and preconceived views, while at the same time providing the participants with a true "voice" as to what they learned from their experience. Certainly, there is a need for more investigations into teacher professional development best practices, like reflection, in order to provide a better understanding of how teachers can effectively build content and thinking skills. At the same time, such information should be better integrated into the planning and development of teacher education programming. A research opportunity that builds on this study might include a focused understanding of the importance of critical reflection in developing professional learning or a more detailed, longitudinal investigation on the reflections of these participants over a several year period in an attempt to better identify individual stories about the journey individual teachers make towards changing their practice and how the international professional development programs challenge their values and attitudes and widen their understanding about the importance of learning about teaching beyond the level of technical success in the classroom. This could provide an important assessment as to how far they have progressed in learning geography content and improving their craft of teaching.

\section{Summary}

Ultimately, the intent of this research was to examine important aspects of international teacher professional development and to consider the C-GEO model in order to investigate the geo-literacy and sense of place learning outcomes experienced by the teacher participants in the 2013 Eurasia program. In the simplest context, professional development is about helping teachers learn about content and pedagogy in order to transform their knowledge into practice for the benefit of their students' learning. As this 
research discovers and most educators already recognize, learning can often be of a random and unexpected nature. This aspect of learning is a vital part of any international professional development program because teachers are experiencing and learning in complex settings with new and different people, cultures, activities and opportunities. Such non-traditional learning environments can often produce major learning breakthroughs which are both unpredictable and not likely to occur in typical learning environments (e.g., schools). As such, it is critical that school administrators and professional development leaders both recognize and foster the potential that can only come from these types of unique learning environments.

Another factor that this research addresses is the need for professional development to provide new methods of engaging learners. This is not just about providing new opportunities for professional development but about providing effective professional development. Availability alone is not an issue. A recent study found that while 90 percent of teachers reported participating in professional development, most of those teachers also reported that it was totally useless (Darling-Hammond et al, 2009). Hence, the real issue is not that teachers are not being provided with professional development opportunities, but that the typical offerings are ineffective at changing teachers' practice or student learning. Education researchers and teachers are woefully aware of training approaches that do not help them improve their teaching (e.g., passive lectures or workshops with little or no innovation, hands-on practice, contextual learning, or reflection). The mixed methods approach in this study gave the participants more input over the research process in that it encouraged them to include additional information that might otherwise be outside of their comfort zones (e.g., personal meanings about the 
places they visited). In addition, the teachers learned new skills (e.g., how to carry out an interview or use photography in a learning context) and knowledge that was useful to them in their everyday lives (e.g., reflection).

There is a critical need to help teachers work with the rapid economic, social, and political changes that are now a constant feature of the globalized world. Today's classrooms consist of an increasing diversity of cultures, where a multitude of languages are spoken. This research emphasizes the need for a much broader view of teacher professional development, which allows teachers to engage with, and respond to the breadth and depth of issues they face today. It is important that teachers are encouraged to see beyond short-term goals if they are to gain a more holistic view of education. And, they should be encouraged to examine and reflect on wider political and ethical issues all of which have significant impact on teachers' lives at both a personal and professional level. 


\section{CONCLUSION}

As the world becomes increasingly complex and interconnected, it necessitates American citizens be more involved in and dependent upon a global community. At the same time, work environments require more cooperation, collaboration, and crosscultural understanding than ever before. This research explored the multifaceted benefits that accrue from learning within an international, experiential context using a qualitative, case study approach to analyze the Center for Geography Education in Oregon's (C-GEO) 2013 Overseas Teacher Institute — a professional development program that took 11 teachers to Russia, Mongolia, and China for a total of 17 days to learn about the geography that makes the cultures and the physical landscapes of the places visited unique and special. The focus of the research was two-fold and examined: 1) processes involved in gaining, synthesizing and applying a sense of place; 2) geo-literacy gains that result from the teachers' international experience.

Education leaders often ask questions about how students learn, but not as often about how teachers learn. This study focuses on teachers, by ascertaining how international professional development affects the professional and personal lives of the participants. There is a debate, which is examined in the literature review, as to how teachers should be continually educated in order to respond to the future needs of their students and schools. A major argument, which this research reinforces, is that teachers need to be geo-literate if they are to fulfill their role in a more and more globalized world. At the same time, the geographic concept "sense of place" is given equal weight to geoliteracy since the focus on international learning is one that necessitates and sets forth to improve one's sense of place. 
This study identifies the perspectives that teachers have gained through their experience participating in an international professional development program and investigates the impact such an opportunity had on the participants both immediately and over a one-year period. Data was collected using a mixed method approach: an in person pre- and post- survey was administered, in-situ observations were conducted during the overseas program, and all of the participants took part in semi-structured, photoelicitation interviews approximately one year after the trip. A unique feature of the data collection was that it gave the participants a voice to describe their rich and interesting first-hand experiences in a number of ways, including the use of participant conducted photography, which added significant value to the findings. The limitations specifically associated with the methodology were discussed in some detail in Chapter Four, but it is worth examining the wider limitations which apply to the research as a whole.

This was a relatively small-scale study in that it was looking at data gathered from only one international professional development program with eleven participants. A larger, more diverse sample could allow for examination of demographic differences, such as age, race, or gender, which would be particularly interesting as it relates to sense of place development. At the same time, the size of the region explored was perhaps too large to effectively measure sense of place since the journey covered three countries and much of the experience was train-based. Hence, caution must be exercised when generalizing from the findings and their transferability to other programs. The relatively small sample also means that it is not representative of the total number of teachers who participate in international professional development programs or even other C-GEO international programs over the years. However, the use of multiple methods for 
gathering information and the detailed information collected from the interviews attempts to offset the low numbers of participants and the use of photography and the comparatively unique and rather exotic experience provides a broader dimension to the responses.

Finally, since it is always important that the researcher try to ensure no personal bias, it is worthy to note that the researcher worked with the National Geographic Education Foundation for many years, and part-time for C-GEO at times before and during this research, and has, perhaps, insider information about the organizations and their missions. The researcher certainly shares a passion for geography and is a known advocate for geography education at all levels of the education system, including nonformal education. However, the researcher fully recognized these biases at the outset and made every attempt to not let this personal background influence the process. The researcher maintained a high level of continuous, critical self-reflection throughout the entire research process and consistently questioned assumptions, motivations, values, and past involvement with the program, using a mind-set receptive to new and unexpected findings.

Despite the aforementioned research limitations, the study is of particular value to anyone interested in improving geo-literacy within the K-12 arena. As has been suggested, globalization and the increasing diversity in today's classrooms dictate that a more in-depth understanding of geographic knowledge be established for students, as well as a cultivation of global perspectives and tolerance of different viewpoints and opinions. Thinking geographically helps people to be aware of the connections among and between places and to see how important events are shaped by where they take place. 
At the same time, knowing geography enriches one's personal life by promoting curiosity about and appreciation for other people and places.

This research argues that geography education provides essential background information that enables people to be geo-literate and have a heightened sense of place, allowing them to more effectively interact and collaborate with diverse partners, including those from other cultures and countries. Hence, well-planned geography education, at all levels, helps make learners more aware of other countries and cultures and prepares students to take their place in the global community. Teacher professional development in geography education is critical, especially for teachers who never took a geography course at the university level. Based on this research, a principal reason this situation exists is that current education policies in the United States are dominated by attainment targets, which put significant pressure on teachers to ensure their students attain prescribed levels of achievement often to the exclusion of other aims that are also important for the education of young people.

This research also supports the idea that immersion, as opposed to simply delivering cultural information, prepares teachers with a greater cultural awareness and sensitivity. Based on the literature review, it seems fair to say that the primary aim of international professional development programs is to give the participants an opportunity to widen their experience in a different environment, offering insights and opportunities that help broaden their thinking and develop the skills they need to be more competent, well prepared, and confident teachers. Based on this research, programs like C-GEO are succeeding in these goals. The sample of teachers investigated in this study clearly showed that their subsequent teaching had been influenced by their overseas 
experience and they were better equipped to exhibit a wider understanding of the world, rather than one confined to the local environment where they live.

The teachers in this research repeatedly suggest that their in-depth experience in Eurasia led to new discoveries and a deeper understanding of the global place they visited, the local place to which they returned, and that, upon their return, they were more enthusiastic as teachers and transformed as individuals. From this, it is clear that international education and experience not only expose teachers' to interesting sites around our globe, but can, if well designed and supported, allow through direct experience a deeper and more important sense of the global places and consequently a clearer and more compelling sense of our responsibilities as global citizens. While teachers can be encouraged to travel internationally for the novelty and excitement of the experiences, those explanations do not hold the same promise and power as those that describe the value of understanding deeply the relations and dynamics of different places around the globe. This cohort in this study clearly gained important insights into the processes of seeking meaning and gaining an intelligent connection to the places they visited, and the world more broadly, through active participation and direct experience. It is also clear that they will share what they have learned with generations of students. 


\section{BIBLIOGRAPHY}

Achieve, Inc. 2005. As many as 40 percent of American public high school graduates are unprepared for college and work. Available at http://www.achieve.org/many-40 -percent-american-public-high-school-graduates-are-unprepared-college-andwork (last accessed 13 October 2015).

Allianz. 2015. Top 20 megacities by population. Available at https://www.allianz.com /en/about_us/open-knowledge/topics/demography/articles/150316-top-20 -megacities-by-population.html/ (last accessed 28 December 2015).

American Association of Colleges of Teacher Education and the Partnership for $21^{\text {st }}$ Century Skills. 2010. $21^{\text {st }}$ century knowledge and skills in educator preparation. Available at http://www.p21.org/storage/documents/aacte_p21 _whitepaper2010.pdf (last accessed 13 October 2015).

American Council on Education. 2000. College-bound students' strong interest in international education contrasts with actual college experiences. Student Poll 4 (3). Available at http://www.artsci.com/studentpoll/archivedissues/4_3.pdf (last accessed 22 February 2016).

American Forum for Global Education. 2003. http://www.globaled.org (last accessed 11 December 2013).

Arendale, D. 2015. What is a best educational practice? National Mid-America Association of Educational Opportunity Program, Personnel Educational Practices Center. University of Minnesota-Twin Cities. Available at http://www.besteducationpractices.org/what-is-a-best-practice/ (last accessed 11 December 2013).

Association for Experiential Education. 2013. What is experiential education? Available at http://www.aee.org/what-is-ee (last accessed 11 September 2015).

Aud, S., M. Fox, and A. Kewal-Ramani. 2010. Status and trends in the education of racial and ethnic groups. Publication \#NCES 2010-15, U.S. Department of Education, National Center for Educational Statistics.

Babanine, F. 2003. Circumbaikal railway. Available at http://www.irkutsk.org/baikal /railway.htm (last accessed 4 January 2015).

Ball, D. L., and D. K. Cohen. 1999. Instruction, capacity, and improvement. Consortium for Policy Research in Education report series RR-4. Philadelphia: University of Pennsylvania, Graduate School of Education.

Beavers, A. 2009. Teachers as learners: Implications of adult education for professional development. Journal of College Teaching and Learning 6(7): 25. 
Beckstead, Z. 2010. Liminality in acculturation and pilgrimage: When movement becomes meaningful. Culture and Psychology 16(3): 383-93.

Bednarz, S., J. Stoltman, and J. Lee. 2004. Preparing geography teachers in the United States. International Research in Geographical and Environmental Education 13(2): 176-83.

Binder, R. 2008. Sense of place in sustainable tourism development. In 16th ICOMOS General Assembly and International Symposium: Finding the spirit of place between the tangible and the intangible. Quebec, Canada.

Bochner, S. 2003. Culture shock due to contact with unfamiliar cultures. Online Readings in Psychology and Culture 8(1). Available at http://scholarworks.gvsu.edu/orpc /vol8/iss1/7/ (last accessed 30 January 2015).

Boehm, R., and S. Bednarz. 1994. Geography for life: National geography standards. Washington, DC: National Council for Geographic Education.

Boser, U. 2014. Teacher diversity revisited: A new state-by-state analysis. Center for American Progress. Available at https://www.americanprogress.org/issues/race /report/2014/05/04/88962/teacher-diversity-revisited/ (last accessed 26 December 2015).

Bouillion, L. M., and L. M. Gomez. 2001. Connecting school and community with science learning: Real world problems and school-community partnerships as contextual scaffolds. Journal of Research in Science Teaching 38: 878-98.

Boynton, C. 2002. Sensing our five senses. Yale National Initiative. Available at http://teachers.yale.edu/curriculum/viewer/initiative_09.06.02_u (last accessed 26 September 2015).

Briggs, A., and B. Burn. 1985. Study abroad: A European and an American perspective. Paris: European Institute of Education and Social Policy.

Brown, B. 1981. Sense of place. Massachusetts Institute of Technology. Available at http://dspace.mit.edu/handle/1721.1/71325 (last accessed 17 May 2015).

Buttimer, A. 1980. Home, reach and the sense of place. In The human experience of space and place, ed. A. Buttimer and D. Seamon. New York: St. Martin's Press.

Buttimer, A., and D. Seamon. 1980. The human experience of space and place. London: Croom Helm.

Casey, E. 1996. How to get from space to place and back again in a fairly short stretch of time: Phenomenological prolegomena. In Sense of place, ed. S. Field and K. Basso. Santa Fe, CA: School of American Research Press. 
Cele, S. 2006. Communicating place: Methods for understanding children's experiences of place. Stockholm: Almqvist \& Wiksell International.

Chickering, A., and L. A. Braskamp. 2009. Developing a global perspective for personal and social responsibility. Peer Review 11(4).

Ching, B., and G. W. Creed, eds. 1997. Knowing your place: Rural identity and cultural hierarchy. New York: Routledge.

Clarke, J. A. 1998. Students' perceptions of different learning environments. Higher Education Research and Development 17(1): 107-17.

Cohen, D. K., and C. Hill. 2001. Learning policy: When state education reform works. New Haven: Yale University Press.

Cresswell, T. 2004. Place: A short introduction. Malden, MA: Blackwell Publishing.

Creswell, J. W. 1998. Qualitative inquiry and research design: Choosing among five traditions. Thousand Oaks, CA: Sage.

Creswell, J. W. 2007. Qualitative inquiry and research design: Choosing among five approaches, 2nd ed. Thousand Oaks, CA: Sage.

Cross, J. E. 2001. What is sense of place? Prepared for the 12th Headwaters Conference, Western State College. Available at http://western.edu/sites/default /files/documents/cross_headwatersXII.pdf (last accessed 4 January 2015).

Cushner, K. 2007. The role of experience in the making of internationally-minded teachers. Teacher Education Quarterly, Winter 2007: 27-39.

Cushner, K., and S. Brennan, eds. 2007. Intercultural student teaching: A bridge to global competence. Lanham, MD: Rowman and Littleton Education.

Darling-Hammond, L., R. Chung Wei, A. Andree, and N. Richardson. 2009. Professional learning in the learning profession: A status report on teacher development in the United States and abroad. Oxford, OH: National Staff Development Council.

Dean, P. S. 2007. Preparing teachers for education in a diverse world. National Social Science Association. Available at http://www.nssa.us/journals/2007-29-1/2007 -29-1-09.htm (last accessed 28 December 2015).

Delanty, G., and P. Strydom. 2003. Philosophies of social science. Philadelphia: Open University Press.

Denn, R. 2011. Food is bringing a sense of place to the table with terroir. Seattle Times, 30 April. Available at http://www.seattletimes.com/pacific-nw-magazine/food-is -bringing-a-sense-of-place-to-the-table-with-terroir/ (last accessed 24 July 2015). 
Desimone, L. M., A. C. Porter, M. S. Garet, K. S. Yoon, and B. F. Birman. 2002. Effects of professional development on teachers' instruction: Results from a three-year longitudinal study. Educational Evaluation and Policy Analysis 24: 81-112.

Dewey, J. 1915. The school and society. Chicago: The University of Chicago Press.

Dewey, J. 1933. How we think. A restatement of the relation of reflective thinking to the educative process. Boston: D.C. Heath.

Dewey, J. 1938. Experience and education. New York: Kappa Delta Pi.

Discovery News. 2013. Great Wall crumbles as tourism soars. DNews, 11 February. Available at http://news.discovery.com/earth/great-wall-of-chinadeteriorating.htm (last accessed 11 February 2015).

Drummond, D. 2001. Travel abroad: A sine qua non for geography teachers. Journal of Geography 100(5): 174-75.

Duckett, J. 1993. Many Americans just can't read maps. The Morning Call, 5 August. Available at http://articles.mcall.com/1993-08-05/features/2934587_ 1_cartographers-franklin-maps-social-studies (last accessed 11 September 2015).

Economist Intelligence Unit. 2010. Global firms in 2020: The next decade of change for organizations and workers. Available at http://www.shrm.org/research /surveyfindings/articles/documents/economist\%20research\%20 -\%20global\%20firms\%20in\%202020.pdf (last accessed 26 December 2015).

Economist Intelligence Unit. 2012. Competing across borders: How cultural and communication barriers affect business. Available at http://www .economistinsights.com/countries-trade-investment/analysis/competing-across -borders (last accessed 11 September 2015).

Edelson, D. C. 2011. What is geo-literacy? National Geographic. Available at http://education.nationalgeographic.com/education/media/what-is-geo-literacy (last accessed 18 December 2013).

Edwards E., and K. Bhaumik. 2008. Visual sense: A cultural reader. New York: Berg.

Elert, G. 2015. Color. In The physics hypertextbook. Available at http://physics .info/color/ (last accessed 14 December 2015).

Fennema, E., T. P. Carpenter, M. L. Franke, L. Levi, V. R. Jacobs, and S. B. Empson. 1996. A longitudinal study of learning to use children's thinking in mathematics instruction. Journal for Research in Mathematics Education 27: 403-34.

Flickr Hive Mind. n.d. Pectopah. Available at http://flickrhivemind.net /Tags/pectopah/Interesting (last accessed 16 January 2015). 
Franke, M. L., T. P. Carpenter, M. L. Franke, L. Levi, and E. Fennema. 2001. Capturing teachers' generative change: A follow-up study of professional development in mathematics. American Educational Research Journal 38: 653-89.

Galazy, G. I. 2015. Lake Baikal. In Encyclopedia Britannica. Available at http://www. britannica.com/place/Lake-Baikal (last accessed 4 January 2015).

Gardner, D. 2012. Miles out: The Great Wall of China is 13,170 miles long... that's more than twice the length of previous estimates. Dailymail.com, 6 June. Available at http://www.dailymail.co.uk/news/article-2155457/Miles-The-Great-Wall-China -13-170-miles-long--thats-twice-length-previous-estimates.html (last accessed 23 July 2014).

Garet, M. S., A. C. Porter, L. Desimone, B. F. Birman, and K. S. Yoon. 2001. What makes professional development effective? Results from a national sample of teachers. American Educational Research Journal 38(4): 915-45.

George Lucas Foundation-Edutopia. 2008. Why is teacher development important? Because students deserve the best. Available at http://www.edutopia.org/teacher -development-introduction (last accessed 25 February 2012).

Glaser, B., and A. Strauss. 1967. The discovery of grounded theory: Strategies for qualitative research. Chicago: Aldine.

Global Exploration for Educators Organization. 2013. Map of trans-Siberian route. Available at http://www.geeo.org/tours/OGATransMongolian/ (last accessed 12 August 2013).

Graumann, C. F. 2002. The phenomenological approach to people-environment studies. In Handbook of Environmental Psychology, ed. R. B. Bechtel and A. Churchman, 98. New York: John Wiley \& Sons.

Gritzner, C. F. 2003. Why geography? Journal of Geography 102: 90-91.

Gruenewald, D. A. 2003. Foundations of place: A multidisciplinary framework for placeconscious education. American Educational Research Journal 40: 619-54.

Gulamhussein, A. 2013. Teaching the teachers: Effective professional development in an era of high stakes accountability. Center for Public Education. Available at http://www.centerforpubliceducation.org/Main-Menu/Staffingstudents/Teaching -the-Teachers-Effective-Professional-Development-in-an-Era-of-High-Stakes -Accountability/Teaching-the-Teachers-Full-Report.pdf (last accessed 19 December 2015).

Harth, C. 2007. Adaptive education for our emergent global era. The Global Studies Foundation. Available at http://www.globalstudiesfoundation.org /ShowContents.cfm?CategoryID=68 (last accessed 7 November 2014). 
Harvey, D. 1989. The condition of postmodernity. Oxford: Blackwell.

Harvey, D. 1990. Between space and time: Reflections on the geographic imagination. Annals of the Association of American Geographers 80: 418-34.

Harvey, D. 1993. Class relations, social justice, and the politics of difference. In Place and the politics of Identity, ed. M. Keith and S. Pile, 41-66. London: Routledge.

Hay, R. 1998. Sense of place in developmental context. Journal of Environmental Psychology 18(1): 5-29.

Haymes, S. N. 1995. Race, culture, and the city: A pedagogy for Black urban struggle. Albany: State University of New York Press.

Herod, A., and W. M. Wright, eds. 2002. Geographies of power: Placing scale. Oxford: Blackwell.

Herzog, T. R., A. M. Black, K. A. Fountaine, and D. J. Knotts. 1997. Reflection and attentional recovery as distinctive benefits of restorative environments. Journal of Environmental Psychology 17: 165-70.

History.com. 2010. Great Wall of China. Available at http://www.history.com /topics/great-wall-of-china (last accessed 29 March 2015).

Hoffa, B. 2005. Know your enemy: Confronting the case against study abroad. Transitions Abroad. Available at http://www.transitionsabroad.com/publications /magazine/9605/confronting_the_case_against_study_abroad.shtml (last accessed 22 December 2015).

Holeman, B. 2015. Traveling on the Trans-Siberian Railway. This battered suitcase, 3 March. Available at http://www.thisbatteredsuitcase.com/travelling-on-the-transsiberian-railway (last accessed 23 September 2015).

Hudson, R. 2001. Producing places. New York: The Guilford Press.

Hummon, D. M. 1986. Place identity: Localities of the self. In Proceedings of the 1986 International Conference on Built Form and Culture Research: Purposes in understanding socio-cultural aspects of built environments, ed. J. W. Carswell and D Saile, 34-37. Lawrence: University of Kansas Press.

Hyser, M. 2005. Campus internationalization: A study of American universities' internationalization efforts. International Education 35(1): 35.

Irkutsk International Travel Bureau "Sputnik." n.d. Irkutsk. Available at http://baikalsp.ru/en/node/68 (last accessed 4 January 2015). 
Ismail, B., M. Morgan, and K. Hayes. 2006. Effect of short study abroad course on student openness to diversity. Journal of Food Science Education 1: 15-18.

Israel, A. L. 2012. Putting geography education into place: What geography educators can learn from place-based education, and vice versa. Journal of Geography 111(2): 76-81.

Jackson, J. B. 1984. Discovering the vernacular landscape. New Haven: Yale University Press.

Jacob, B. A., and L. Lefgren. 2002. The impact of teacher training on student achievement: Quasi-experimental evidence from school reform efforts in Chicago. Working Paper 8916, National Bureau of Economic Research. Available at http://www.nber.org/papers/w8916 (last accessed 19 December 2013).

Kawulich, B. 2005. Participant observation as a data collection method. Forum: Qualitative Social Research 6(2): Art. 43. Available at http://nbn -resolving.de/urn:nbn:de:0114-fqs0502430 (last accessed 22 September 2015).

King-Irani, L. 2006. Exiled to a liminal legal zone: Are we all Palestinians now? Third World Quarterly Special Issue: Reshaping Justice — International Law and the Third World 27(5): 924-26.

Klein, E. J., and M. Riordan. 2011. Wearing the "student hat": Experiential professional development in expeditionary learning schools. Journal of Experiential Education 34(1): 35-54.

Knapp, N. F., and P. L. Peterson. 1995. Teachers' interpretations of "CGI" after 4 years: Meanings and practices. Journal for Research in Mathematics Education 26: 40-65.

Kolb, A., and D. Kolb. 2005. Learning styles and learning spaces: Enhancing experiential learning in higher education. Academy of Management Learning and Education 4(2): 193-212.

Kyle, G., and G. Chick. 2007. The social construction of a sense of place. Leisure Sciences 29: 209-25.

Lanegran, D., and P. H. St. Peter. 1993. The five fundamental themes of geography as advance organizers in instructional design. International Research in Geographical and Environmental Education 2: 51-63.

Larmer, B. 2008. The Great Wall of China is under siege. Smithsonian Magazine, August. Available at http://www.smithsonianmag.com/people-places/the-great -wall-of-china-is-under-siege-825452/?no-ist (last accessed 4 January 2015). 
Lehman, M. L. 2009. Designing a sense of place: Don't forget memory. Sensing architecture, 23 February. Available at http://sensingarchitecture.com 1581/designing-a-sense-of-place-dont-forget-memory (last accessed 22 June 2015).

Lieberman, A., and M. W. McLaughlin. 1992. Networks for educational change: Powerful and problematic. Phi Delta Kappan 73(9): 673-77.

Lipton, R. 2014. Which states have adopted national curriculum frameworks? Alchemy learning. Available at http://alchemylearning.com/states-adopted-national -curriculum-frameworks/ (last accessed 15 August 2015).

Loucks-Horsley, S., N. Love, K. E. Stiles, S. Mundry, and P. W. Hewson. 2003. Designing professional development for teachers of science and mathematics, 2nd ed. Thousand Oaks, CA: Corwin Press.

Mahboob, T. 2012. Gallery/Interview: Photographer documents rugged lives of Kazakh eagle hunters. Asia Society. Available at http://asiasociety.org/blog/asia /galleryinterview-photographer-documents-rugged-lives-kazakh-eagle-hunters (last accessed 12 August 2015).

Mandal, A. 2014. Hippocampus functions. News-medical.net. Available at http://www.news-medical.net/health/Hippocampus-Functions.aspx (last accessed 20 October 2015).

Massey, D. 1991. A global sense of place. Marxism today, June 1991: 24-29.

Massey, D. 1994. A global sense of place. In Space, place and gender, ed. D. Massey. Minneapolis: University of Minnesota Press.

McLaughlin, M. W., and J. Talbert. 2001. Professional communities and the work of high school teaching. Chicago: University of Chicago Press.

McLaughlin, M. W., and J. Talbert. 2006. Building school-based teacher learning communities: Professional strategies to improve student achievement. New York: Teachers College Press.

McLeod, S. A. 2015. Observation methods. Simply psychology. Available at http://www.simplypsychology.org/observation.html (last accessed 22 September 2015).

Measham, T. G. 2006. Learning about environments: The significance of primal landscapes. Environmental Management 38(3): 426-34.

Merleau-Ponty, M. 2002. Phenomenology of perception. London: Psychology Press. 
Merriam, S. B. 1998. Qualitative research and case study applications in education. San Francisco: Jossey-Bass.

Merriam-Webster. n.d. Definition of "place.” Available at http://www.merriamwebster.com/dictionary/place (last accessed 18 February 2012).

Merryfield. K. M. 2000. Why aren't teachers being prepared to teach for diversity, equity and global interconnectedness? A study of lived experiences in the making of multicultural and global educators. Teaching and Teacher Education 16: 429-43.

Michalski, D. 2015. The dialectic of taste: On the rise and fall of tuscanization and other crises in the aesthetic economy. New York: Palgrave Macmillan.

Miles, K. H., A. Odden, M. Fermanich, and S. Archibald. 2004. Inside the black box of school district spending on professional development: Lessons from comparing five urban districts. Journal of Education Finance 30(1): 1-26.

Mohan, A. M. 2009. Teacher efficacy in geography: A mixed methods study of formal and informal teacher education. Ph.D. diss., Department of Geography, Texas State University-San Marcos.

Mongoluls.net. 2007. Monasteries and temples in Mongolia: Gandan monastery. Available at http://mongoluls.net/khiid/gandan.shtml (last accessed 12 January 2015).

Morin, C. 2009. Reality is what your brain makes of it. Neuromarketing, 24 April. Available at http://neuromarketing.ning.com/profiles/blogs/reality-is-what-your -brain (last accessed 4 January 2015).

Moscow.info. n.d. St. Basil's Cathedral. Available at http://www.moscow.info /red-square/st-basils-cathedral.aspx (last accessed 4 January 2015).

National Center for Education Statistics. 2015. The nation's report card: 2014 U.S. history, geography, and civics at grade 8 . Available at https://nces.ed.gov /pubsearch/pubsinfo.asp?pubid=2015112 (last accessed 12 August 2015).

National Council for the Social Studies. 2013. The college, career, and civic life (C3) framework for social studies state standards: Guidance for enhancing the rigor of $\mathrm{K}-12$ civics, economics, geography, and history. Available at http://www .socialstudies.org/system/files/c3/C3-Framework-for-Social-Studies.pdf (last accessed 23 March 2014).

National Geographic. 2002. National Geographic-Roper 2002 global geographic literacy survey. Available at http://www.nationalgeographic.com/geosurvey2002 /download/RoperSurvey.pdf (last accessed 4 January 2012). 
National Geographic. 2006. Final report: National Geographic-Roper public affairs 2006 geographic literacy study. Available at http://www.nationalgeographic.com /roper2006/pdf/FINALReport2006GeogLitsurvey.pdf (last accessed 4 January 2012).

National Geographic Education. 2015. Geography. Available at http://education .nationalgeographic.com/encyclopedia/geography/ (last accessed 16 December 2014).

National Geographic Education. 2015. What is geo-literacy? Available at http://education.nationalgeographic.com/media/what-is-geo-literacy/ (last accessed 16 December 2014).

National Geographic Education Foundation. 2013. The state of geography education in America. Available at http://education.nationalgeographic.com/programs/policy -initiative (last accessed 18 December 2013).

National Geographic Education Foundation. n.d. Teacher professional development works in geography education. Available at http://education.nationalgeographic .com/media/file/Teacher_Professional_Development_Works_in_Geography _Education.pdf (last accessed 12 December 2013).

Nisbet, E. K., J. M. Zelenski, and S. A. Murphy. 2009. The nature relatedness scale: Linking individuals' connection with nature to environmental concern and behavior. Environment and Behavior 41(5): 715-40.

Oberg, K. 1960. Culture shock: Adjustment to new cultural environments. Practical Anthropology 7: 177-82.

Opper, S., U. Teichler, and J. Carlson. 1990. Impacts of study abroad programmes on students and graduates. London: Jessica Kingsley Publishers.

Orr, D. W. 1994. Earth in mind: On education, environment and the human prospect. Washington, DC: Island Press.

Othman, S., Y. Nishimura, and A. Kubota. 2013. Memory association in place making: A review. Procedia-Social and Behavioral Sciences 85: 554-63.

Palmer-Moloney, L .J., and E. Bloom. 2001. The classroom as the field for studying geographical education. Geographical Review 91(4): 641-54.

Pine, B. J., and J. H. Gilmore. 1998. Welcome to the experience economy. Harvard Business Review.

Pink, S. 2007. Doing visual ethnography: Images, media and representation in research. London: Sage. 
Proshansky, H. 1978. The city and self-identity. Journal of Environment and Behavior 10(2): 147-69.

Proshansky, H. M., A. K. Fabian, and R. Kaminoff. 1983. Place-identity: Physical world socialization of the self. Journal of Environmental Psychology 3: 57-83.

Prosser, J. 1999. Image-based research: A sourcebook for qualitative researchers. London and New York: Routledge Falmer.

Putnam, R. T., and H. Borko. 2000. What do new views of knowledge and thinking have to say about research on teacher learning? Educational Researcher 29(1): 4-15.

Raby, R. 2011. Community college education abroad foundation and future concerns. Diversity Abroad. Available at http://www.diversitynetwork.org/articles /community-college-education-abroad-foundation-and-future-concerns (last accessed 30 September 2013).

Relph, E. 1976. Place and placelessness. London: Pion.

Rice, J. K. 2003. Teacher quality: Understanding the effectiveness of teacher attributes. Washington, DC: Economic Policy Institute.

Roberts, A. 2007. Global dimensions of schooling: Implications for internationalizing teacher education. Teacher Education Quarterly 34(1): 9-26.

Roberts, T. G. 2003. An interpretation of Dewey's experiential learning theory. Available at http://www.eric.ed.gov:80/PDFS/ED481922.pdf (last accessed 27 February 2012).

Rock, D., and J. Schwartz. 2006. The neuroscience of leadership. Strategy+Business, 43 (Summer).

Rollero, C., and N. De Piccoli. 2010. Place attachment, identification, and environment perception: An empirical study. Journal of Environmental Psychology 30: 198203.

Rowley, J. 2002. Using case studies in research. Management Research News 25(1). Available at http://arfasia.org/resources/using_case_study_in_research.pdf (last accessed 30 March 2014).

Rucai, L. 2008. The Great Wall past and present. China Today, 8 January. Available at http://china.org.cn/english/culture/238548.htm (last accessed 7 July 2015).

Russian Geographical Society. 2013. History. Available at http://www.rgo.ru/en/society/history (last accessed 24 August 2015). 
Sanger, M. 1997. Sense of place and education. The Journal of Environmental Education 29(1): 4-9.

Schell, E. M., K. J. Roth, and A. Mohan, eds. 2013. A road map for $21^{\text {st }}$ century geography education: Instructional materials and professional development. Washington, DC: National Council for Geographic Education.

Schmuck, P., and W. P. Schultz, eds. Psychology of sustainable development. Dordrecht, Netherlands: Kluwer Academic Publishers.

Schultz, P. W. 2002. Inclusion with nature: The psychology of human-nature relations. In Psychology of sustainable development, ed. P. Schmuck and W. P. Schultz. Dordrecht, Netherlands: Kluwer Academic Publishers.

Scott, J. 2001. Meeting the diverse needs of all students. Boston: Houghton Mifflin Company. Available at http://www.eduplace.com/science/profdev/articles /scott.html (last accessed 12 March 2013).

Seamon, D. 1979. A geography of the lifeworld: Movement, rest and encounter. London: Croom Helm.

Seamon, D. 2000. A way of seeing people and place: Phenomenology in environmentbehavior research. In Theoretical perspectives in environment-behavior research, ed. S. Wapner, J. Demick, T. Yamamoto, and H. Minami, 157-78. New York: Plenum.

Semken, S., C. Butler-Freeman, N. Bueno-Watts, J. J. Neakrase, R. Escobar-Dial, and D. R. Baker. 2009. Factors that influence sense of place as a learning outcome and assessment measure of place-based geoscience teaching. Electronic Journal of Science Education 13(2).

Semken, S., D. Williams, J. Ross, B. Kerr, and R. Monhardt. 2010. Design elements and learning outcomes of two place-based teacher professional programs situated in the southwest United States: Concordance with universal design for learning. Proceedings of the National Association for Research in Science Teaching, Philadelphia. Reston, VA: National Association for Research in Science Teaching.

Serpell, Z., and L. Bozeman. 1999. Beginning teacher induction: A report on beginning teacher effectiveness and retention. Washington, DC: National Partnership for Excellence and Accountability in Teaching.

Sheehy, K. 2012. High school students not prepared for college, career. U.S. News and World Report, 22 August. Available at http://www.usnews.com/education /blogs/high-school-notes/2012/08/22/high-school-students-not-prepared-for -college-career (last accessed 10 March 2013). 
Sheppard, E., and R. B. McMaster, eds. 2004. Scale and geographic inquiry: Nature, society, and method. Oxford: Blackwell.

Smith, N. 1995. Remaking scale: Competition and cooperation in prenational and postnational Europe. In Competitive European peripheries, ed. H. Eskelinen and F. Snickars, 59-74. Heidelberg: Springer.

Sobel, D. 2004. Place-based education: Connecting classrooms and communities. Great Barrington, MA: The Orion Society.

Stachowski, L. L., V. A. Visconti, and D. L. Dimmett. 2000. U.S. student teachers on overseas youth culture: Observations, reflections, and implications for teaching practice. International Education 30(1): 5-16.

Sternberg, E. M., and M. A. Wilson. 2006. Neuroscience and architecture: Seeking common ground. Cell 127(2): 239-42.

Stokes, S. M., A. E. Watson, and S. S. Mastran. 1997. Saving America's countryside: A guide to rural conservation, 2nd ed. Baltimore: Johns Hopkins University Press.

Strauss, A., and J. Corbin. 1990. Basics of qualitative research: Grounded theory procedures and techniques. Newbury Park, CA: Sage Publications.

Strong, M., S. Fletcher, and A. Villar. 2004. An investigation of the effects of teacher experience and teacher preparedness on the performance of Latino students in California. Santa Cruz, CA: New Teacher Center.

Szanto, D. 2013. Touring taste: Intersections of tongues, temperament, terroir, and taters. Centre for Sensory Studies. Available at http://www.centreforsensorystudies.org /the-sensory-city-workshop-sensing-the-city-through-touch-and-taste/\#_ftn5 (last accessed 12 January 2015).

Taylor, S.A.P. 2001. Place identification and positive realities of aging. Journal of CrossCultural Gerontology 16: 5-20.

Teachershelp.ru. 2015. Symbols of Russia - official and unofficial. Available at http://teachershelp.ru/symbols-of-russia-official-and-non-official/ (last accessed 4 January 2015).

The Borgen Project. 2013. Teaching geography is fundamental, and America is failing. Borgen Magazine, 23 October. Available at http://www.borgenmagazine.com /teaching-geography-fundamental-america-failing/ (last accessed 13 October 2015).

The Teaching Commission. 2004. Teaching at risk: A call to action. New York: The CUNY Graduate Center. 
Thrift, N. 2008. Non-representational theory. New York: Routledge.

Tomlinson, J. 1999. Globalization and culture. Chicago: The University of Chicago Press.

Tsing, A. 2000. The global situation. Cultural Anthropology 15(3): 327-60.

Tuan, Yi-Fu. 1975. Place: An experiential perspective. Geographical Review 65(2): $151-65$.

Tuan, Yi-Fu. 1977. Space and place: The perspective of experience. Minneapolis: University of Minnesota Press.

Tuan, Yi-Fu. 1980. Landscapes offear. Oxford: Basil Blackwell.

Tucker, P. D., and J. H. Stronge. 2005. Linking teacher evaluation and student learning. Alexandria, VA: Association for Supervision and Curriculum Development.

Tummala, R. B. 2014. Transcript copy of Great Wall of China-I205. Available at https://prezi.com/ns3emsxnd7vf/copy-of-great-wall-of-china-i205/ (last accessed 10 December 2015).

Turner, V. 1969. The ritual process: Structure and anti-structure. New York: Aldine De Gruyster.

Turner, V. 1974. Dramas, fields and metaphors: Symbolic action in human society. Ithaca, NY: Cornell University Press.

Turner, V., and E. Turner. 1978. Image and pilgrimage in Christian culture. New York: Columbia University Press.

Ulrich R. S., R. G. Simons, B. D. Losito, E. Fiorito, M. A. Miles, and M. Zelson. 1991. Stress recovery during exposure to natural and urban environments. Journal of Environmental Psychology 11: 201-30.

UNESCO. 2015. World heritage list. Available at http://whc.unesco.org/en/list/ (last accessed 4 December 2015).

Van Gennep, A. 1909. The rites of passage. Chicago: University of Chicago Press, 1960.

Wang, J., A. Peyvandi, and J. M. Moghaddam. 2009. Impact of short study abroad programs on students' diversity attitude. International Review of Business Research Papers 5(2): 349-57.

Wikipedia. 2013. Zaisan Memorial. Available at https://en.wikipedia.org/wiki /Zaisan_Memorial (last accessed 4 January 2015). 
Wikipedia, 2015a. GUM (department store). Available at https://en.wikipedia.org/wiki /GUM_(department_store) (last accessed 4 January 2015).

Wikipedia. 2015b. Red Square. Available at https://en.wikipedia.org/wiki/Red_Square (last accessed 4 January 2015).

Williams, D. R. 2000. Notes on measuring recreational place attachment. Available at http://www.fs.fed.us/rm/value/docs/pattach_notes.pdf (last accessed |28 December 2015).

Williams, D. R., and S. I. Stewart. 1998. Sense of place: An elusive concept that is finding a home in ecosystem management. Journal of Forestry 96: 18-23.

Williams, D. R., and J. J. Vaske. 2003. The measurement of place attachment: Validity and generalizability of a psychometric approach. Forest Science 49: 830-40.

Willis, P. 2001. The things themselves in phenomenology. Indo-Pacific Journal of Phenomenology 1(4): 1-21.

World Wildlife Fund. 2015. Lake Baikal, Russia. Available at http://wwf.panda.org/what _we_do/where_we_work/lake_baikal (last accessed 4 December 2015).

Yatskevich, I. 2011. Trans-Siberian railway: Longest railway in the world. Russian Geographical Society. Available at http://www.rgo.ru/en/article/trans-siberian -railway-longest-railway-world (last accessed 4 January 2015).

Yoon, K. S., T. Duncan, S.W.-Y. Lee, B. Scarloss, and K. Shapley. 2007. Reviewing the evidence on how teacher professional development affects student achievement. Issues and Answers Report REL 2007-No. 033, U.S. Department of Education, Institute of Education Sciences, National Center for Education Evaluation and Regional Assistance, Regional Educational Laboratory Southwest. Available at http://ies.ed.gov/ncee/edlabs (last accessed 8 September 2014).

Young, R. Y. 2010. International study tours and the development of sociocultural consciousness in K-12 teachers. Ph.D. diss. University of Massachusetts. Available at http://scholarworks.umass.edu/open_access_dissertations/222 (last accessed 26 February 2012).

Zhang, J. W., P. K. Piff, R. Iyer, S. Koleva, and D. Keltner. 2014. An occasion for unselfing: Beautiful nature leads to prosociality. Journal of Environmental Psychology 37: 61-72. 
APPENDICES 


\section{Appendix A}

\section{OGA Summer Program in Eurasia: Orientation Meeting of February 23, 2013}

8:30 to 9:00 - Coffee, munchies, and introductions (Teresa and Gwenda)

9:00 to 9:15 - Pre-test (Gwenda)

9:15 to $10: 00$ - Travel preparation

- Trip insurance

- Medical information

- Emergency contact information

- Air itinerary

- Trip extensions

- Packing

- Tips

- In-country transportation

- Gifts for homestay families and schools

- Roommates

10:00 to 11:00: Nancee Hunter (research)

11:00 to 12:00: A day in a life of a train/ger/home stay (Teresa and Gwenda)

12:00 to 1:00: Lunch

1:00 to 2:00: Project requirements (for credit or refund) (Gwenda)

What you have to do (travel guide, family geography activity, two presentations)

- When they are due

- Volunteer for OGA

- Conference presentations (OGA and other)

2:00 to $3: 00$

- Visas and Letter of Invitation

- Distribute t-shirts for participants and family

- Complete any items left over from morning session 


\section{Appendix B}

OGA Summer Program in Eurasia: Orientation Meeting of May 18, 2013

8:30 to 9:00 - Coffee, munchies, and introductions (Teresa and Gwenda)

Travel preparation (Teresa)

- Visas and Passports

- Trip insurance

- Medical information

- Emergency contact information

- Air itinerary

- Packing

- Tips

- In-country transportation

- Gifts for homestay families and schools

- New St. Petersburg Hotel

Research (Nancee)

Project requirements (for credit or refund) (Gwenda)

What you have to do (travel guide, family geography activity, two presentations)

- When they are due

- Volunteer for OGA

- Conference presentations (OGA and other)

Lunch with OGA Steering Committee 


\section{Appendix C \\ Eurasian Institute Project Requirements}

\section{Assignments}

\section{Language Assignment: Key Vocabulary Terms}

Share your vocabulary terms with the group (due May 18)

\section{Core Geography Concept Assignment}

\section{Part I: Core Concepts Research Paper (due May 18)}

- Hand out a copy of your assigned concept to each person

- Give a brief overview of your findings

\section{Part II: Task During the Institute}

You will be looking for and identifying examples of how each of these concepts is manifested throughout the journey. You may use sketches, photos, text, or a combination of the three to demonstrate your examples. These are to be sent digitally to the OGA office by August 15, 2013.

\section{Family Geography Activity}

You are to create a Family Geography Activity. You can check the Family Geography Manual on the OGA web site for examples. These are to be sent digitally to OGA office by August 15, 2013.

\section{Post Journey Mental Map and Reflection}

On the last day you will be given another blank outline map of Eurasia and asked to create a mental map of the region. You will then receive your original mental map. Using the pre and post mental maps as a guide, you are to write a short reflection on the learning that occurred form this journey. 
This reflection is not a travelogue or a description of the trip. Rather, it is an analysis and a collection of your insights on how physical and cultural geography were manifested in the landscape. These are to be sent digitally to OGA office by August 15, 2013.

Presentations

Over the course of the year (2013-2014) you are to make two presentations on the trip. This can be to you school, school district, or at a professional conference. You will need to send the OGA Office a statement of the date, place, and event at which you presented, the number of attendees and the completed evaluation forms for each attendee. OGA has an evaluation for you can use.

We expect you to support OGA activities like serving on the Steering Committee, tasks forces, or helping out at the annual conference. We are a volunteer organization and we depend on your support for the organization's success 


\section{Appendix D \\ Russia/Mongolia/China Itinerary}

July 11: St. Petersburg

Arrive in the St. Petersburg.

July 12: St. Petersburg

Visit to Russian Geographical Society. Explore the Hermitage museum - Winter

Palace. Board overnight train for the ride to Moscow (approximately 7 hours).

\section{July 13 to July 14: Moscow}

Arrive to the Russian capital in the early morning on day 3.

Visit to Kremlin and Armory, the Red Square, and St Basil's Cathedral. Explore the streets of the city to gain a sense of Muscovite life. Explore the famous subways stations.

In the afternoon of Day 4 we board the train for 3 days and 4 nights long trip to Irkutsk.

\section{July 15 to July 17: Trans-Siberian Railway}

Trans-Siberian Railway from Moscow to Irkutsk (approx. 78 hours). Pass through mountain ranges and taiga, big Russian cities and small Siberian villages.

\section{July 18: Listvyanka-Lake Baikal}

Arrive in Siberian city of Irkutsk and transfer to a bus to Listvyanka (approx. 2 hours), a small village on the shores of Lake Baikal. Explore the area by boat and foot. Dinner with host family. 


\section{July 19 to July 20: Trans-Mongolian Railway}

Free day in Listvyanka then re-boarded the train for a two-night journey that crosses the Russia/Mongolia border and takes us into the Mongolian capital of Ulaan Baatar.

\section{July 21 to July 23: Ulaan Baatar and Traditional Ger Camp}

Visit to Mongolian School and meeting with numerous geography teachers. Time to explore museums and temples in the Mongolian capital. The city shows many signs of its Soviet past contrasted with an increasing Chinese influence and a re-emergence of traditional Mongolia.

We also spend overnight (day 12) in the Ger camp - enjoying nomadic life in traditional Mongolian "house" - ger.

\section{July 24: Trans Mongolian Railway}

Train from Ulaan Baatar (Day 14) to Beijing, China (arrive on Day 15), traversing dramatic desert-scapes that give way to the rugged mountainous terrain that is home to China's ancient defense system, The Great Wall.

\section{July 25 to July 26: Beijing}

Explore Beijing, China's capital city, including: Tiananmen Square, Forbidden City, the Temple of Heaven, Summer Palace, the Lama Temple Monastery, and hutongs traditional alleys hiding a labyrinth of courtyard dwellings.

\section{July 27: Depart Beijing}

Depart Beijing for home on day 17. 


\section{Appendix E}

\section{OGA Advanced Summer Institute 2013 Application}

\section{OGA Advanced Summer Institute 2013: Russia/Mongolia/China by Rail}

The Oregon Geographic Alliance 2013 Advanced Summer Institute will travel by rail through Russia, Mongolia, and China. The following information describes the program and application process. For further information, contact OGA at geogall@pdx.edu.

Dates: Departure - July 10 (We will depart as one group.)

Return - July 28 (You may extend your stay at your own cost.)

Who is eligible? Any Oregon teacher who has completed an OGA program and pre-service teachers

General itinerary: Russia/Mongolia/China - See details at: http://www.geeo.org /tours/OGATransMongolian/

Physical requirements: http://www.geeo.org/tours/OGATransMongolian/ (under "need to know" - medical)

Graduate credit: Participants may enroll for five graduate credits (in Geography or C\&I) at thecost of $\$ 100$ per credit (pre-service teachers: tuition free)

Cost: OGA will pay for airfare, lodging, and most meals. Participants' costs are:

- Non-refundable application fee (due November 1): \$25

- Overseas travel/health insurance (due in January): $\$ 40.00$

- Refundable deposit or graduate tuition (due November $30^{\text {th }}$ ): $\$ 500$ (terms described below)

- Passport and visa: All participants must have a passport valid for at least 6 months after the return date (July 28) and must pay for visas for Russia and China (approx. \$140 each) 
- The meals not paid by OGA (estimated $\$ 100$ to $\$ 300$ depending on your tastes)

- Personal and incidental expenses such as tips, laundry, alcohol and the like

Important dates:

Applications are due in the OGA office November 1, with \$25 application fee (check payable to "PSU").

Applicants will be notified of acceptance on or about November 20th.

Participant's $\$ 500$ deposit is due in OGA office on Nov. $30^{\text {th }}$. If payment is not received by the due date, your slot in the program will be given to a person on the wait list.

Terms of $\$ 500$ deposit (due Nov. 30" , payable to "PSU"):

The deposit will be applied toward tuition for those who wish to enroll for 5 graduate credits. Those who do not wish to enroll for credit will be refunded upon successful completion of the program requirements no later than June 14, 2014. Completion of the program means:

- Attendance at two pre-trip orientations (tentatively February 23 and May 18, 2013)

- Completion of institute in Eurasia

- Completion of projects related to the trip (short travel guide, family geography activity, two presentations)

If you drop out of the program prior to May 1, 2013, your deposit will be refunded only if OGA is able to replace you with another participant from the wait list. If OGA cannot replace you, the deposit will be forfeited.

The deposit will be forfeited if you drop out of the program on or after May 1, 2013. 
Wait lists: Accommodations on this trip are in double rooms. OGA will create two wait lists (one for each gender). If one of the participants drops out of the program we will fill the slot with the first person from the wait list of the same gender, and so on down the list. If you are put on a wait list, you do not have to pay the $\$ 500$ deposit until you are accepted into the program.

In November 2012, OGA will notify you if you are on the wait list and what your position is on the list.

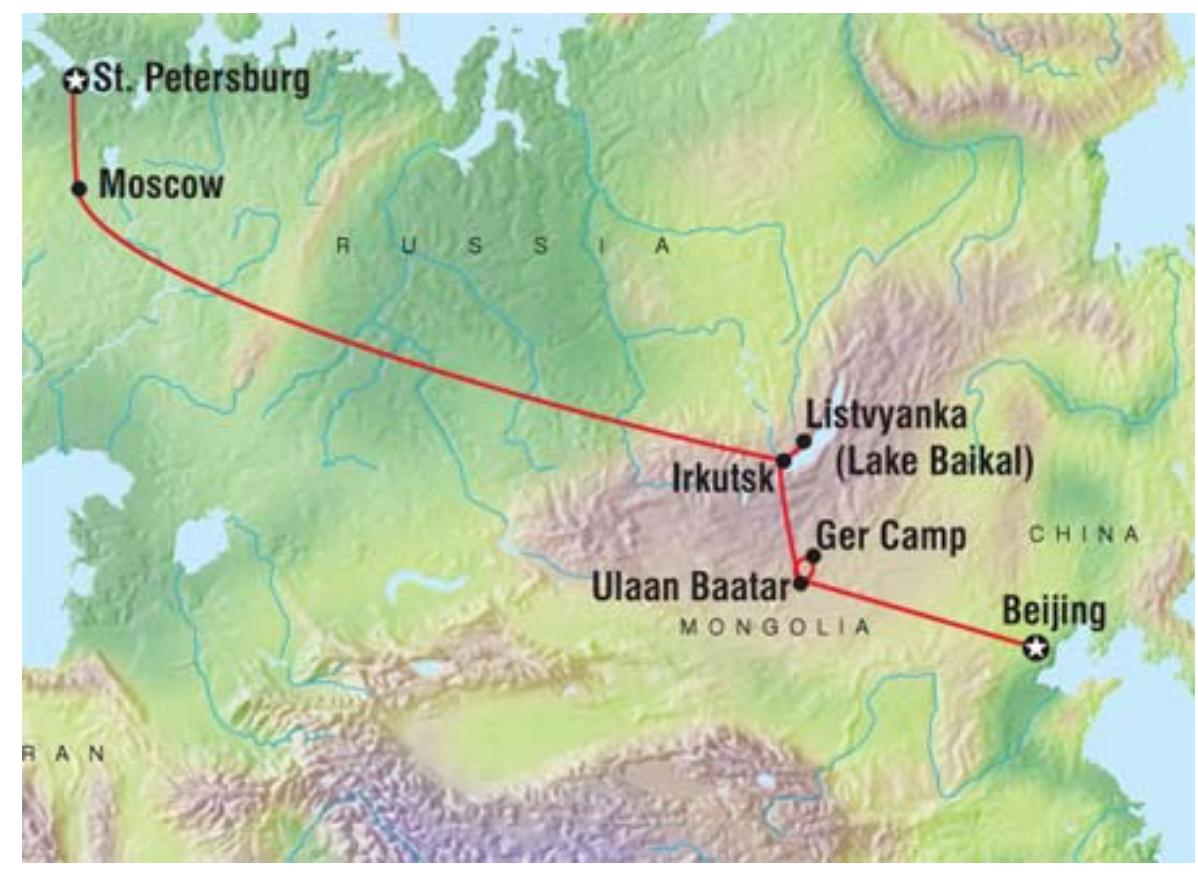

Application form: There are separate application forms-one for OGA members (anyone who has attended an OGA program), and one for pre-service teachers (whether an OGA member or not). Please select the appropriate form.

Note: Acceptance into this program is the decision of the OGA co-coordinators, at their sole discretion. 


\section{OGA Overseas Institute in Eurasia 2013 \\ Application Form for $\underline{O G A \text { Members }}$}

Name:

Mailing address:

Phone number:

Email:

(PLEASE NOTE: We will use email as our main means of communication. We will contact you by email when we receive your application, and we will notify you of acceptance by email. It is your responsibility to give us the correct email and to check that email for notices from us!)

What OGA program(s) have you attended?:

Gender (accommodations are in double rooms)

Please answer the following three questions ( 2 typed, double-spaced pages maximum for all 3 questions together).

Q1: Assume it is September 2013. You are back in the classroom after participating in the Eurasia Institute. Your students ask you why you went to Eurasia. What do you answer? 
Q2: How do you expect participation in this program will enhance your teaching (be specific) and what impact do you think the program will have on you as a teacher, geographer, and citizen?

Q3: Since your participation in an alliance program, how have you advocated for or promoted geography in your school, district, or community?

REMEMBER to enclose a check, payable to "PSU", for $\$ 25.00$.

Mail this application and the check to:

Oregon Geographic Alliance

Portland State University

P.O Box 751-GEOG

Portland, Oregon 97207-0751

\section{DUE DATE: November 1, 2012 in the OGA office}




\section{Appendix F \\ Eurasia Participant Pre-Post Survey}

Pseudonym

1. Gender (circle one)

Male

Female

Other

3. What grade level(s) do you teach?

4. How many years of teaching experience do you have (sub and full-time)?

2. Race/Ethnicity (circle one)

Hispanic or Latino

White

Black or African American

American Indian

Asian

Hawaiian or Pacific Islander

Other

5. What subject(s) do you teach?

6. On average, how many days of professional development do you participate in each year (examples include institutes, workshops, in-service, conferences)?

7. How many students are you teaching this year? 
8. Cultural diversity refers to differences from the norm in race, language, ethnicity, and religion. Given that, approximately what percentage of your students are from culturally diverse backgrounds?

9. Which of the following best describes your school's location? (circle one)

Rural Urban $\quad$ Suburban

10. What is the highest level of education you have attained? (circle one)

$$
\text { Bachelor's Degree Master's Degree Doctoral Degree }
$$

11. How much geography education have you had? (circle as many as apply)

No Geography Education

Some Geography in Elem./High School

Undergraduate Minor in Geography

Undergraduate Major in Geography

Graduate Degree in Geography

Professional Development in Geography

Other - Explain:

12. Measured by the length of time you lived there, please list up the top three countries and states where you have lived.

Countries

1.

2.

3.

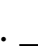

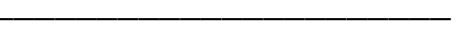

States

1.

2.

3.

13. In which state or country were you born? 
14. Which of the following best describes the environment that you grew up in? (circle as many as apply)
Rural
Urban
Suburban

15. Why do you want to participate in this particular professional development experience?

16. Have you visited Eurasia before? (circle one)

Yes

No

17. How many courses do you teach with "geography" in the title or courses with geography as a specific subject area? (circle one)

$$
\begin{array}{llll}
0 & 1 & 2 & 3 \text { or more }
\end{array}
$$

a). What geographic topics (e.g. climate, religion) do you teach in these courses?

b). Do you teach about a particular region (e.g. Africa, Europe, Asia)? If so,

which one(s)?

c). What geographic skills (e.g map reading, interpreting geovisualizations) do you teach in these classes?

18. Based on your present understanding of what geography is, do you believe that you think geographically? (circle one)
Yes
No
Don't Know

19. Oregon has geography content standards, but there are limited resources available for teaching to these standards. Based on what is available to you, how would you rate the 
effectiveness of your current geography lessons (not your teaching) in addressing the standards? (circle one)

Excellent
Very Good
Good
Mediocre
Poor
Very Poor
I don't teach geography lessons

20. Where do you consider your "home" - not necessarily your physical address, but based on "where your heart is"?

21. Based on your personal experiences, what place or type of place do you most identify with and why? (could be a city, region, landscape, whatever)

22. What city or town do you live in now?

23. When you think about where you live now, what five adjectives would you use to describe your feelings for this place? 
24. How would you categorize your current knowledge of Eurasia's landscape and people? (circle one)

I know much about the entire region

I know a small amount about the entire region

I know much about a particular aspect of the region

I know a small amount about a particular aspect of the region

I know little to nothing about the region

25. Please circle the top five words that you think best describe Eurasia:

Ancient

Ecologically important

Pristine

Fun

Scenic

Threatened

Beautiful

Crowded

Remote

Dangerous

Unique

Interesting

Important to preserve

Educational

Authentic
Tranquil

Privilege to visit

Spiritually valuable

Relaxing

Fragile

Culturally important

Wilderness

Overdeveloped

Historical

Temperate

Exotic

Unusual

Adventurous

Scientifically valuable

Comfortable 
Please rate the following statements using 1 for Strongly Agree, 2 for Somewhat Agree, 3 for Somewhat Disagree, 4 for Strongly Disagree or 5 for Don’t Know

The leaders at my school support and encourage opportunities for teacher professional development.

At my school, time is available for me to plan and prepare lessons.

I have quality instructional materials available to me.

I have access to computers for instruction.

I have access to funds for purchasing equipment and supplies for my classroom.

I am respectful of all my students.

I have a good relationship with my students.

I communicate effectively with my students.

I enjoy having discussions with people whose ideas and values are different from my own.

I enjoy talking to people who have values different from mine because it helps me understand myself and my values.

I enjoy taking courses that make think about things from a different perspective.

Contact with individuals whose background is different from our own is an essential part of an educational experience

I believe geography is important.

I teach geography in my classroom regularly. 
My school places importance on geography education.

My principal supports my teaching of geography.

Please rate the following statements using 1 for Strongly Agree, 2 for Somewhat Agree, 3 for Somewhat Disagree, 4 for Strongly Disagree or 5 for Don’t Know

I feel attachment and belonging to where I live now.

I feel an attachment or connection to Eurasia.

Eurasia holds a special meaning to me.

Eurasia has a strong national identity and character.

Eurasia is rich in history.

Eurasia is rich in symbolism.

I hold Eurasia in high esteem.

In my current teaching, I...

develop students' conceptual understanding of geography.

make connections between geography and other disciplines.

like to help my students understand geography.

make teaching geography fun so that students want to learn.

get bored teaching geography.

believe I can make students interested in geography.

am able to answer students' questions about geography.

am able to explain and help students understand geography

activities.

am confident with my knowledge of geography content. 
believe I can clearly explain geographic information and concepts. use a geography textbook. 


\section{Appendix G}

\section{Final Interview Questions}

NOTE: I will begin the interview by reminding the teachers that my project is about "sense of place" and will by necessity probe their feelings about the place and its impact on them both as teachers and as individuals.

\section{Questions}

In terms of your personal growth, what were the most influential components of the C-GEO Eurasia program?

In terms of affecting your teaching practice, what would you say are the top three things that you learned as part of your experience with the CGEO-Eurasia program?

Would you say this program strengthened your teaching practice? If so, to what extent?

Were there any impediments (e.g., lack of materials, support, resources, training) that you encountered in terms of implementing what you learned from this program?

Are there any strategies that you used to make implementation of what you learned easier and or more successful?

Do you think you have had an impact on your students' learning as a result of your participation in this program? If so, how?

Has your involvement in the CGEO-Eurasia program supported specific objectives and/or needs at your school? If so, how?

How does your current curriculum and teaching-style relate to your experience with this program? 
Are you more apt to teach geography content as a result of participating in this experience? If so, why?

In what ways has your interaction in another cultural context complicated or added to your understanding of yourself?

Are there ways in which you understand yourself differently? If so, what are they?

In what ways has your interaction in another cultural context complicated or added to your understanding of your students?

What activities did you do in Eurasia that were most meaningful to you? Why?

What are the most meaningful places (no more than three) that you visited in Eurasia as part of this experience?

What do you feel are the special or unique characteristics of these special places?

Were there special or unique characteristics of places that you anticipated seeing or experiencing before departure, but which you did not see or experience? Explain.

Do you feel a personal connection to Eurasia? Why or why not?

What are your most significant memories from this experience?

What cultural aspects of the Eurasia experience most affected you and how?

What physical aspects of the Eurasia landscape most affected you and how?

Did you feel unsafe or at risk (afraid) at any time during this experience?

If so, are you comfortable elaborating?

How did these experiences impact your sense of place?

How does your experience in Eurasia influence your feelings toward Oregon?

How does your experience in Eurasia influence your perceptions and feelings about Oregon as a place? 
Has this experience changed the way you relate to your students?

If so, can you describe the change?

What tools have you used to communicate your Eurasia experience with your school and communities? (e.g. blog, photos, lesson plans, etc.)?

\section{Examine 3 Photos with Participants:}

Tell me about these photos.

Describe the content.

What is being represented?

*Researcher to make note of how the images are situated within the natural environment and how well photos relate to/exhibit Eurasia's historical and cultural development and uniqueness.

How do you feel about what is being represented in the photo(s)?

How does what the image represents make you feel?

Why did you choose these photos?

What is meaningful to you about them?

What was your personal experience as it relates to each photo?

How did you feel about the narrowing down process of the photo component and did it serve as part of your reflective process? Explain.

Do you have any additional comments that you want to share about this experience?

Please provide any evidence of implementation or impact (e.g., blogs, journal entries, student data, lesson plans, pictures, etc.) 
Willing to provide journal entries that might be matched up with sense of place photos? 